Florida International University

FIU Digital Commons

6-16-1995

\title{
Areal and vertical distribution of total soil mercury and total phosphorusin the southern half of water conservation area 3-A, Everglades, Southern Florida
}

Cleone Botelho Arfstrom

Florida International University

DOI: $10.25148 /$ etd.FI14032337

Follow this and additional works at: https://digitalcommons.fiu.edu/etd

Part of the Geology Commons

\section{Recommended Citation}

Arfstrom, Cleone Botelho, "Areal and vertical distribution of total soil mercury and total phosphorusin the southern half of water conservation area 3-A, Everglades, Southern Florida" (1995). FIU Electronic Theses and Dissertations. 1305.

https://digitalcommons.fiu.edu/etd/1305 


\title{
FLORIDA INTERNATIONAL UNIVERSITY
}

\section{Miami, Florida}

\begin{abstract}
Areal and Vertical Distribution of Total Soil-Mercury and Total Phosphorus in the Southern Half of Water Conservation Area 3-A, Everglades, Southern Florida
\end{abstract}

A thesis submitted in partial satisfaction of the requirements for the degree of MASTER OF SCIENCE

IN

GEOLOGY

by

Cleone Botelho Arfstrom 
To: Dean Arthur $W$. Herriott

College of Arts and Sciences

This thesis, written by Cleone Botelho Arfstrom, and entitled Areal and Vertical Distribution of Total Soil-Mercury and Total Phosphorus in the Southern Half of Water Conservation Area 3-A, Everglades, Southern Florida, having been approved in respect to style and intellectual content, is referred to you for judgement.

We have read this thesis and recommend that it be approved.

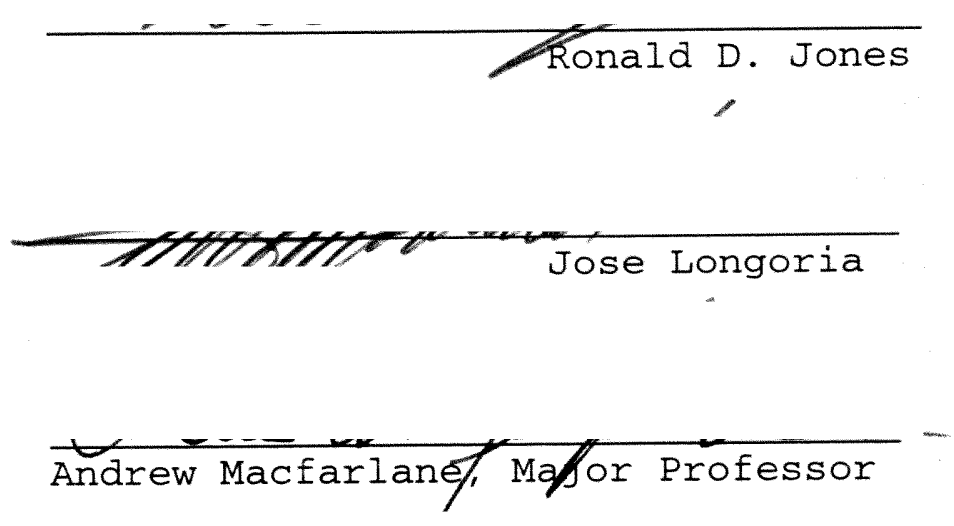

Date of Defense: June 16, 1995.

The thesis of Cleone Botelho Arfstrom is Approved.

Dean Adthur w. Herriott

college of Arts and Sciences

Dr. Richard L. Campbell

Dean of Graduate Studies

Florida International University, 1995 


\section{DEDICATION}

I dedicate this thesis to my parents for teaching me to appreciate and respect nature which eventually lead me to choose the field of natural sciences. Without their patience, understanding, support and encouragement, I would not have become the outspoken and mentally free individual that I am. 
ACKNOWLEDGEMENTS

I would like to express my gratitude to Dr. Andrew Macfarlane for his advisorship. I also wish to thank Dr. Jose Longoria for his insightful suggestions and emotional support. A very special thanks goes to Dr. Ronald Jones, for providing me, a stranger from the geology department, unconditional access to his labs. I will be eternally grateful for the financial, technical and moral support Dr. Jones gave me from the very beginning to the end of this project. Without his financial and academic support, this project would have not become reality. Thanks goes to Pete Lorenzo for teaching me how to analyze total phosphorus in soils. I also wish to thank my friends from the Southeast Environmental Research Program and from the Department of Geology, particularly Jennifer Thomas, Elaine Kotler, Kate Davis, and Martha Longoria. A special thanks goes to Lois Geier and Rosa for always helping with the never-ending paper work necessary for the completion of this thesis. Last, but not least, I wish to thank my husband, John Arfstrom, for his love and support. 
ABSTRACT OF THE THESIS

AREAL AND VERTICAL DISTRIBUTION OF TOTAL SOIL-MERCURY AND TOTAL PHOSPHORUS IN THE SOUTHERN HALF OF WATER CONSERVATION AREA 3A, EVERGLADES, SOUTHERN FLORIDA by

\section{Cleone Botelho Arfstrom}

Florida International University, 1995 Dr. Andrew Macfarlane, Major Professor

Total soil-mercury and phosphorus concentrations were determined in 64 sites in the southern half of Water Conservation Area 3A, an area of approximately $500 \mathrm{~km}^{2}$. Surface soil-Hg concentrations ranged from 117 to $300 \mathrm{ng} \cdot \mathrm{g}^{-1}$; total phosphorus concentrations range from 350 to $850 \mu \mathrm{g} \cdot \mathrm{g}^{-1}$. No consistent north-south or east-west trends are found in the mercury or phosphorus surface concentrations when they are normalized to soil bulk density. Nine sites were used for the determination of the vertical distribution of soilmercury. Vertical profiles of soil-Hg revealed decreasing concentrations with depth and correlated well with phosphorus in soil profiles. Mercury concentrations in soil profiles may be interpreted as an increase in the rate of deposition of mercury in the region in recent decades and/or as postdepositional mobilization of mercury to surface layers. 


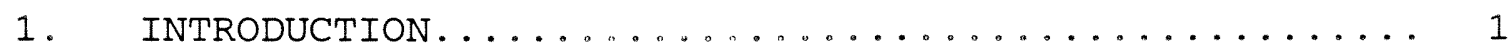

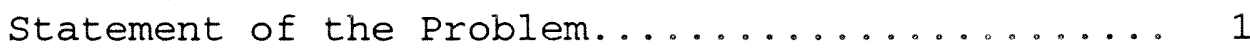

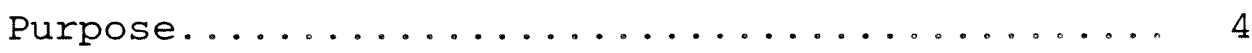

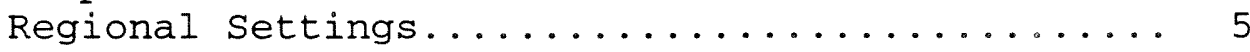

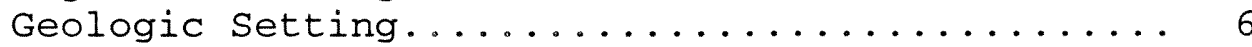

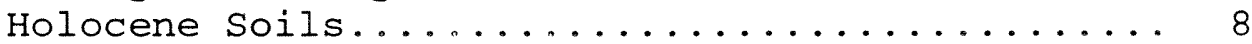

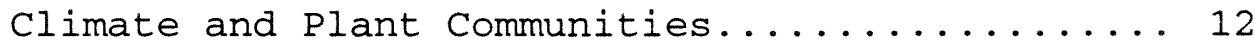

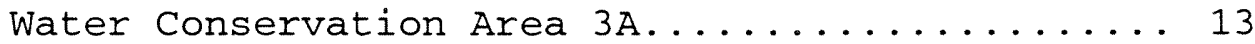

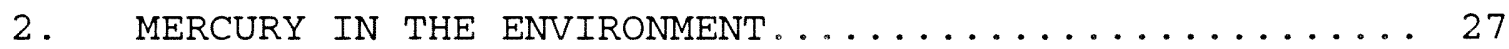

Sources of Environmental Mercury............. 27

Chemistry of Mercury in Natural Environments.... 31

Environmental Accumulation of Mercury......... 34

Previous Studies of Mercury in the Environment.. 37

Atmospheric Emissions of Mercury in Florida.... 40

3. METHODS......................... 45

Field Techniques................. 45

Laboratory Techniques............... 47

Total Mercury Analysis............ 47

Soil Bulk Density............... 48

Percentage of Total Organic Carbon........4 48

Total Phosphorus................ 49

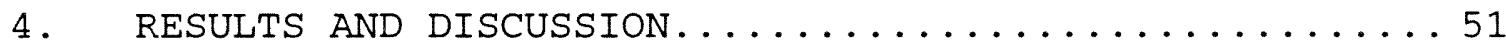

Results.................... 51

Areal Distribution of Total Mercury....... 51

Areal Distribution of Total Phosphorus..... 53

Vertical Distribution of Total Mercury..... 54

Vertical Distribution of Total Phosphorus.. 56

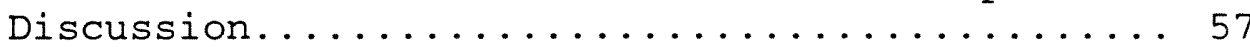

Areal Distribution of Total Mercury...... 57

Areal Distribution of Total Phosphorus..... 60

Vertical Distribution of Total Mercury..... 64

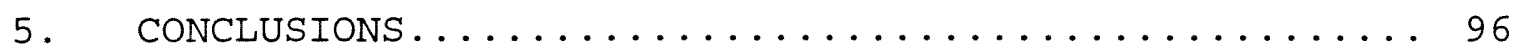

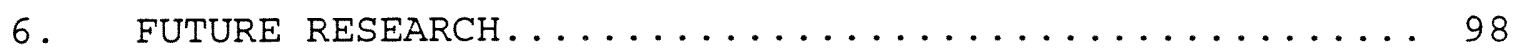

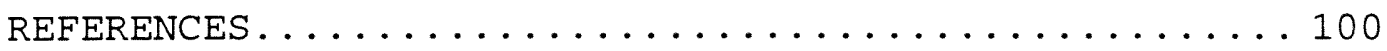

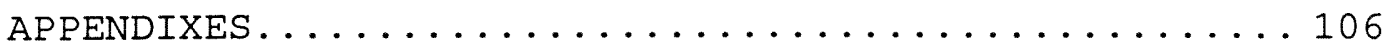


1.1. Location of the historical Everglades............ 17

1.2. Location of main hydrological compartments that form the present Everglades................. 18

1.3. Location of study area in WCA-3A............. 19

1.4. Topographic map of South Florida showing the Everglades Trough.................... 20

1.5. Physiographic boundaries of the Everglades......... 21

1.6. Geologic map of South Florida.............. 22

1.7. Stratigraphic cross-section of WCA-3A......... 23

1.8. Map of the soil types in the Everglades........... 24

1.9. Illustration of plant communities in the Everglades.. 25

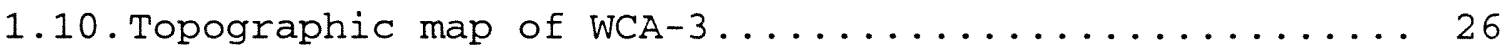

2.1. Cycle of mercury in the atmosphere........... 43

2.2. Cycle of mercury in aquatic systems............ 44

3.1. Location of sites in WCA-3A............... 50

4.1. Contour map of the areal distribution of soil-mercury concentrations in WCA.......... 72

4.2. Log-probability plot of the areal distribution of soil-mercury concentrations.............. 73

4.3. Linear correlation between $\frac{8}{8}$ of total organic carbon and areal soil-mercury concentration........ 74

4.4. Map of the areal distribution of 8 of total organic

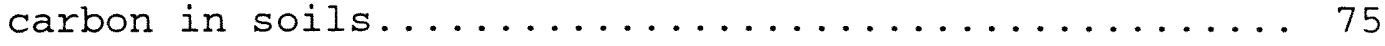

4.5. Map of the areal distribution of soil-mercury concentrations normalized to bulk density.........76

4.6. Log probability plot of soil-mercury concentrations

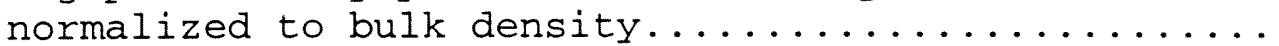


4.7. Map of the areal distribution of soil bulk density...

4.8. Map of the areal distribution of total phosphorus concentrations. .

4.9. Linear correlation between total phosphorus and soil-mercury concentrations in surface samples......

4.10. Log-probability plot of the areal distribution

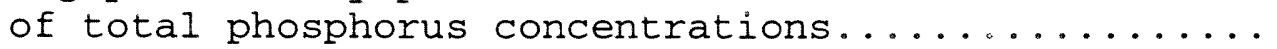

4.11. Map of the areal distribution of total phosphorus

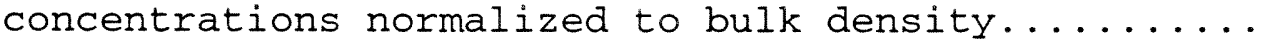

4.12. Linear correlation between total phosphorus and mercury concentrations normalized to bulk density...

4.13. Log probability plot of the areal total phosphorus concentrations normalized to bulk density...........

4.14. Vertical distribution of mercury concentrations

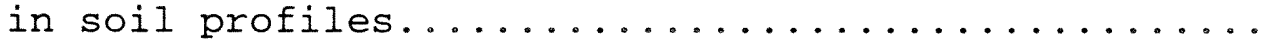

4.15. Vertical distribution of mercury concentrations in soil profiles normalized to soil-bulk density...... 86

4.16. Vertical distribution of total phosphorus concentrations in soil profiles in WCA-3A.........

4.17. Areas of highest phosphorus input to the WCAs

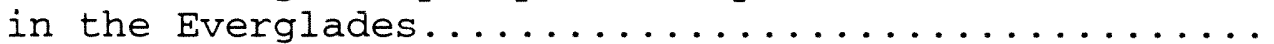

4.18. Correlation between phosphorus concentrations in surface water and distance to canal structures....

4.19. Graph of redox potential, $\mathrm{pH}$ and methane production in soil profiles in the Everglades..............90

4.20. Log-probability plots of total mercury concentrations in soil profiles............... 91

4.21. Log-probability plots of total phosphorus

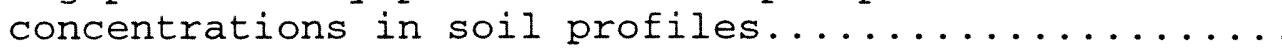

4.22. Plots of linear correlations between phosphorus and mercury concentrations in soil profiles.........

4.23. Diagram showing how sedimentation rates would affect mercury concentrations in soil profiles......994

4.24. Mercury concentrations versus intervals in soil profiles. 


\section{Statement of the Problem}

Water Conservation Area $3 A$ (WCA-3A) is one of the hydrologic compartments of the freshwater wetland in South Florida known as the Everglades (Fig. 1.1 and 1.2). Since the late 1800 's, canals and levees have been built to drain the Everglades for farming, housing and flood control. These structures have lead to considerable decrease in the surface area of the Everglades and have altered the natural hydrology of the area. Farming activities in the Everglades Agricultural Area have caused nutrient pollution as agricultural runoff containing high levels of nutrients, especially phosphorus, are transported by canals and drained into the Everglades (Reddy et al., 1991). The Everglades developed as an oligotrophic ecosystem where native plants thrive in low-nutrient conditions. Displacement of the natural Everglades flora by plants that thrive in nutrientenriched waters is a major threat to the Everglades natural balance.

Recently, researchers have been concerned about high levels of $\mathrm{Hg}$ found in fish from the Everglades which could pose a threat to humans as well as to animals living in the area. Methylmercury constitutes $99 \%$ of the mercury found in organisms and is the most toxic form of mercury. This 
organomercurial compound biomagnifies in the food chain reaching dangerous levels in predators that feed on fish. Mercury may cause irreversible damage to the nervous system and even death (Mitra, 1986). Mercury levels in fish in the Everglades have been found to be up to $3 \mathrm{ppm}$ (Hand and Friedeman, 1990). These levels have lead state agencies to issue health advisories that recommend no consumption of fish in the Everglades. Since most of the remaining Everglades is considered to be relatively pristine; i.e., only used for recreation, water supply and flood control purposes, and there are no point sources of $\mathrm{Hg}$ in the region, it was initially surprising to encounter this environmental contamination problem in the area.

Previous cases of environmental Hg contamination were usually associated with local point sources such as Minamata Bay in Japan. Several people died and a few hundred more were contaminated when inorganic $\mathrm{Hg}$ disposed in Minamata Bay from a chloralkali plant became methylated and accumulated in fish and shellfish which were consumed by local residents (Mitra, 1986). More recently, researchers in Canada, The United States and Scandinavia have reported high levels of $\mathrm{Hg}$ in fish from temperate lakes in remote areas (Jensen and Jensen, 1991; Swain et al., 1992). Increased atmospheric deposition of $\mathrm{Hg}$ along with increasing acidification of lakes by acid rain are believed to cause environmental contamination in these temperate remote lakes. In addition 
to low $\mathrm{pH}$, high levels of $\mathrm{Hg}$ in fish from these lakes have also been associated with low oxygen content, and low dissolved organic carbon (DOC) in seepage lakes and high DOC in drainage lakes.

These conditions are believed to favor mercury methylation, which is the transformation of inorganic $\mathrm{Hg}$ in sediment and water to the more toxic form, methylmercury.

$$
\left(\mathrm{Hg}^{2+---} \mathrm{CH}_{3} \mathrm{Hg}^{+}\right)
$$

According to recent studies, mercury methylation may occur via microorganisms living in sediments or by chemical reactions involving humic substances.

Environmental conditions in the Everglades differ in several ways from other places where dispersed accumulation of $\mathrm{Hg}$ has been studied. Waters in the Everglades are near neutral (6.5 to 7.8 ), oxygen content is relatively high and there is abundant organic matter in soils throughout the area. The Everglades are subtropical wetlands where, in addition to interaction between sediment and water, plants and animals may also be important parts of the mercury cycle. Jones (1992) has hypothesized that higher phosphorus in the Everglades may be related to higher levels of mercury because phosphorus pollution in the Everglades creates more areas under anaerobic conditions which favor methylation of mercury in the substrate. Information on mercury pollution in the Everglades is recent and scarce. Therefore, we must thoroughly investigate the region to determine how Hg cycles 
and what local environmental parameters contribute to mercury methylation and its movement through the food chain in the Everglades.

\section{Purpose}

The primary goal of this study was to determine the areal distribution of total soil-Hg and phosphorus in the southern half of Water conservation Area 3-A. Information regarding the distribution of total $\mathrm{Hg}$ in soils in the Everglades is important for the following reasons: 1) Mercury environmental contamination results from methylation of ambient mercury by biotic and abiotic mechanisms which occur at the sediment-water interface where there is high microbial activity. The results of this study will provide information on the levels of ambient mercury which are available for methylation. 2) Trends observed in the surface distribution of mercury may help determine the origin of the source(s) of mercury in region. The surface distribution of total phosphorus was studied in order to determine a possible correlation between mercury and phosphorus in the study area.

A secondary goal of this study was to determine the vertical distribution of total soil-Hg and phosphorus. This information may serve as an indicator of the depositional history and/or post-depositional mobility of mercury in soils from the Everglades. 


\section{Regional Settings}

Water Conservation Area $3 \mathrm{~A}(\mathrm{WCA}-3 \mathrm{~A})$ is located in central Everglades, with the northern half located mostly in Broward County and the southern half in Dade County (Fig. 1.2 and 1.3). Water Conservation Area 3 is the largest of all water conservation areas, covering an area of $2,370 \mathrm{~km}^{2}$ (Reddy et al., 1991). The present Everglades is divided by levees into hydrological compartments which include the Everglades Agricultural Area (EAA), Everglades National Park (ENP) and Water Conservation Areas 1, 2, and 3.

The Everglades is the largest freshwater marshland in the contiguous United States (Gunderson and Loftus, 1993). This unique ecosystem developed in the Holocene when the climate became more tropical, providing abundant seasonal precipitation. These conditions allowed the accumulation of organic matter in the central area of South Florida in an irregular shallow topographical low known as the Everglades Trough (Fig. 1.4; Gleason et al., 1984; Myers and Ewel, 1991).

The Everglades used to cover the entire central area of southern Florida, from Lake Okeechobee to Florida Bay. This system extended about $209 \mathrm{~km}$ along a longitudinal axis and was about $77 \mathrm{~km}$ wide at its widest point (Fig. 1.1). Due to extensive draining of the land for farming, housing and flood 
control, about $60 \%$ of the original Everglades has been lost (Myers and Ewel, 1991). The frequency and distribution of the natural hydroperiods (periods of inundation) that are essential for the existence of the Everglades have been completely altered. Some areas receive less water than necessary while other areas are subject to permanent inundation.

\section{Geologic Setting}

The Everglades peatland developed in the Everglades Trough which is an irregular topographic low in the central portion of South Florida (Fig. 1.4). This trough is bordered on the east by the Atlantic Coastal Ridge, on the west by the Big Cypress Swamp, on the north by Lake Okeechobee and on the south by Florida Bay (Fig. 1.5, Davis and Ogden, 1994). The Everglades is underlain by Pleistocene sedimentary rocks of freshwater and shallow marine origin (Fig. 1.6; Gleason and Stone, 1994). The Atlantic Coastal Ridge is a physiographic feature to the east of the Everglades and is composed of Pleistocene limestone that formed as a broad marine shoal of oolitic sand (Gleason et al., 1984). On the west, the boundary between the Everglades and the Big Cypress Swamp is an unconformity between the Pliocene Tamiami Formation and the lower Pleistocene Miami Limestone (Gleason et al., 1984).

The formations immediately underlying Everglades soils 
are part of a thick sequence of sedimentary rocks that form the southern portion of the Peninsula of Florida (Scott, 1992). This sequence is up to $6.1 \mathrm{~km}$ thick and was deposited on Triassic or Jurassic volcanic basement rocks. The entire sequence was deposited under shallow water conditions indicating that the southern half of the Peninsula of Florida has been slowly subsiding for the most of its existence (Missimer, 1984). The soils in the Everglades overlay Pliocene-Pleistocene sedimentary rocks which are part of the following formations: Anastasia, Fort Thompson, Tamiami, and the Miami Limestone (Fig, 1.6).

The Anastasia Formation underlies a small portion of the northeastern region of the Everglades (Fig. 1.6). This Pleistocene formation forms a wedge that is thicker (up to $30.5 \mathrm{~m})$ along the coastline and thinner landward to the west (Scott, 1992). This formation is characterized by interbedded quartz sands and limestones, mostly coquinas. The quartz sand beds are composed of calcareous fossiliferous medium-grained particles and quartz grains. The Anastasia Formation forms most of the Atlantic Coastal Ridge which stretches along the eastern coast of Florida. Towards the south, the Anastasia Formation grades into the Miami Limestone (Scott, 1992).

The Fort Thompson Formation underlies the northern half of the Everglades. This Pleistocene formation consists of interbedded shell beds and limestones. The shell beds are 
sandy and may be either slightly indurated or unindurated (Fig. 1.6; Scott, 1992). The sandy limestones that form the Thompson Formation are of both marine and freshwater origins (Scott, 1992).

The Miami Limestone underlies the southern half of the Everglades (Fig. 1.6). This formation is characterized by two distinct facies: Bryozoan and oolitic. The bryozoan facies is exposed in the western portion of the Everglades while the oolitic facies is exposed in the eastern portion (Scott, 1992). This Pleistocene formation may be up to 12.2 $m$ thick toward the east coastline and thins to the west.

All three formations form portions of the surficial aquifer system of southern Florida.

A cross-section of the formations underlying soils in the study area is illustrated in figure 1.7.

Holocene Soils

The Holocene soils in the Everglades are mostly peats and marls. These soils are histosols and entisols, respectively, based on the United States soil classification. Histosols are soils that are composed of organic materials (peats and mucks) which comprise at least half of the upper $80 \mathrm{~cm}$ of the soil profile. The organic material in the soil profile is expected to be more than twice as thick as minerals in the soil above the bedrock (Brown et al., 1991). 
In the Everglades, histosols are usually flat, poorly drained organic soils underlain by marl and/or limestones. In the Everglades, entisols are those soils of recent limestone origin. These soils are flat, poorly drained marls and thin sandy soils underlain by limestone (Brown et al., 1991).

The oldest peats from the Everglades have given radiometric ages of about 5,000 years (Gleason and stone, 1994). This is about the time when the climate in South Florida changed to subtropical conditions. With abundant precipitation and a shallow water table, plant material began to accumulate in the shallow trough in the central portion of South Florida.

Figure 1.8 illustrates soil types found in South Florida. There are two major groups of Holocene soils in the Everglades; the Everglades Peat and the Loxahatchee Peat. Minor Holocene sediments include Okeelanta Peaty Muck located around the south and southeast borders of Lake Okeechobee and carbonate mud (=calcitic mud by Gleason and Stone, 1994) located in the western margin of Water Conservation Area 3 , and in the southern Everglades in the area of the Everglades National Park (Fig. 1.8). The deposition of the two major types of peats that form the Everglades seems to have been controlled by topography. The bedrock surface of the Everglades Trough is irregular with many broad topographical highs and low points (Gleason and Stone, 1994). The Loxahatchee Peats developed in topographical lows and the 
Everglades Peats developed in topographical highs (Gleason and Stone, 1994).

The Everglades peat Formation covers an area of 4,420 $\mathrm{km}^{2}$ and occupies the central portion of the Everglades Trough, extending from Palm Beach County to Dade County (Fig. 1.8). These soils are derived primarily from degraded sawgrass, but parts of other plants are also present. The mineral content of these peats is quite low, usually less than $10 \%$ of the dry mass (Gleason and Stone, 1994). Everglades peats are typically brown to black in color. Fire has been a frequent phenomenon in the history of the Everglades and the black color in some of the peats that from the Everglades Peat is believed to result from charcoalized material produced by fire (Gleason and Stone, 1994). A large portion of the Everglades peat lies in the EAA and much of it has been drained to provide land for agriculture (Gleason and stone, 1994).

The Loxahatchee Peat Formation covers an area of about $2,950 \mathrm{~km}^{2}$ and is formed chiefly from the remains of roots and rhizomes of white water lily (Nymphae sp). Loxahatchee peats form two main patches in the Everglades basin, one in the region of Water Conservation Areas 1 and 2 and another narrow long patch which extends from the western portion of WCA-3A and into ENP (Fig. 1.8). Loxahatchee peats tend to be fibrous and spongy with light reddish-brown color and low mineral content (Gleason and Stone, 1994). These peats form 
some of the deepest peat deposits in the Everglades, but are also found in shallow sediment profiles (Gleason et al., 1984). Due to its tendency to shrink when drained, and because its organic material is easily oxidized, Loxahatchee peats have not been altered for the purpose of farming and housing.

The carbonate mud is found in some parts of the Everglades, especially in the southern region in ENP (Fig. 1.8). These non-stratified units are shelly, fine lowmagnesium calcium carbonates which are usually overlain by periphyton. Periphyton is a spongy algal mat formed by bluegreen algae and diatoms mixed with calcite crystals. Most of the calcite crystals are silt-sized. The carbonate muds are usually white to cream in color, but their color may be darker with increasing organic matter content (Gleason and Stone, 1994). Carbonate mud seems to form in areas that experience short hydroperiods. In these areas dry conditions predominate for most of the year leading to the oxidation of organic material that might have accumulated during the short wet period.

According to Gleason et al. (1984), dry conditions are required for the accumulation of carbonate mud for two main reasons:

1. dry conditions probably inhibit the growth of peat forming plants and favors the oxidation of organic material.

2. Long dry periods are necessary for the precipitation 
of calcium carbonate minerals which are weathered from exposed limestones. Abundant rain water would probably lead to the dissolution of these sediments and dilution of the concentration of calcium and carbonate ions.

\section{Climate and Plant Communities}

The climate in southern Florida is subtropical, with wet, hot summers and dry, mild winters. Most of the precipitation falls from May to October. During this time, water levels in the Everglades rise and reach their maximum in late summer to fall, and start to drop around November. The average annual rainfall over the Everglades is about 130 cm (Gunderson and Loftus, 1993). The region is also subject to violent seasonal storms such as hurricanes. Because of the flat topography of South Florida $(\sim 3 \mathrm{~cm} / \mathrm{km})$ and abundant grasses, natural surface waters in the Everglades have "sheet flow" from north to south which may range from zero to one $\mathrm{cm} / \mathrm{sec}$ (Gunderson and Loftus, 1993).

The diverse plant communities in the Everglades are a result of different factors such as length of hydroperiods, topography and soil types. In the Everglades, common plant communities include wet prairies, sawgrass marshes, sloughs, ponds, and tree islands (hammocks) (Fig. 1.9). Ponds and sloughs occupy the wettest sites in the Everglades, and are inundated all year-round, except in the driest years. Wet 
prairies, on the other hand, have short hydroperiods. Sawgrass marshes are the dominant plant community in the Everglades. Sawgrass marshes can either form very dense or sparse marshes. Dense sawgrass marshes are found in high ground overlying deep organic soils while sparse sawgrass marshes are found in lower elevations in shallow peats or marls. Tree islands occupy the highest elevations and are usually above surface water levels. These islands are long and narrow and are formed parallel to the direction of surface water flow; i.e., north-south. Tropical and subtropical hardwood trees are dominant and may include Mahogany, Gumbo-limbo, Oak and Royal Palm (Gunderson and Loftus, 1993).

Water Conservation Area 3A

In its natural state, the source of water in the Everglades was mainly rainwater with occasional overflow from Lake okeechobee. Farming and housing along with the need for flood control lead to the construction of canals and levees which changed the natural hydrological system in the Everglades (Light and Dineen, 1994). Light and Dineen (1994) provide a historical review of the development of the water control system in southern Florida. By 1917, the Miami Canal which cuts across WCA-3A and the North New River Canal which forms the northeastern border of WCA-3A had already been 
emplaced (Fig. 1.3). The eastern perimeter levee which forms the eastern boundary of WCA-3A was finished in 1954. Levees L-4 and L-5 that separate WCA-3 from the EAA were completed in 1959. The western and southern boundaries of WCA-3, L-28 and L-29 respectively, and the L-67A levee which separates WCA-3A from WCA-3B were all completed in 1964. The separation of WCA-3 into WCA-3A and WCA-3B by levees L-67A and later L-67C was intended to prevent excessive seepage through the porous aquifer in WCA-3B to eastern lands. Another important function of $\mathrm{L}-67 \mathrm{~A}$ is the transportation of surface water through WCA-3 and into ENP. After the construction of the above mentioned structures, only slight modifications to the pattern of surface water flow in WCA-3 have been made since 1963 .

With an area of $2,370 \mathrm{~km}^{2}$, Water Conservation Area 3 is the largest water conservation area in the Everglades. About $80 \%$ of this area is designated Water Conservation Area 3-A (WCA-3A, Fig. 1.3). WCA-3A is hydrologically separated from WCA-3B by levees $67 \mathrm{~A}$ and $67 \mathrm{C}$ (Fig. 1.3). The southern border of WCA-3A is the Tamiami Canal which parallels US Highway 41 (Fig. 1.3). The western boundary of the southern half of WCA-3A is levee 28 (Fig. 1.3). This levee is interrupted for 7.5 miles, but its northern portion extends to L-4, south of the EAA (Fig. 1.3). This 7.5 mile gap in the L-28 allows surface water to flow eastward from the Big Cypress Swamp into the southern half of WCA-3A. The northern portion of 
WCA-3A is located in Broward County south of the EAA (EAA) and the southern portion in Dade County north of ENP. In addition to levees and canals, several other structures control the flow of surface water to the Everglades. In WCA3 surface water is artificially controlled by structures which include S-8, S-9 and S-140 pump stations, S-150 spil1 way and S-11. There is also surface water flow from the Big Cypress Swamp through the gap in the L-28. At times of high precipitation, in addition to rainwater, water overflows from canals into WCA-3A.

The southern half of WCA-3A was chosen for this investigation because it is centrally located and may be representative of average conditions in the Everglades. In addition, it is near FIU, easily accessible by airboats, and high levels of $\mathrm{Hg}$ in fish tissues have been found in this area. A previous study by Delfino et al. (1993) determined soil-Hg concentrations at three sites inside the southern half of WCA-3A and more data regarding $\mathrm{Hg}$ concentrations in soils from this area were necessary.

WCA-3A provides a wide range of environmental conditions. Water depths during sampling varied from about $0.3 \mathrm{~m}$ in the west near the Big Cypress Swamp to about 1.2 to 1.4 $\mathrm{m}$ near $\mathrm{L}-67 \mathrm{~A}$ and $\mathrm{L}-29$. The variable water depth results from the topography of the area (Figure 1.10). Sediments in the southwestern and western portions of WCA-3A were usually more marly; i.e., these sediments had higher carbonate mud 
than those found to the east which were mostly peat soils. Depth to the bedrock also varies from west to east. Thickness of the soil profiles in the southwestern region of WCA-3A may be less than $20 \mathrm{~cm}$ while thickness of the soil profiles increases to the east up to $3 \mathrm{~m}$.

The southern area of WCA-3A is covered by a variety of plant communities. In areas to the east and southeast (near canals) water depths reach greatest depths and water lily communities are more predominant. Adjacent to canals, cattails form dense stands. The central area of the southern half of WCA-3A is covered by sawgrass marshes interspersed with wet prairies and tree islands. In these areas sawgrasses can form both dense marshes in shallower waters and sparse marshes in deeper waters. Tree islands become more predominant westward near the area of the Big Cypress Swamp. 


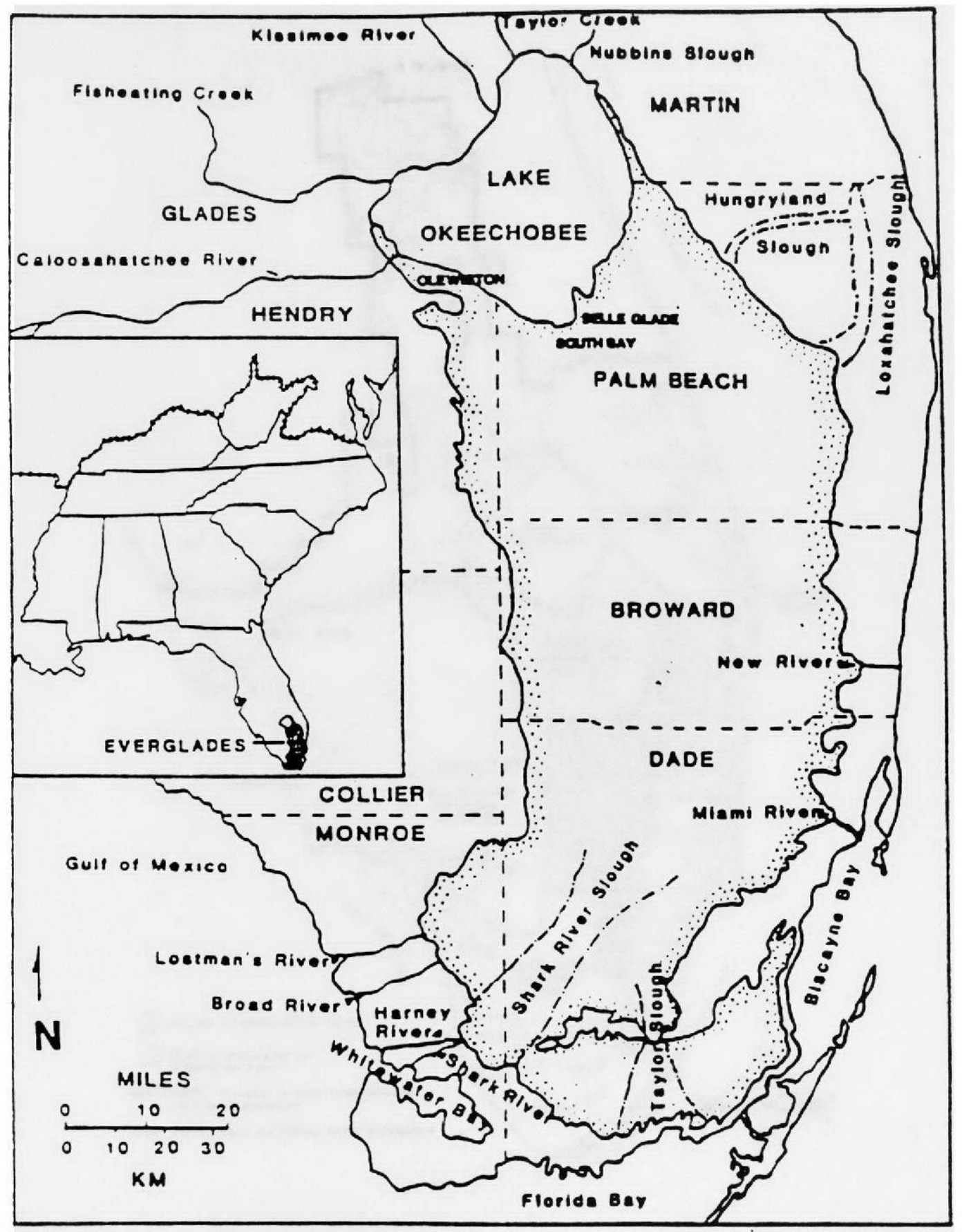

Figure 1.1. Location of the historical Florida Everglades Marsh. (From Gunderson and Loftus, 1993). 


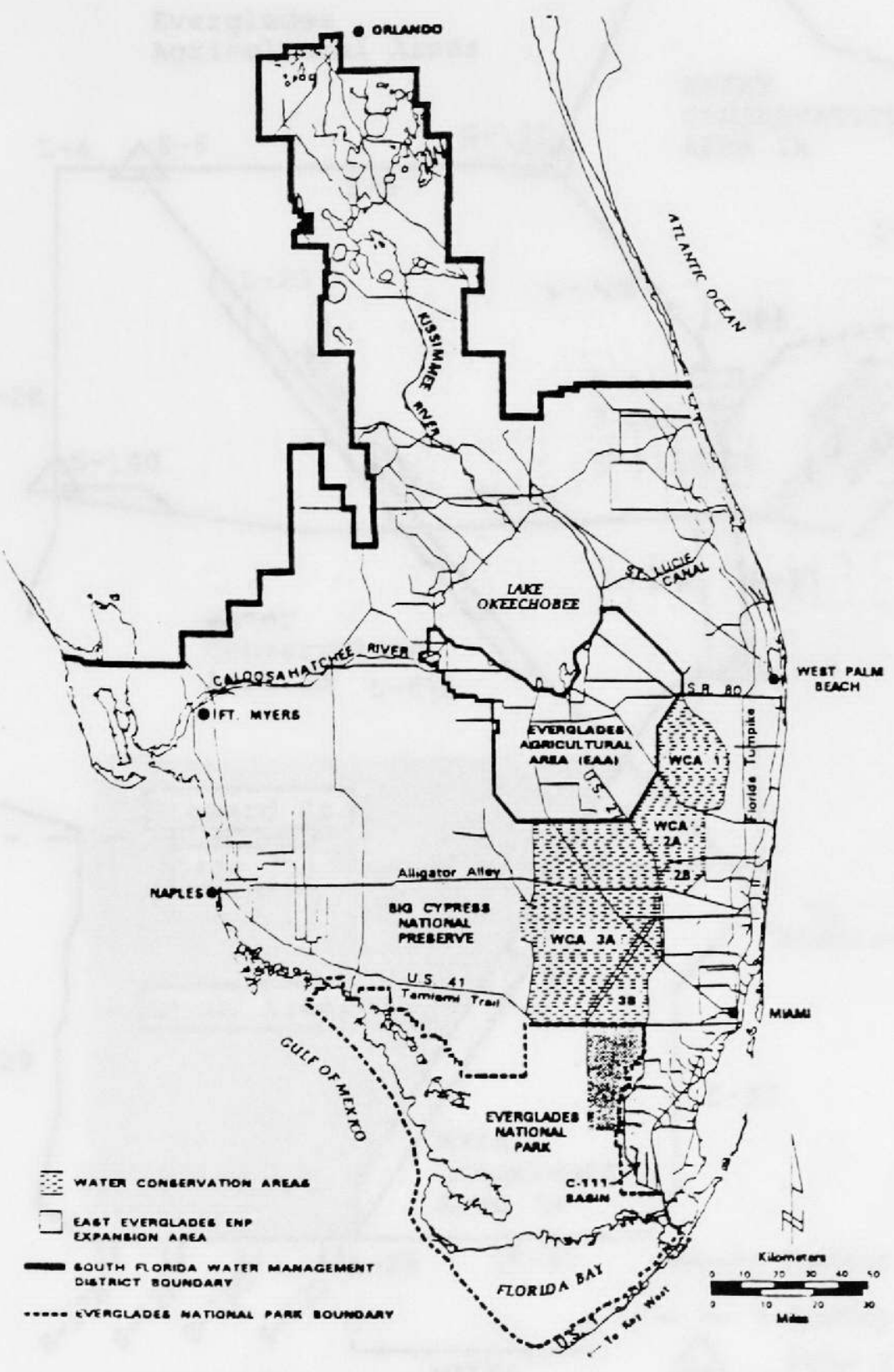

Figure 1.2. Location of the present Everglades and their main hydrological compartments: EAA, WCA 1, 2, 3 and ENP. Canals and levees separate the present Everglades into distinct hyarological units. (From Davis and Ogden, 1994). 


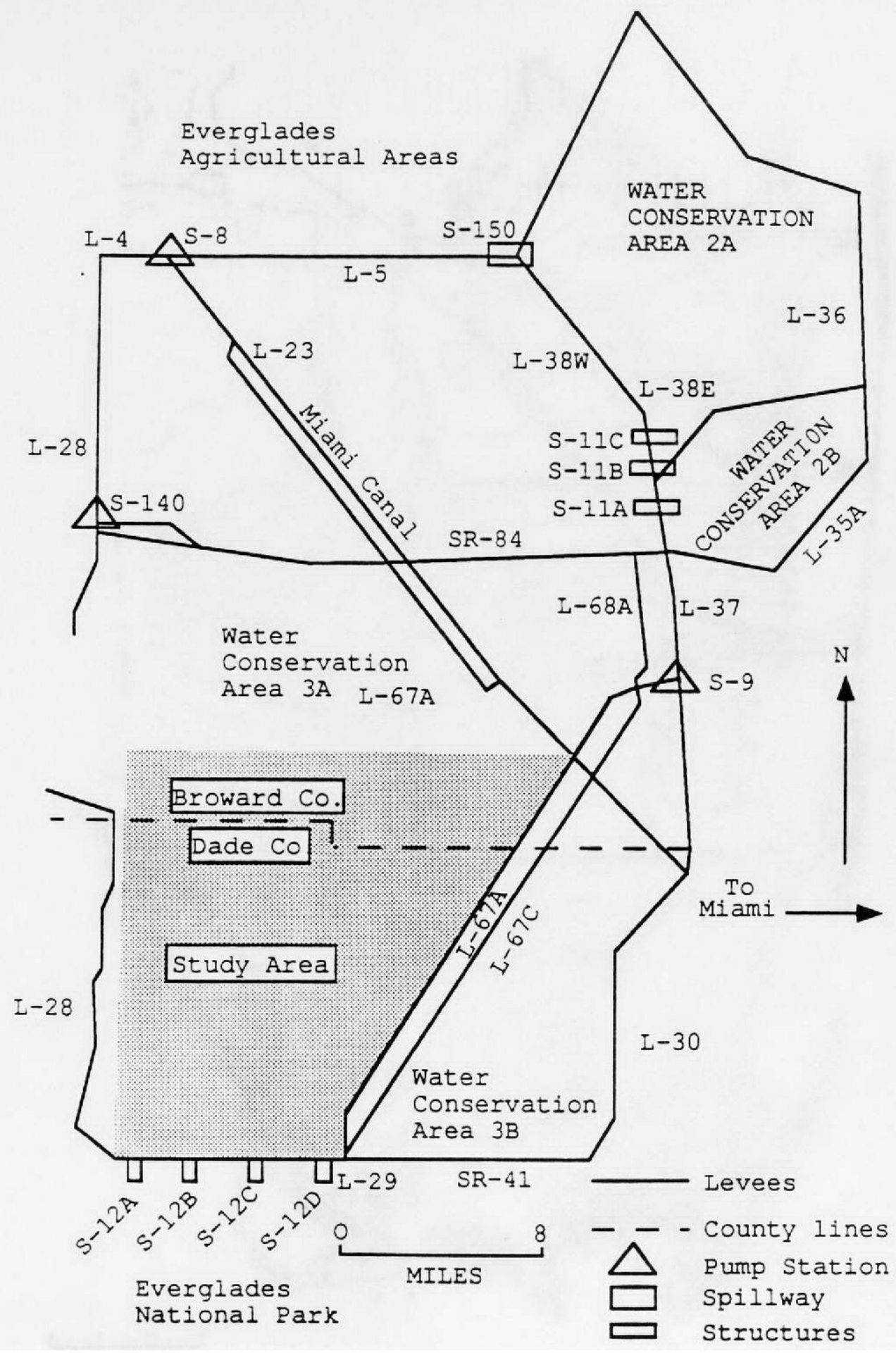

Figure 1.3. Location of the study area in WCA-3A. Main water control structures are also illustrated. (Modified from Fish and Stewart, 1991). 


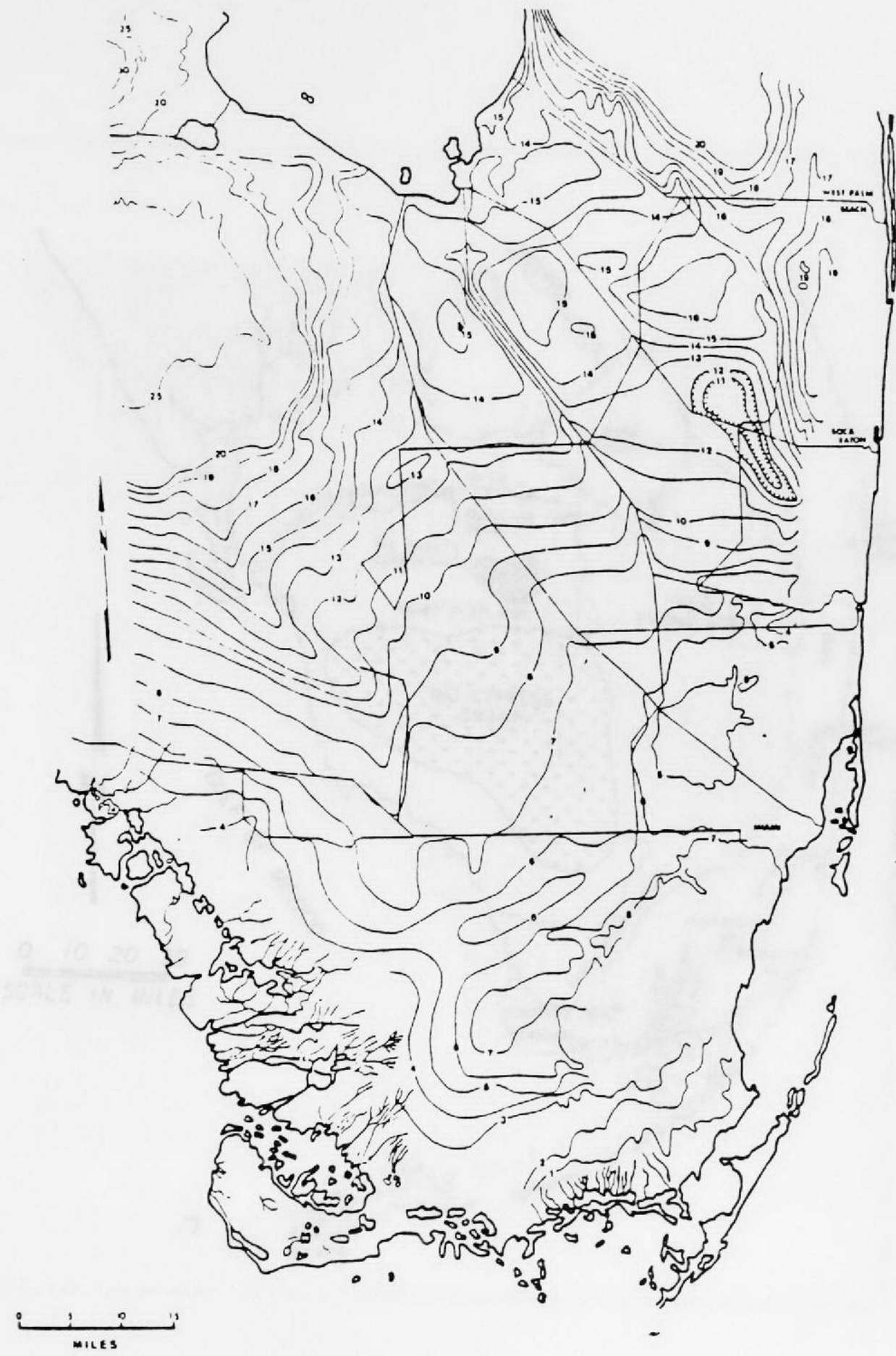

Figure 1.4. Topographic map of South Florida showing the Everglades Trough. Contour interval is $1.0 \mathrm{ft}$. (From GLeason et al., 1984). 


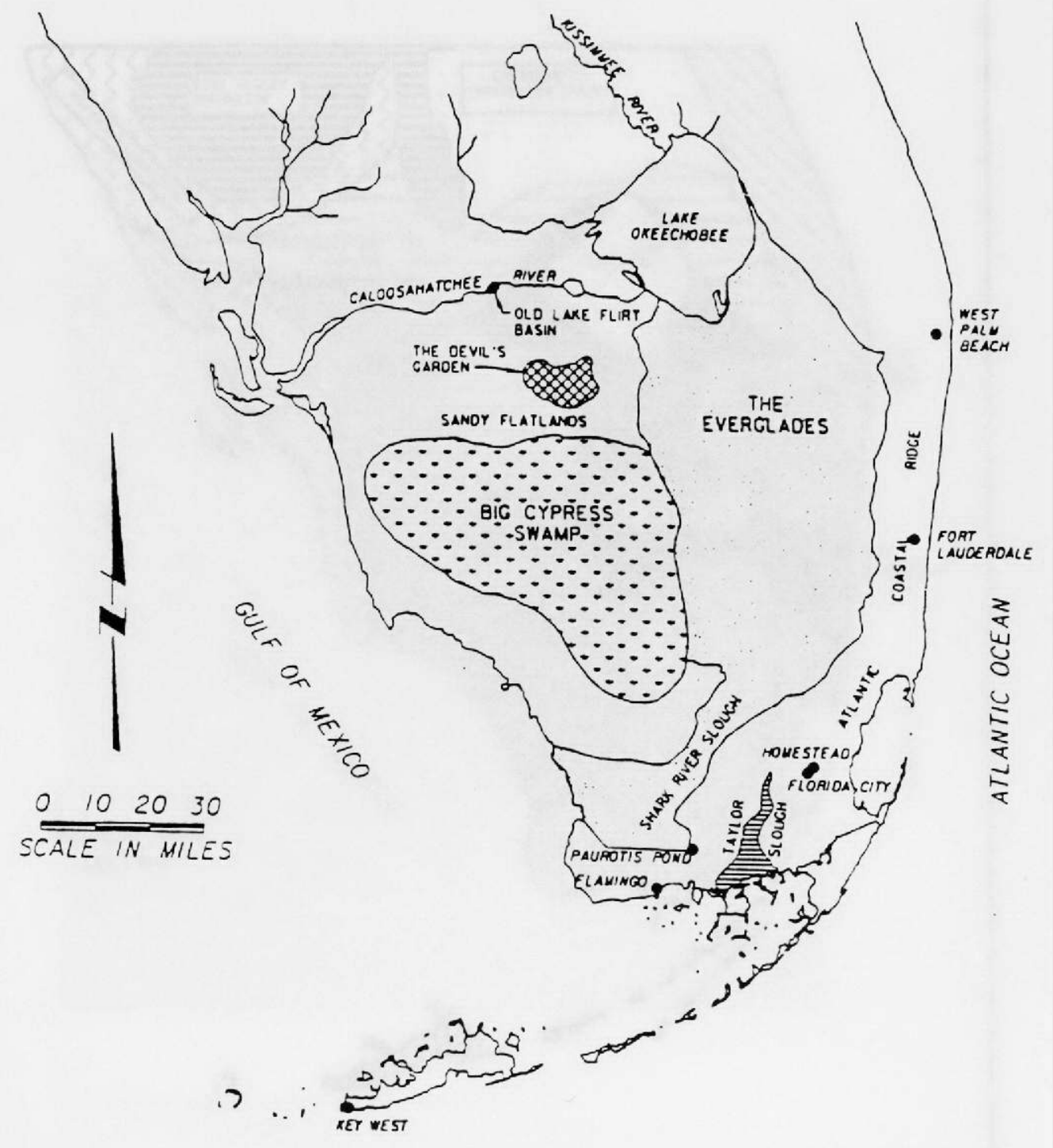

Figure 1.5. Physiographic boundaries of the historical Everglades. (From Davis and Ogden, 1994). 


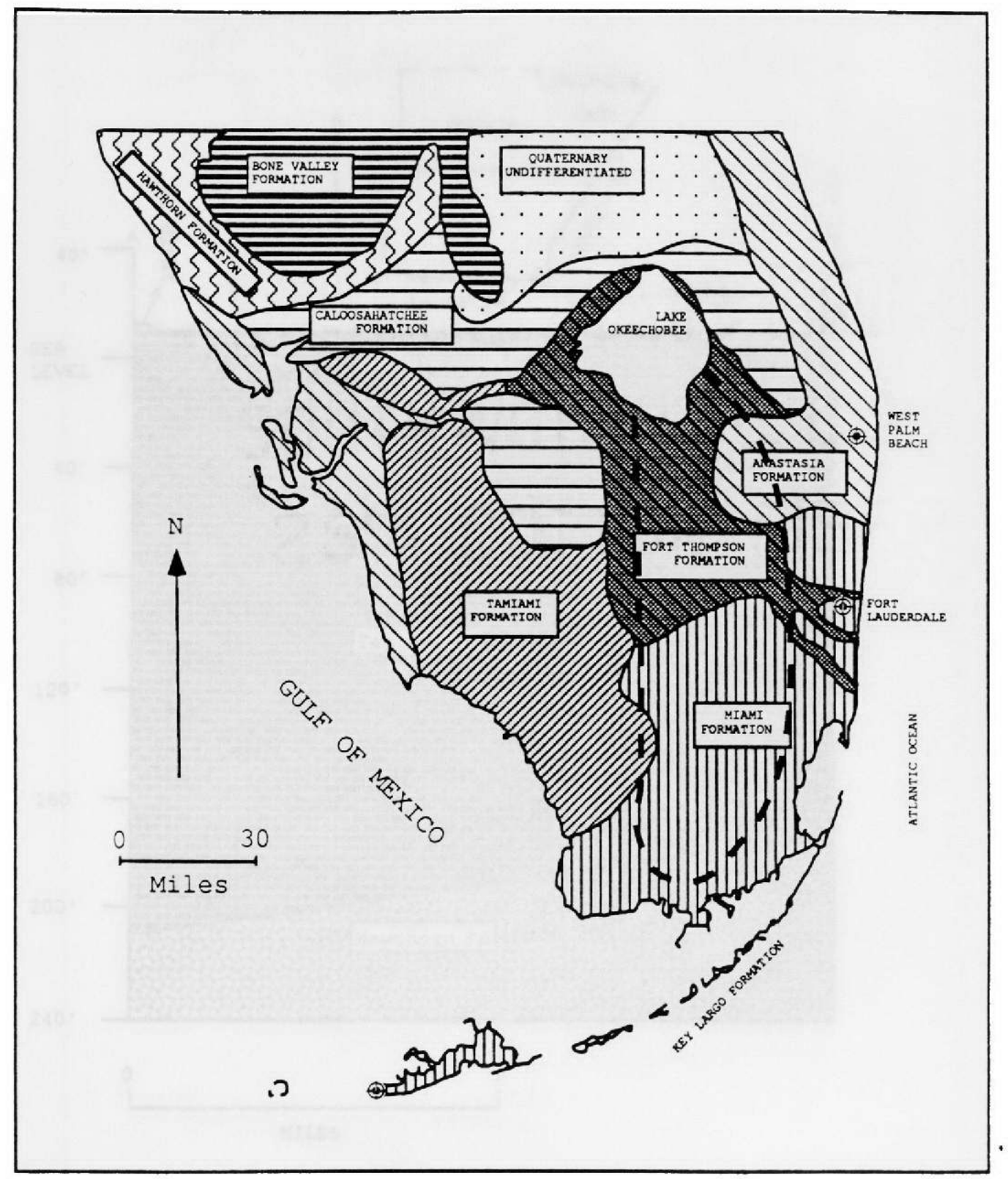

Figure 1.6. Geological map of South Florida showing PlioPleistocene formations that underlie the Everglades Marsh. (Modified from Puri and Vernon, 1964). 


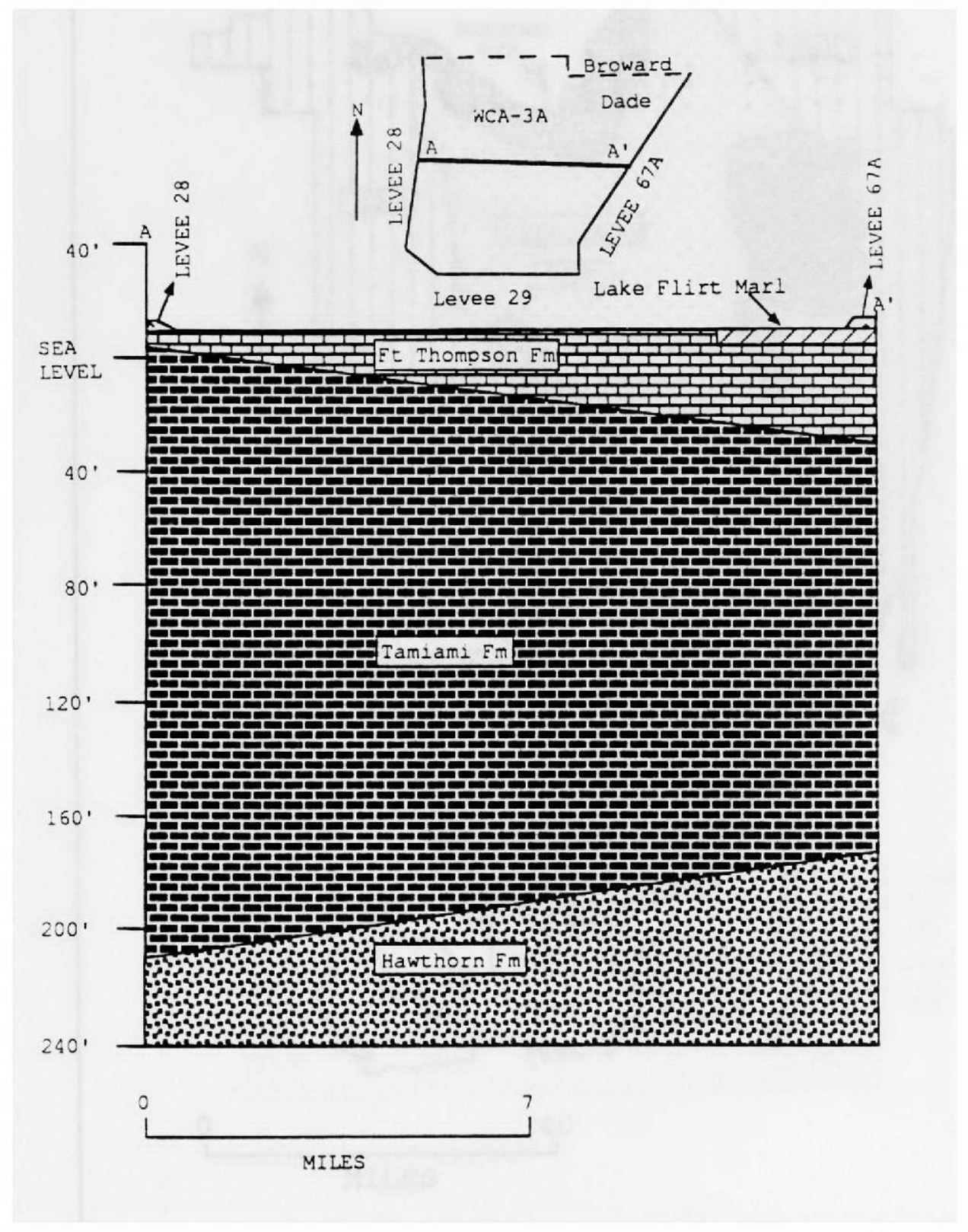

Figure 1.7. Stratigraphic column of the southern half of WCA3A. (Modified from Fish and Stewart, 1991). 


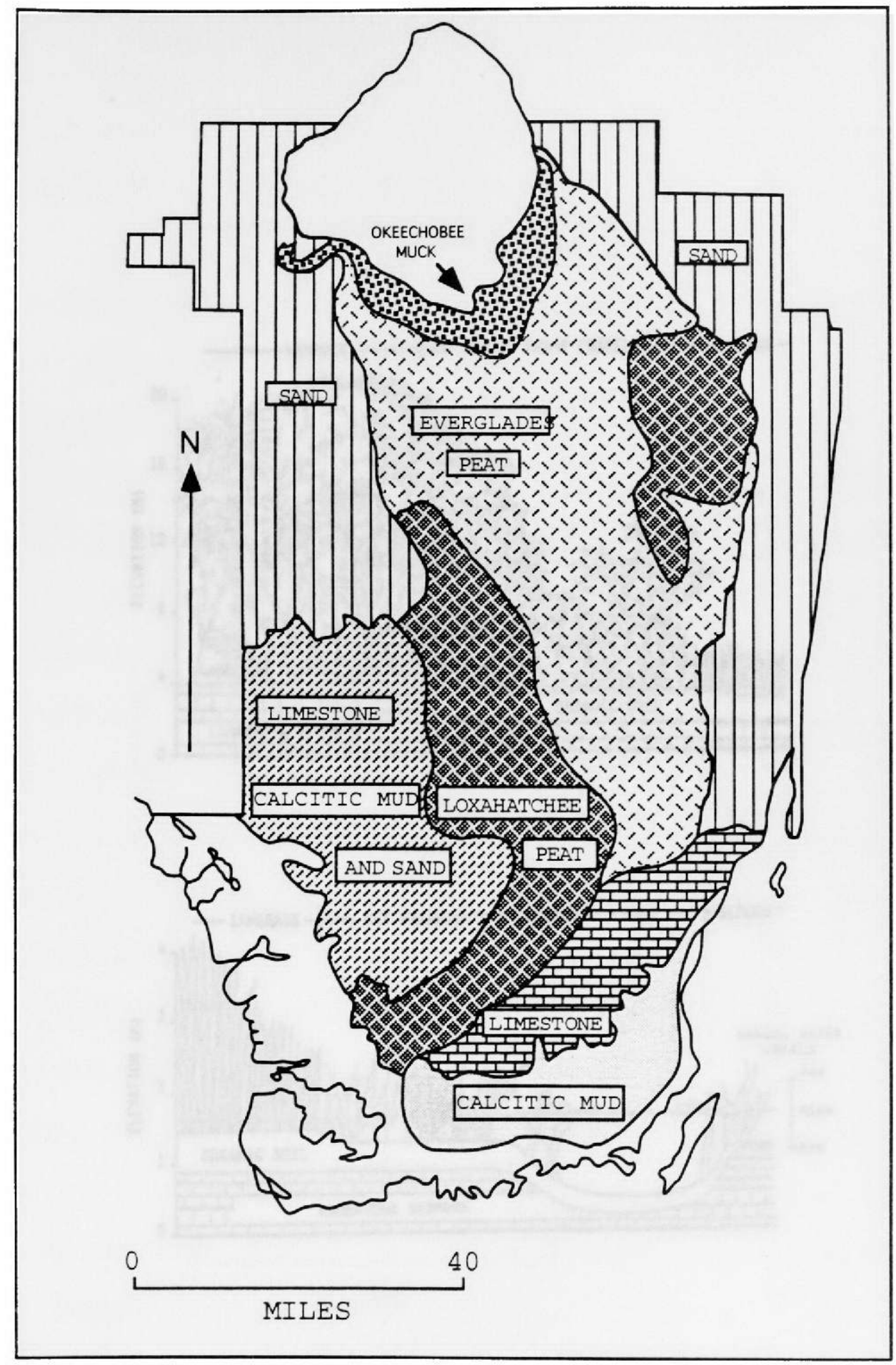

Figure 1.8. Map of the soil types found in South Florida. The Loxahatchee and the Everglades peat formations comprise most of the central and north Everglades. (Modified from Gleason and Stone, 1994). 

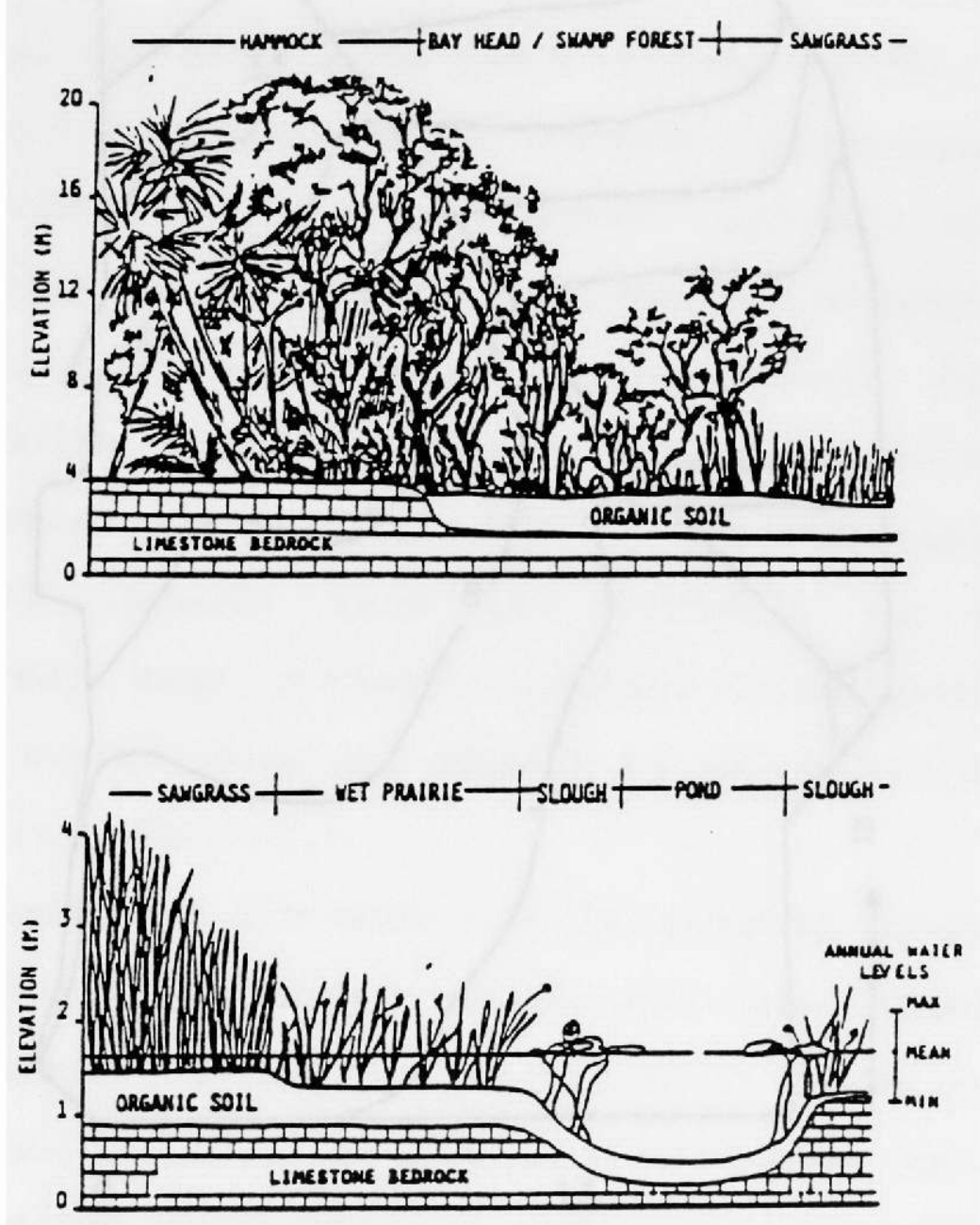

Figure 1.9. Illustration of plant communities in the Everglades. Plant communities vary with surface elevation and water depth. (From Gunderson and Loftus, 1993). 


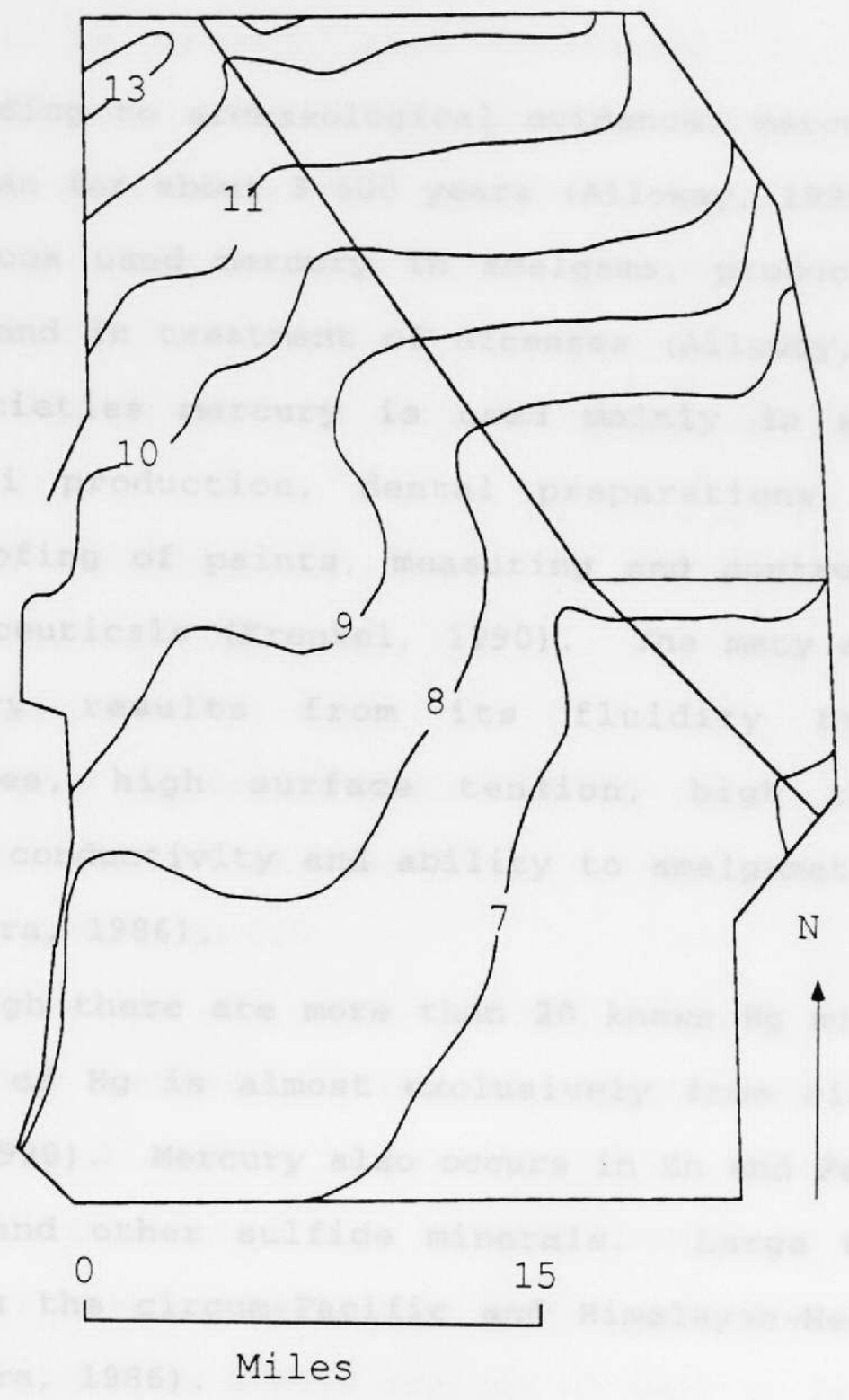

Figure 1.10. Topographic map of WCA-3A. Contour interval is 1 ft. (Modified from Gleason et al., 1984). 


\section{Sources of Environmental Mercury}

According to archaeological evidence, mercury has been known to man for about 3,500 years (Alloway, 1990). Ancient civilizations used mercury in amalgams, production of red pigments, and in treatment of diseases (Alloway, 1990). In modern societies mercury is used mainly in agriculture, chloralkali production, dental preparations, batteries, mildew-proofing of paints, measuring and control apparatus and pharmaceuticals (Krenkel, 1990). The many applications of mercury results from its fluidity at ordinary temperatures, high surface tension, high thermal and electrical conductivity and ability to amalgamate with many metals (Mitra, 1986).

Although there are more than 20 known $\mathrm{Hg}$ minerals, the production of $\mathrm{Hg}$ is almost exclusively from cinnabar, HgS (Alloway, 1990). Mercury also occurs in $\mathrm{Zn}$ and $\mathrm{Fe}$ containing minerals, and other sulfide minerals. Large Hg deposits occur along the circum-Pacific and Himalayan-Mediterranean region (Mitra, 1986).

The average concentration of $\mathrm{Hg}$ in the crust is about 50 $\mathrm{ng} / \mathrm{g}$ or less (Alloway, 1990). Because Hg has high affinity for organic matter and fine-grained minerals, average $\mathrm{Hg}$ 
concentrations in sedimentary rocks are higher than those in igneous and metamorphic rocks (Mitra, 1986). Mercury concentrations in soils vary widely. $\mathrm{Hg}$ in soils may come from the bed rock directly under the soil, from nearby Hg deposits, or be deposited from the atmosphere. According to the United States Geological Survey (USGS), the average normal soil concentration of this metal is approximately 100 ng/g. The following are ranges from common rocks and soils in the United States (Kabata-Pendias and Pendias, 1984; Alloway, 1990). Concentrations are presented in $\mathrm{ng} \mathrm{Hg} / \mathrm{g}$ dry sample (ppb).

Shales: $40-1500$

Limestones: 10-290

Granites: $1.4-28$

Soils over calcareous rocks: $10-500$

Organic light soils: 10-4000

Forest soils: $20-150$

Environmental $\mathrm{Hg}$ comes from natural as well as anthropogenic sources. Natural sources of $\mathrm{Hg}$ include continental and oceanic degassing; i.e., Hg deposited is volatilized and emitted back to the atmosphere. Mercury is also naturally released to the environment in volcanically and hydrothermically active regions as well as from major $\mathrm{Hg}$ and ore deposits (Mitra, 1986). According to recent studies, natural releases may account for about two thirds of the total Hg emitted to the atmosphere. The information 
presented below was extracted from Krenkel, 1990.

$\begin{array}{ll}\text { NATURAL EMISSIONS } & \text { METRIC TONS/YEAR } \\ \text { Continental degassing } & 17,800 \\ \text { Oceanic emission } & 7,600 \\ \text { Coastal emission } & 1,420 \\ \text { Emission from land biota } & 40 \\ \text { Volcanic } & 20 \\ \text { TOTAL ANTHROPOGENIC EMISSIONS } & 10,000 \\ \text { TOTAL EMISSIONS } & 36,880\end{array}$

According to Alloway (1990) major anthropogenic sources of $\mathrm{Hg}$ to the environment include:

1. Burning of fossil fuel, mainly coal.

2. Consumption-related discharges, including waste incineration.

3. Mining and smelting of ores, particularly $\mathrm{Cu}, \mathrm{Zn}$, and $\mathrm{Au}$.

4. Industrial production processes, in particular the $\mathrm{Hg}$ cell chloralkali process for the production of $\mathrm{Cl}$ and caustic soda.

Anthropogenic emissions have increased since the beginning of the industrial age, and are believed to have tripled since the turn of the century due to the burning of 
fossil fuels, especially coal, and urban and industrial waste incineration (Mitra, 1986). Although $\mathrm{Hg}$ is present in fossil fuels at trace levels, enormous amounts of these fuels are consumed worldwide.

The atmosphere plays a major role in the global cycle of Hg (Fitzgerald and Clarkson, 1991). Approximately 850 metric tons of $\mathrm{Hg}$ reside in the atmosphere, about 998 in the form of Hgo vapor and the remaining $1 \%$ being particulate $\mathrm{Hg}$ and organomercury compounds (Mitra, 1986).

Hg emitted to the atmosphere will be transported and deposited over varying distances. Particulate Hg associated with ash and soot may be efficiently removed from the atmosphere by precipitation and deposited relatively close to the source (Alloway, 1990). Elemental Hg, on the other hand, may have a longer residence time in the atmosphere and reach remote areas away from major point sources (Mitra, 1986). Precipitation of $\mathrm{Hg}$ will depend on chemical reactions in the atmosphere. Figure 2.1, from Lindqvist (1991), shows possible reactions involving mercury in the atmosphere. About 95 to $998 \mathrm{Hg}$ in the atmosphere is in elemental form $\left(\mathrm{Hg}^{0}\right)$. Elemental mercury may be oxidized to $\mathrm{Hg}^{2+}$, and may then combine with other ions such as $\mathrm{Cl}^{-}$or $\mathrm{HSO}_{3}{ }^{-} \cdot \mathrm{Hg}^{2+}$ may also be hydrolyzed to $\mathrm{Hg}(\mathrm{OH})_{2}$ which may in turn be broken down by ultraviolet light to form elemental Hg. Mercury is usually removed from the atmosphere by precipitation in the $\mathrm{Hg}^{2+}$ state. 
The behavior of mercury in terrestrial and aquatic ecosystems depends partly on the physico-chemical properties of these systems. In soils and sediments, important factors affecting the movement of $\mathrm{Hg}$ include soil mineralogy, organic matter content and $\mathrm{pH}$. In aquatic systems, the $\mathrm{pH}$, availability of nutrients, dissolved organic matter, redox potential and composition of bottom sediments may affect the pathways of the deposited $\mathrm{Hg}$ (Hogg et al., 1978). In both systems, plant and microbial activity may also affect the adsorption and transformation of mercury.

Adsorption of mercury onto soil and sediment particles seems to be the most important process, especially if the soils are rich in organic matter. Some Hg may also be leached downwards in the soil profile, taken up by plant roots, volatilized by photochemical reaction involving UV light, reduced by microbes, or transported by runoff water bound to fulvic and humic substances (Hogg et al., 1978). Rogers and McFarlane (1978) demonstrated experimentally that volatilization of mercury applied to soils occurs rapidly and accounts for the loss of up to $20 \%$ of the deposited mercury. However, the remaining $80 \%$ was strongly bound to the soil and did not participate in microbial activity. Under reducing conditions Hg may form highly insoluble compounds such as mercury sulfide (HgS). 
The effect of $\mathrm{pH}$ on Hg mobility and methylation has been the focus of many investigations of $\mathrm{Hg}$ as an environmental pollutant. $\mathrm{pH}$ appears to be inversely correlated with high $\mathrm{Hg}$ in the tissues of fish from remote lakes (Compeau and Bartha, 1984; Bloom et al. 1991). Researchers believe that low $\mathrm{pH}$ affects equilibria between $\mathrm{Hg}$ and humic-fulvic substances, making it more available for methylating processes.

However, $\mathrm{pH}$ is not the only factor affecting mobility of Hg. For over two years, Mierle and Ingram (1991) studied two lakes in Canada to determine the role of humic substances in the mobilization of mercury from wetlands. Their results indicated a direct relationship between dark-colored waters (enriched in organic matter) and the export of $\mathrm{Hg}$ from watersheds. The darker the water the higher the concentration of $\mathrm{Hg}$. The authors suggest that this correlation results from complexing of $\mathrm{Hg}$ by humic substances, and that the geochemistry of $\mathrm{Hg}$ in streams and lakes is controlled by its interaction with humic substances. However, the amount of $\mathrm{Hg}$ exported from the watersheds in runoff was much less than the amount of $\mathrm{Hg}$ deposited by precipitation on the watersheds: up to $25 \%$ for dark waters and about $10 \%$ for clear waters. The amount transported seems to be even less $(\sim 5 \%)$ if wetlands are present in the watershed (zillioux et al., 1994). Therefore, wetlands appear to be net $\mathrm{Hg}$ sinks rather than sources of $\mathrm{Hg}$ to aquatic environments. The results of 
Lindberg et al. (1975) and Patrick (1990) also agree with those of Mierle and Ingram (1991).

Clays and organic matter have been determined to adsorb Hg more strongly than siliceous or calcitic soils. Organic matter strongly adsorbs $\mathrm{Hg}$ even at low $\mathrm{pH}$ or increasing salinity while soils with low organic matter content more readily release mercury under these conditions (Mitra, 1986; Lindqvist, 1991).

In aquatic systems humic substances in sediments adsorb more Hg than other solid phases such as oxides and clay minerals (Xu and Allard, 1991). While humic substances in soils and sediments act as adsorbents under normal environmental $\mathrm{pH}$ conditions (4.7 to 6.6), dissolved humic substances may act as ligants and may be important in the mobility of $\mathrm{Hg}$ (Xu and Allard, 1991).

Figure 2.2 illustratse the cycle of mercury in aquatic systems (Modified from NAS, 1978). Atmospheric Hg is usually deposited as inorganic $\mathrm{Hg}^{2+}$, but $\mathrm{Hg}$ in $\mathrm{fish}$ tissue is $99 \%$ methylmercury (zillioux et al., 1993). Mercury entering aquatic systems via surface runoff also occurs as $\mathrm{Hg}^{2+}$ form, sorbed to detrital clay particles and particulate organic carbon (POC) or complexed with terrestrial dissolved organic carbon (DOC) (Zillioux, et al., 1993). Small amounts of methylmercury $\left(\mathrm{CH}_{3} \mathrm{Hg}^{+}\right)$may also enter aquatic systems via surface runoff. Once in aquatic systems, $\mathrm{Hg}^{2+}$ may be subject to transformations which will affect its dispersion in the 
environment. Although the common form of $\mathrm{Hg}$ emitted to the environment is inorganic, what is predominantly found in organisms is methylmercury $\left(\mathrm{CH}_{3} \mathrm{Hg}^{+}\right)$, an organic mercury compound (Mitra, 1986). Methylation, which is the transformation of inorganic $\mathrm{Hg}$ to methylmercury in natural environments, is currently a priority of study in many countries. The formation of methylmercury $\left(\mathrm{CH}_{3} \mathrm{Hg}^{+}\right)$may occur via biotic or abiotic methylation ( $\mathrm{M}$ ), under both oxic and anoxic conditions (Zillioux, 1993). Microbes may transform methylmercury to dimethylmercury $\left(\mathrm{CH}_{3}\right)_{2} \mathrm{Hg}$ which is volatile and may escape to the atmosphere. Demethylation (D) is the process by which methylmercury is transformed to the inorganic form $\mathrm{Hg}^{2+}$; this process may occur under the same conditions as methylation since it is also mediated by microbes. Demethylation occurs because some bacteria have resistance to organic mercury compounds.

\section{Environmental Accumulation of Mercury}

For over a decade, research on mercury as an environmental contaminant has shifted from studying areas directly affected by nearby industries that dispose of mercury to understanding mercury contamination caused by dispersed deposition of $\mathrm{Hg}$; i.e., contamination that occurs in remote areas.

Environmental contamination results when the rate of 
methylation of $\mathrm{Hg}$ by microbes in sediments and water and by chemical reactions involving fulvic and humic substances exceeds the rate of demethylation reactions. The rate of methylation by microbes seems to be very high in surficial sediments where microbial activity is most intense (Matilainen et al., 1991). Methylation in the water column seems to happen at much lower rates and may be abiotic via reactions involving $\mathrm{Hg}$ bound to $\mathrm{DOC}$ and $\mathrm{POC}$ (Matilainen et al., 1991). Abiotic methylation seems to be less important than biomethylation (Matilainen et al., 1991).

The United States, Canada and the Scandinavian countries are the leaders in researching the environmental contamination of temperate lakes in remote areas. Studies have established a correlation between some lake parameters and high $\mathrm{Hg}$ concentrations found in fish. For instance, there is a strong inverse correlation between $\mathrm{pH}$ and $\mathrm{Hg}$ concentrations in lake fish (Bloom et al., 1991). In some remote areas in North America and Scandinavia lake waters have become acidified due to acid rain (Bloom et al., 1991). It is not clear whether $\mathrm{pH}$ affects the structure of the microbial ecosystem, the release of $\mathrm{Hg}^{2+}$ from the substrate to the methylating organisms or other lake parameters that could be related to methylating processes (Bloom et al., 1991).

Other studies have examined the effect of DOC on mercury methylation. Miskimmin et al., (1992), carried out experiments to determine the influence of $\mathrm{DOC}$ and $\mathrm{pH}$ on 
methylmercury production. They found that increasing concentrations of DOC inhibited methylation and favored demethylation. However, at lower $\mathrm{pH}$, the ratio of methylation to demethylation rates was higher, regardless of the concentration of DOC. The authors explained that the reduction in $\mathrm{pH}$ may change the behavior of DOC by increasing desorption of metals. Xun et al. (1987) concluded that the observed increased methylation in water and sediment-water interface at low $\mathrm{pH}$ could result from reduced binding of inorganic $\mathrm{Hg}$ to DOC which causes $\mathrm{Hg}$ to be available for methylating organisms. Miskimmin et al. (1992) proposed explanations for three different situations which are linked to high $\mathrm{Hg}$ in lake fish. (1) contamination in fish in low-pH seepage lakes with clear waters results from in-lake methylmercury production only. (2) in drainage lakes that have near-neutral organic-rich waters where in lake production is inhibited by high DOC, methylmercury brought in by runoff from the catchment area is probably the main source of $\mathrm{Hg}$ found in fish. (3) in drainage lakes with low $\mathrm{pH}$ and high DOC, both in-lake production and runoff may contribute to the $\mathrm{Hg}$ found in fish.

The importance of oxygen content for the formation of methylmercury has also been studied by many researchers. Regnell and Tunlid (1991) carried out experiments in lake sediments from Sweden to compare methylation rates under anoxic and oxic conditions. Their results suggest greater 
rates of methylation under anoxic conditions. However, Bisogni and Lawrence (1975) observed a greater net methylmercury production in aerobic lake sediments. It is clear that methylation is carried out by microorganisms under both aerobic and anaerobic conditions. Therefore, there must be other factors yet not completely understood that enhance or inhibit activity of methylating bacteria leading to one parameter or a combination of parameters to favor mercury methylation in some lakes but not in others.

\section{Previous Studies of Mercury in the Everglades}

After statewide investigations indicated that fish tissues with some of the highest Hg levels in Florida were found in the Everglades, Delfino et al., (1993), carried out a study to determine the spatial and temporal distributions of mercury in this ecosystem. They sampled and analyzed soil cores from 42 sites to obtain preliminary information on $\mathrm{Hg}$ distribution from areas having different hydroperiods, sediment types and degrees of modification by human activities. They found a slightly gradient with higher $\mathrm{Hg}$ values in sites in WCA-1 and parts of WCA-2. Some high values were also observed in the southern half of Water Conservation Area 3-A.

Lower values were predominant in area of the ENP where soils are mostly calcitic mud containing low percentage of 
organic carbon. These areas also experience short hydroperiods; i.e., they are inundated for short periods of time. Delfino et al. (1993) explained these low values as a result of a combination of factors. Mercury has a higher affinity for organic matter than for calcite, and calcitic muds have less organic matter than peats. Also, because calcitic muds occur in areas with short hydroperiods, they are exposed to drying and oxidation which may induce the release of $\mathrm{Hg}$ from soils. Hg concentrations in organic-rich peats showed a wide range with some values being as low as values observed in calcitic mud. Therefore, Delfino et al. (1993) concluded that there was no correlation between soil organic matter content and $\mathrm{Hg}$ concentrations. However, peats with lower Hg concentrations were typically found in areas that experience short hydroperiods such as sites located in western WCA-3A. Lodenius et al. (1987) concluded that repeated wetting/drying of peats is a major mechanism leading to leaching of $\mathrm{Hg}$ from peat soils; their results were used to explain low concentrations in organic-rich soils found by Delfino et al. (1993).

Delfino et al. (1993) also proposed an increase in the rate of deposition of $\mathrm{Hg}$ in more recent decades. Sediment ages were determined by radio-isotope analysis of $210 \mathrm{~Pb}$ and 137Cs. Eight of the sixteen dated core profiles showed higher concentrations in more recent layers $(0-10 \mathrm{~cm})$. Five of the sixteen core profiles suggested no concentration change while 
three showed distinct decreases in concentrations. Based upon radiometric dating of all cored sediments, mercury accumulation rates were found to be between 2 and $29 \mu \mathrm{g} / \mathrm{m}^{2} / \mathrm{y}$ around the turn of the century. Mercury accumulation rates after 1985 were found to average 6.3 times higher (23-141 $\left.\mu \mathrm{g} / \mathrm{m}^{2} / \mathrm{y}\right)$. The authors concluded that "There is no recurrent trend in mercury concentration profiles that would suggest post-depositional mobility of mercury in our wetland cores." They also observed that when mercury concentration profiles were compared to sediment accumulation profiles it appeared that mercury concentrations were diluted by increased rates of sedimentation; i.e., mercury soil profiles showed more gradual increases in mercury concentrations from the bottom to the top layers in areas that experience higher rates of soil deposition.

The study of Delfino et al. (1993) also indicated that the magnitude of increased deposition varied from area to area. For instance, cores collected in WCA-1 and WCA-2 seem to have had greater increases in deposition of $\mathrm{Hg}$ than those in WCA-3 and in ENP. The authors proposed three possible explanations for this distribution:

1. The source of $\mathrm{Hg}$ is overland sheet flow from the north.

2. The atmospheric deposition of $\mathrm{Hg}$ is non-uniform and there is more deposition in the northern portion of the 
Everglades.

3. The post-depositional mobility of $\mathrm{Hg}$ in soils is nonuniform probably due to varying retention by different soil types from north to south.

Delfino et al. (1993) list several papers which describe experiments and investigations on post depositional mobility of Hg, including Rogers and McFarlane (1978), Henning et al. (1989), Lodenius (1990), and Winfrey and Rudd (1990). A common conclusion of these papers is that a portion of the deposited Hg gets volatilized and methylated, but this loss is not enough to alter the overall soil profile. However, Delfino et al. (1993) acknowledge the need for further studies on the physico-chemical behavior of $\mathrm{Hg}$ in the Everglades to determine all processes that might be related to the mobility of $\mathrm{Hg}$.

Atmospheric Emissions of Mercury In Florida

Once high levels of mercury in fish were found in many rivers and lakes throughout Florida, state and federal agencies engaged in determining the sources of mercury emissions in this state. In 1992, the Florida Department of Environmental Regulation released a report entitled "Mercury Emissions to the Atmosphere in Florida." This report lists estimated ranges of mercury emissions from both anthropogenic 
and natural sources in recent decades. Anthropogenic sources were divided into 16 categories which include: municipal solid waste combustion, electric utility industry, medical waste incineration, sugar cane industry, pulp and paper industry, cement industry, other fossil fuel combustion sources, paint manufacturing and application, electrical apparatus, dental preparation usage, laboratory usage, transportation fuel burning, open burning, miscellaneous sources, and by product disposal areas. Of these, municipal solid waste, fossil fuel, medical waste disposal, paint application and electrical apparatus disposal account for $92 \%$ of the mercury emissions by anthropogenic sources.

Soil degassing and forest/natural fires were listed as the only two categories for natural mercury emissions in Florida. Soil degassing is estimated to be the largest single source of mercury to the atmosphere in Florida, and it is estimated to account for 35 to $40 \%$ of total emissions in the state.

Anthropogenic emissions comprise $60 \%$ of the total mercury emissions to the atmosphere in Florida while natural emissions account for about $40 \%$. The total mercury emissions to the atmosphere in Florida in 1990 were estimated to be 62,888 1b. This value suggests that Florida contributes about $3.0 \%$ and $0.5 \%$ to the total mercury emissions in the United States and the world, respectively. However, this study does not provide estimates of the percentage of mercury that is 
deposited regionally. It is important to estimate the total amount of mercury emitted to the atmosphere in South Florida, and it seems that this amount is significant, but environmental contamination results from the mercury that is deposited in the environment, and estimates on the rates of mercury deposition are not available. 


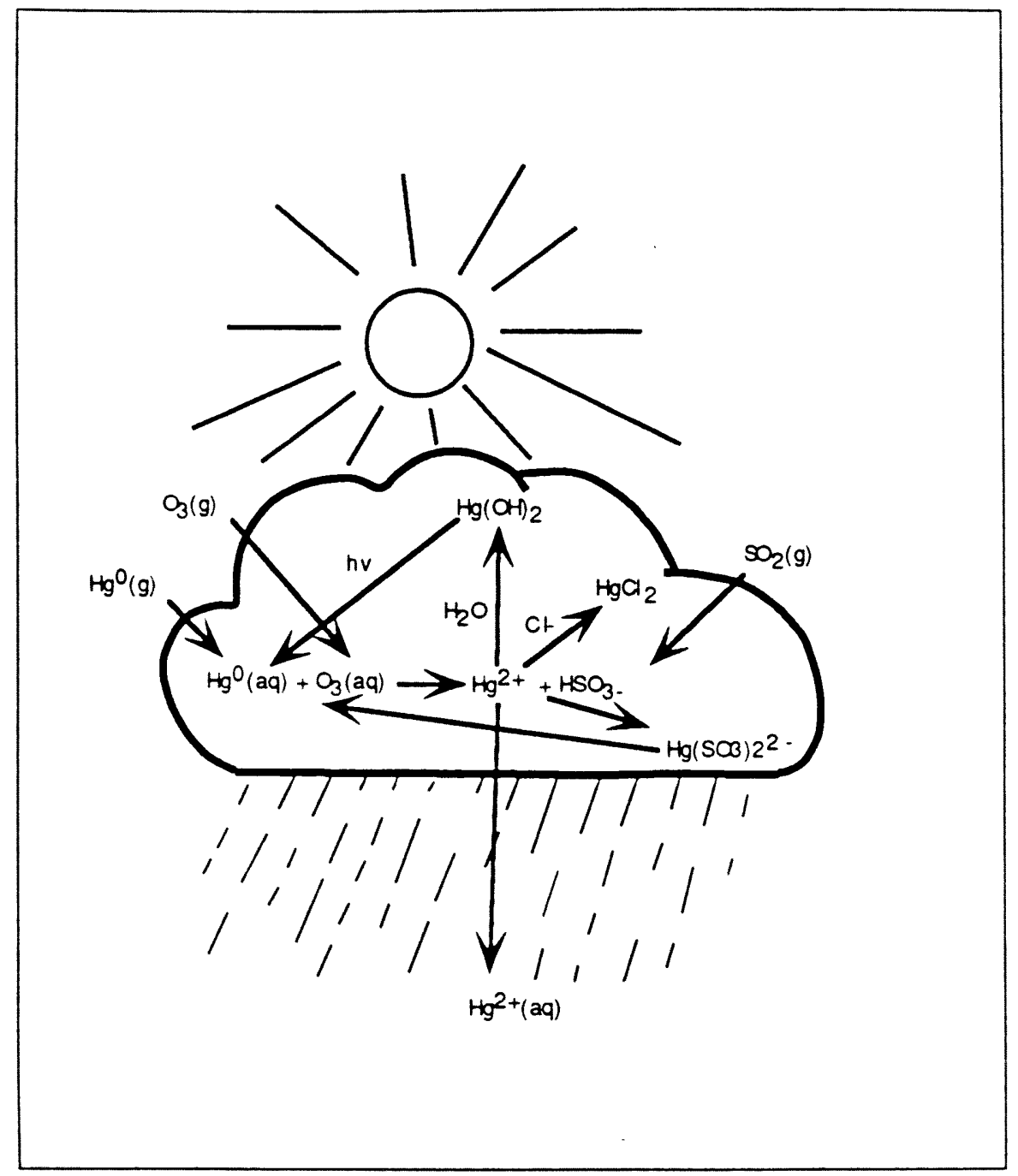

Figure 2.1. Diagram illustrates the cycle of mercury in the atmosphere. (Modified from Lindqvist, 1991). 


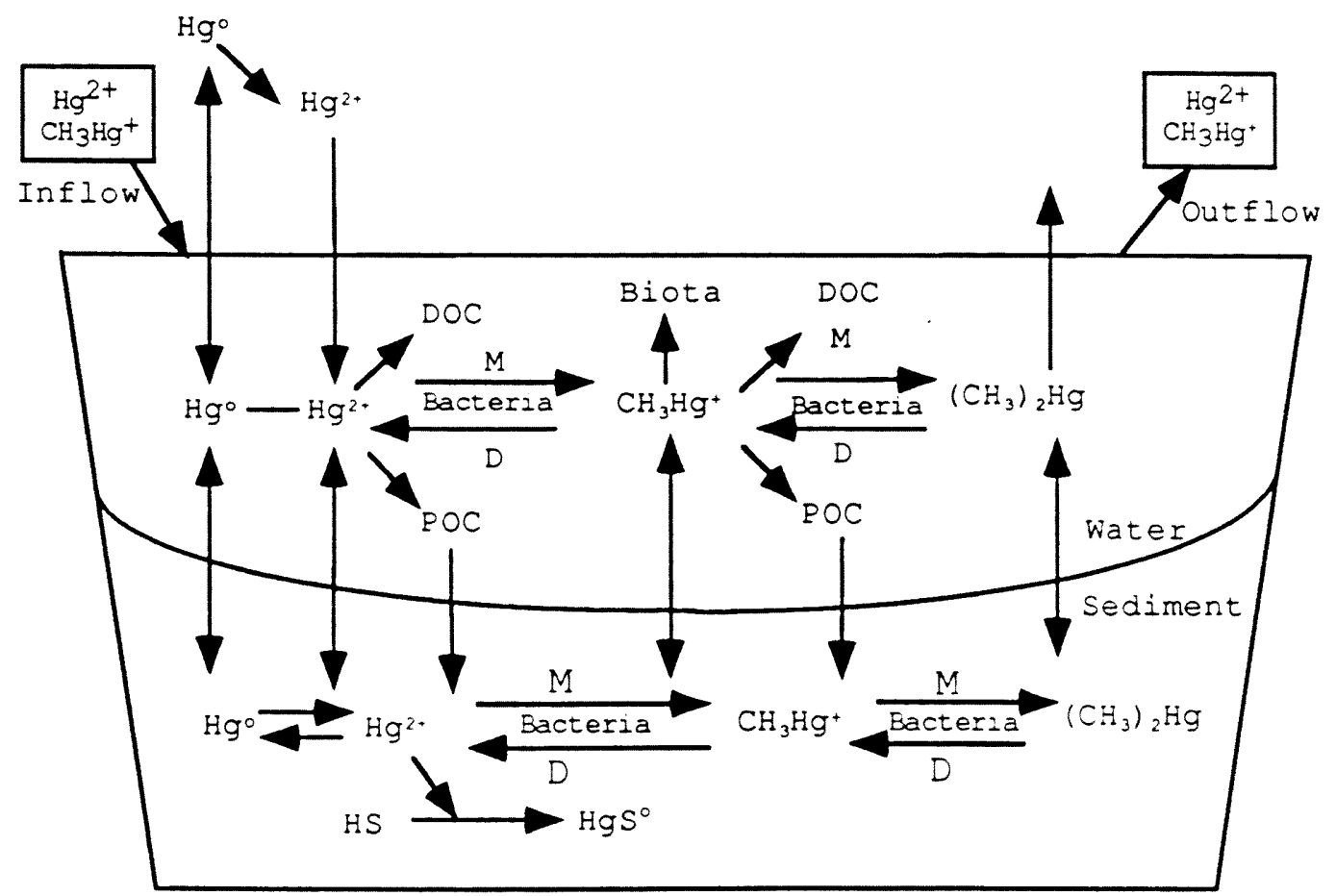

Figure 2.2. Diagram illustrates the biogeochemical cycle of mercury in aquatic systems. (Modified from NAS, 1978). 


\section{Field Techniques}

The 64 sites used to produce the distribution of soil-Hg concentrations in the southern half of WCA-3A were chosen based on a two-mile interval grid (Fig. 3.1), covering about $500 \mathrm{~km}^{2}\left(200 \mathrm{mi}^{2}\right)$. East-west traverses were labeled A to J, with $A$ being the westernmost traverse and $J$ the easternmost traverse. North-south traverses were numbered from 6 to 14, with 6 being the northernmost traverse. Initially, northsouth traverses were expected to go from 1 to 14 . Traverse 1 was located in Broward County near and parallel to state Road 84. Due to time constraints and difficulties created by dense vegetation, the northern part of WCA-3A was not accessible by airboat, so traverses 1 to 5 were not sampled. The northern edge of the study area had no distinct break in hydrology or topography.

Grab samples for the determination of surface soil-Hg distribution were collected from September 25 to December 17 , 1993. Triplicate samples were collected at each site for a total of 192 samples used in this study. Sites were accessed by an airboat provided by the Southeast Environmental Research Program. Latitude/longitude coordinates of sample locations were determined using an on-board Global 
Positioning system (GPS) which is accurate to plus or minus $10 \mathrm{~m}$.

All samples were under water at the time of collection. Water depths varied from about $0.4 \mathrm{~m}$ on the west to about 1.5 $m$ on the east and southeast sites near canals. Samples were stored in $120 \mathrm{ml}$ polypropylene specimen cups and kept in a cooler during the field work. In the lab, specimen cups were stored in a freezer until they were prepared for analysis.

Core samples used for the determination of vertical distribution of $\mathrm{Hg}$ were collected on December 17,1993 and February 12, 1994. Nine of the 64 surface sample sites were cored to provide information on the vertical distribution of $\mathrm{Hg}$ (Fig. 3.1). Cores were collected using three inch (7.6 $\mathrm{cm}$ ) internal diameter polycarbonate tubes which were $60 \mathrm{~cm}$ long. The top of each tube was threaded so that an aluminum handle could be screwed on for better handling and control during coring. The bottom edge of each tube was sharpened so that the tube would cut the peat soil with minimal compression.

Cored samples were kept inside tubes which were placed in black plastic bags for safe-keeping and stored vertically, preserving their original upward position. In the lab, cores were extruded and sliced in two-centimeter intervals. The sliced portions were placed in labeled polypropylene specimen cups and stored in a freezer until they were prepared for analysis. 


\section{Laboratory Techniques}

Total Mercury Analysis

The first phase of this study was devoted to developing a method to analyze total mercury in soil by cold vapor atomic fluorescence spectrometry (Jones et al., 1995). In this procedure $100 \mathrm{CC}$ of soil sample which were either peats or marly peats, are homogenized by adding 30 to $50 \mathrm{ml}$ of deionized water and blended for three minutes to form a consistent slurry. Five $\mathrm{ml}$ of this slurry are transferred to a clean polypropylene cup and diluted with $45 \mathrm{ml}$ of $0.6 \mathrm{~N} \mathrm{HCl}$ solution. The addition of the $0.6 \mathrm{~N} \mathrm{HCl}$ solution is necessary to neutralize any calcium carbonate in the soil. One $\mathrm{ml}$ of this mixture is placed in a $10 \mathrm{ml}$ glass ampule with $2 \mathrm{ml}$ of concentrated nitric acid and left to stand under the hood for 20 minutes. The ampule is sealed, autoclaved in a water bath for one hour at $105^{\circ} \mathrm{C}$, and then allowed to cool to room temperature. Immediately prior to analysis by cold vapor atomic fluorescence, the ampule is broken and $0.5 \mathrm{ml}$ of the digested material is transferred to a polyethylene vial containing $19.5 \mathrm{ml}$ of $0.1 \mathrm{~N} \mathrm{HCl}$ solution. The vial is shaken well and placed in the autosampler of a Merlin atomic fluorescence detector (P.S. Analytical, model No. PSA 10.023). The digested samples are reacted with acidic stannous chloride to convert any $\mathrm{Hg}^{2+}$ present into $\mathrm{Hg} \circ$ vapor. 
The mercury vapor is removed from the solution by a stream of Argon, and the mercury is detected by atomic fluorescence. The Hg-Merlin Fluorescence detector has a detection limit better than 1 part per trillion.

\section{Soil Bulk Density}

Soil bulk density is measured by lightly packing wet soil samples into a $10 \mathrm{ml}$ beaker. Wet soil samples are then transferred to labeled pre-weighed aluminum weighing boat and their wet weights are determined and recorded. The weighing boats containing the wet soil samples are placed in an oven and dried overnight at $80{ }^{\circ} \mathrm{C}$. The weighing boats are removed from the oven and weighed twice on an analytical balance. Dry weights soil samples are obtained by subtracting the weight of the aluminum weighing boat. Bulk density of soil samples is calculated as the dry weight of soil per $10 \mathrm{~cm}^{3}$ and the data are given as $\mathrm{g} / \mathrm{cm}^{3}$.

\section{Percentage of Total Organic Carbon}

The percentage of total organic carbon in soil samples was determined by loss on ignition. For this measurement, an aluminum weighing boat is weighted on an analytical balance and its weight recorded. One gram of dried soil sample is weighed on the weighing boat. The weighing boat is placed in a furnace and combusted at $550{ }^{\circ} \mathrm{C}$ for 3.5 hours. After combustion, the weighing boat with its ashed content is 
removed from the furnace and weighed. The weight of the ashed sample is compensated for the weight of the aluminum weighing boat and the percentage of total organic carbon is obtained using the following formula:

$$
\text { \&TOC }=[(\text { dry wt-ashed wt }) / \text { dry wt }] \star 100
$$

\section{Total Phosphorus}

Total phosphorus is determined by oxidizing and hydrolyzing all of the phosphorus-containing compounds in a sample to soluble reactive phosphate, and measuring the soluble reactive phosphorus concentration with a rapid flow phosphorus analyzer, RFPA (Alpkem, model \# 301). Total phosphorus is determined using duplicate dried and ground soil samples. $25 \mathrm{mg}$ of dry ground soil sample are weighed into a $20 \mathrm{ml}$ glass scintillation vial. $0.20 \mathrm{ml}$ of $0.17 \mathrm{M}$ $\mathrm{MgSO}_{4}$ and one $\mathrm{ml}$ of distilled water are added to the weighed sample. The sample is evaporated to dryness in an oven at 80 ${ }^{\circ} \mathrm{C}$. Once dry, the sample is ashed at $550{ }^{\circ} \mathrm{C}$ for 3.5 hours. $10 \mathrm{ml}$ of $0.24 \mathrm{~N} \mathrm{HCl}$ solution are added to the combusted samples and these are placed overnight in a circulating oven at 80 o C. The resultant soluble reactive phosphorus concentration of the sample is measured in an Alpkem RFA 300 by continuous flow analyzer (Solorzano and Sharp, 1980). 


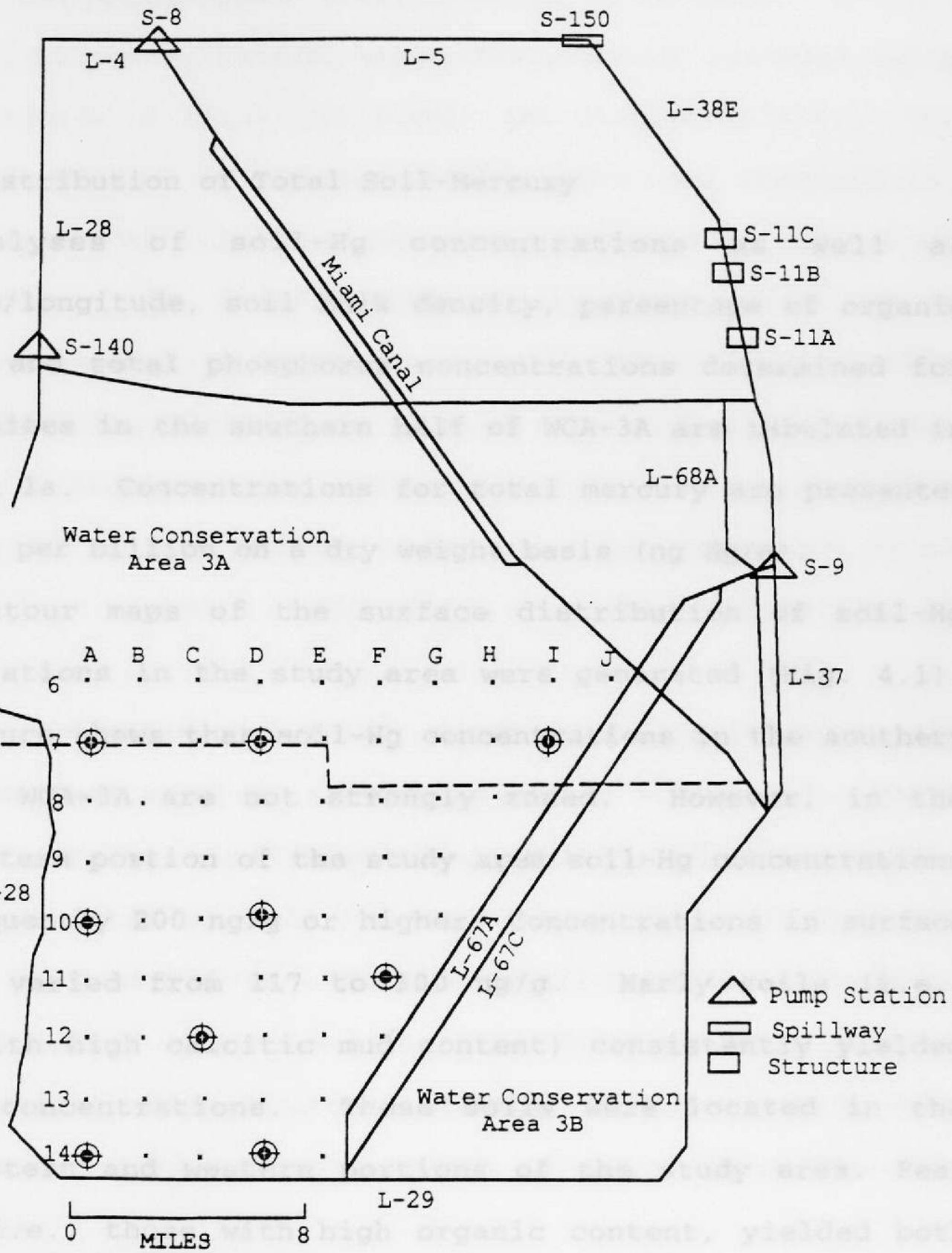

Figure 3.1. Location of sites in the southern half of WCA-3A. Bull's eye symbol shows sites where soil profiles were collected. 
Results

Areal Distribution of Total Soil-Mercury

Analyses of soil-Hg concentrations as well as latitude/longitude, soil bulk density, percentage of organic carbon, and total phosphorus concentrations determined for all 64 sites in the southern half of WCA-3A are tabulated in Appendix 1a. Concentrations for total mercury are presented in parts per billion on a dry weight basis (ng $\mathrm{Hg} / \mathrm{g}$ ).

Contour maps of the surface distribution of soil-Hg concentrations in the study area were generated (Fig. 4.1). This figure shows that soil-Hg concentrations in the southern half of WCA-3A are not strongly zoned. However, in the northwestern portion of the study area soil-Hg concentrations are frequently $200 \mathrm{ng} / \mathrm{g}$ or higher. Concentrations in surface samples varied from 117 to $300 \mathrm{ng} / \mathrm{g}$. Marly soils (i.e., those with high calcitic mud content) consistently yielded low Hg concentrations. These soils were located in the southwestern and western portions of the study area. Peat soils; i.e., those with high organic content, yielded both high and low concentrations. The mean concentration for all samples was $211.6 \mathrm{ng} / \mathrm{g}$ and the median $207.5 \mathrm{ng} / \mathrm{g}$. The samples showed a standard deviation of 44.96 and standard 
error of 5.6. The variance was 2021.6. The figure shows that most of the highest Hg contents in surface samples are found in the northwestern portion of the study area.

Soil-Hg concentrations were statistically analyzed using the procedures of Lepeltier (1969) and Sinclair (1974). The data were plotted on log probability paper and examined for the presence of straight segments indicating individual populations. The distribution of the data points of an individual population is represented as a bell curve. When a log-normal distribution is plotted on a logarithmic scale, it forms a straight line. Figure 4.2 is a log-probability plot of the surface soil-Hg data from this study; it forms one straight segment indicating only one population of samples.

The percentage of total organic carbon in soils are plotted against total $\mathrm{Hg}$ concentrations in figure 4.3. There is a poor correlation between the percentage of total organic carbon and total soil-Hg concentrations in soils from the southern half of WCA-3A. The distribution of the percentage of total organic carbon in soils from the study area is shown in figure 4.4. This figure illustrates the consistently high percentage of total organic carbon in soils throughout the study area.

$\mathrm{Hg}$ concentrations in $\mathrm{ng} \mathrm{Hg} / \mathrm{g}$ were normalized to soil bulk density to compensate for the differences in density between peats and marly peats. After normalizing surface 
soil-Hg concentrations to soil bulk density (ng Hg/CC), a contour map of the surface distribution of mercury was created. Figure 4.5 shows the distribution of mercury concentrations normalized to soil bulk density. This figure illustrates that the concentration gradient from the NNW to the east observed in figure 4.1 seems to be an artifact created by differences in soil bulk density across the study area. Figure 4.5 shows that the surface distribution of mercury is relatively uniform in the study area, and that the highest $\mathrm{Hg}$ concentrations are found in the southwest region of my study area where soil bulk density was highest. Overall, the soil bulk density normalized Hg data show a lack of gradients in the area. When bulk density normalized Hg data points were statistically analyzed by the log probability test, these plotted on a straight line indicating the presence of one Hg population in the study area (Fig. 4.6). The surface distribution of soil bulk density in the study area is illustrated in figure 4.7 .

Areal Distribution of Total Phosphorus

Some areas of the Everglades are affected by nutrientenriched surface waters that drain from the EAA located to the north of WCA $3 A$ and west-northwest of WCA 1 and 2 . In this study, total phosphorus concentrations (in parts per million $(\mu \mathrm{g} / \mathrm{g}))$ were determined at each site. Figure 4.8 illustrates the surface distribution of total phosphorus in 
the study area (contour interval is $50 \mu \mathrm{g} / \mathrm{g}$ ). Phosphorus concentrations are plotted against total soil-Hg concentrations in figure 4.9; these two quantities are very poorly correlated in surface samples. Figure 4.10 is a logprobability plot of total phosphorus in the surface samples, showing only one population of total phosphorus concentrations in the study area.

Phosphorus concentrations were normalized to soil bulk density and used to generate a map of the surface distribution of this element in the study area (Fig. 4.11). Figure 4.11 shows the distribution of total phosphorus normalized data is patchy and random, with several areas showing higher concentrations. Total phosphorus and total $\mathrm{Hg}$ concentrations were normalized to bulk density and plotted against one another (Figure 4.12). Linear correlation between the bulk density normalized data were slightly better than that of original data of phosphorus and mercury. Total phosphorus concentrations normalized to bulk density were statistically analyzed for log-probability test. Figure 4.13 shows that the total phosphorus concentrations normalized to bulk density also attest to the presence of one population in the study area.

Vertical Distribution of Total Soil-Mercury

$$
\text { Sites A-7, A-10, A-14, C-12, D-7, D-10, D-14, F-11, and }
$$

I-7 were chosen for core sampling (Fig. 3.1). Cores varied 
in length from 18 to $36 \mathrm{~cm}$. Appendix $1 \mathrm{~b}$ shows the data generated at each site. Soil-Hg profiles from all nine sites showed higher concentrations near the surface (Figure 4.14).

Delfino et al. (1993) found that depths between 11 to 17 $\mathrm{cm}$ in Everglades soil profiles represent material deposited around the year 1900, which indicates an accumulation rate of 1.2 to $1.8 \mathrm{~mm} / \mathrm{yr}$. Ages of sediments were determined by radiometric dating by $210 \mathrm{~Pb}$ and $137 \mathrm{Cs}$ isotopes. Craft and Richardson (1993), using similar radiometric dating methods, determined higher rates for peat accumulation, $1.6-2.0 \mathrm{~mm} / \mathrm{yr}$ for areas of reduced hydroperiods and $2.8-3.2 \mathrm{~mm} / \mathrm{yr}$ for areas subject to extended hydroperiods and/or phosphorus enrichment. Because it was an objective of this investigation to observe vertical distribution of mercury in sediments deposited in recent decades, cored samples were around $30 \mathrm{~cm}$ long. The $\mathrm{A}-14$ and $\mathrm{A}-10$ sites yielded cores shorter than $30 \mathrm{~cm}$ because the bedrock was shallower in those sites. With the exception of sites $A-10$ and $A-14$, which had higher calcitic mud content, soil profiles were composed of organic-rich soils; i.e., peats. The peat was mostly very porous, dark brown to black in color with low mineral content. Soil profiles at $A-10$ and $A-14$ were composed mostly of carbonate mud. The color of the carbonate mud was characteristically off-white with some gray bands. The transition zone between the bedrock and soil profiles was composed of a very fine gray mud. 
Concentrations of mercury (ng $\mathrm{Hg} / \mathrm{g}$ ) versus depth are shown for each of the profiles in figure 4.14. Total mercury concentrations are substantially higher near the surface than at depth in most profiles, and increase by a factor of 6 in core $A-7$. One profile (D-14) shows relatively high mercury values throughout, but the highest values are still near the surface. Core $\mathrm{C}-12$ has high concentrations near the surface and also between 25 and $35 \mathrm{~cm}$ depth. Several profiles (A-7, D-7, A-10, F-11, and D-14) show a distinct decrease in total mercury at the surface $(0-2 \mathrm{~cm}$ sample).

In addition to the vertical distribution of soil-Hg in $\mathrm{ppb}$ (ng/g), concentrations were normalized to soil bulk density to determine whether soil-Hg concentration patterns result from differences in bulk densities (Appendix 1b). Graphs of total soil-mercury normalized to bulk density are generally similar to those generated from non-normalized concentrations (Figure 4.15). Most of the density-normalized profiles show strong increases in mercury content toward the surface, with the exception of core D-14. The sharp drop in mercury concentration at the surface seen in several cores in Eigure 4.14 is even more pronounced in the density-normalized data.

Vertical Distribution of Total Phosphorus

Total phosphorus concentrations were determined for core samples (Appendix 1b). Total phosphorus soil profiles showed 
higher concentrations in recent layers for all profiles (Fig. 4.16). This type of distribution for total phosphorus in soil profiles is expected since there is a greater accumulation of organic matter and decomposition in the uppermost layer in soil profiles. In addition, phosphorus is transferred to upper layers by plant roots and microbial activities. The vertical distribution of soil-Hg and that of total phosphorus showed good correlation for most of the nine cores.

\section{Discussion}

Areal Distribution of Total Soil-Mercury

Concentrations of total soil-Hg in the samples ranged from 117 to $300 \mathrm{ng} \mathrm{Hg/g}$ which is slightly above the average normal concentration for soils, but typical of organic-rich soils (Chapter 2). Concentrations in some organic-rich soils can be as high as several thousand ng/g (Kabatas-Pendias and Pendias, 1986).

In the early stages of this study, it was hypothesized that higher soil-Hg concentrations might be found in the northern and/or eastern regions of WCA 3A. This was based on the locations of the EAA to the north of WCA $3 \mathrm{~A}$, and of Miami and other large cities to the east. Previous studies have shown that agricultural soils are enriched in $\mathrm{Hg}$ by fungicide applied to seeds and by trace amounts of $\mathrm{Hg}$ in fertilizers, 
especially phosphorus fertilizers (Mitra, 1986, Alloway, 1990). Studies also point to major cities as source of $\mathrm{Hg}$ due to activities such as incineration of waste and combustion of fossil fuels. The results of this study show no increase toward the east coast where urbanization is greatest.

Figure 4.1 reveals that the areal distribution of mercury in the southern half of water Conservation Area $3 \mathrm{~A}$ is not strongly zoned. However, soil-Hg concentrations in the north-northwestern portion of the study area are frequently equal or higher than $200 \mathrm{ng} / \mathrm{g}$. However, higher values disappear when the mercury data are normalized to bulk density. Figure 4.5 shows the map of the distribution of soil bulk density normalized mercury data. This figure shows that mercury is randomly distributed in the study area. The gradient produced by the original mercury data is an artifact caused by differences in soil bulk density across the study area. Small differences in mercury concentrations become more accentuated if soil bulk density is not taken into account.

Assuming that soil mercury is completely immobile after deposition, Delfino et al. (1993) calculated post-1985 mercury accumulation rates to be $23-141 \mu \mathrm{g} / \mathrm{m}^{2} / \mathrm{y}$ with greater accumulation rates in the northern Everglades. They also calculated that mercury accumulation rates from around the turn of the century (1990) were 2-29 $\mu \mathrm{g} / \mathrm{m}^{2} / \mathrm{y}$. Their 
conclusions are similar to those of Lindqvist et al. (1991) and Swain et al. (1992) who concluded that higher concentrations in recent sediments may reflect increasing mercury emissions by anthropogenic activities. The data of Linqvist et al. (1991) and Swain et al. (1992) are from remote temperate lakes in the US and Sweden. Delfino et al. (1993) suggest that higher mercury accumulation rates in the north may indicate that the atmospheric deposition of mercury is non-uniform, with more mercury being deposited in the northern area. Unfortunately, Delfino et al. (1993) did not normalize their data to soil bulk density and did not discuss its biased effect on the distribution of mercury concentrations.

Mercury concentrations determined in this study suggest that the surface distribution of mercury in the southern half of WCA-3A is not zoned. Mercury concentrations when not normalized to bulk density show a weak gradient from west to east. But this gradient disappeared once bulk density was taken into account. The homogenization of mercury concentrations across the study area may suggest that the primary mercury source to the area is the atmosphere. The fact that mercury concentrations do not increase toward the north or east may indicate that overland flow may not be a significant source. Because of the homogeneity of the surface distribution of mercury concentrations, most likely the source of mercury to the Everglades is regional 
atmospheric deposition. Mercury emissions which are associated with large cities (municipal waste incineration, burning of fossil fuels) do not seem to form localized sources. Also, the lack of gradient toward the northern portion of the study area seems to indicate that $\mathrm{Hg}$ emission from agricultural activities do not from localized sources, either. More study is needed regarding the fate of $\mathrm{Hg}$ emissions and the rate of atmospheric deposition in southern Florida.

Areal Distribution of Total Phosphorus

For the past few decades researchers have been concerned about the impact of phosphorus contamination on the Everglades by agricultural runoff that drains into the Everglades. Jones (1992) has hypothesized that the increase of phosphorus causes more areas to be under anaerobic conditions which are conducive to methylation and solubilization of naturally occurring mercury in the Everglades. One objective of this study was to determine a possible correlation between the areal distributions of total mercury and total phosphorus. Figure 4.9 shows a very poor correlation between total phosphorus and total mercury in the southern half of WCA-3A. Figure 4.12 shows the correlation between the bulk density normalized data of phosphorus and mercury. The coefficient of linear correlation of the data in figure $4.12\left(R^{2}=0.46\right)$ is better than that of the original 
data in figure $4.9\left(R^{2}=0.03\right)$, but still not strongly significant. Even though these individual elements form single log-normal populations in the study area, their lack of correlation is not surprising since their chemical behaviors and their sources probably differ from one another.

Total soil-phosphorus concentrations range frcm 350 to $850 \mu \mathrm{g} / \mathrm{g}$. Mean for total phosphorus concentrations is $592 \mu \mathrm{g}$ $\mathrm{P} / \mathrm{g}$. The range of total phosphorus concentrations determined by this study is similar to ranges determine in the interior of WCAs by Craft and Richardson (1992), whose values range from 432-764 $\mu \mathrm{g} / \mathrm{g}$. Volk et al. (1975) also obtained total phosphorus concentrations in the range of $354-752 \mu \mathrm{g} / \mathrm{g}$ for areas in the interior of WCAs. The results of total phosphorus concentrations determined in this investigation seem to be typical of values found in the interior of the WCAs. The grid of $3.2 \mathrm{~km}(2 \mathrm{mi})$ used in this study, and the density of sites near canals, are too coarse to permit study of small scale variations in total phosphorus concentrations which have been observed very near canals due to inflow by control structures. The results obtained in this study do provide a good description of the overall distribution of total phosphorus concentrations across the southern half of WCA-3A and show that total mercury and total phosphorus concentrations are not related.

Like mercury, the log-probability plots of total soilphosphorus (Fig. 4.10 and 4.13) in surface samples show only 
one population in the southern half of WCA (Fig. 4.7). Most $\mathrm{Hg}$ in the atmosphere is in vapor form $\left(\mathrm{Hg}^{0}\right)$ which may reside in the atmosphere for months and even years and travel to remote areas. In the phosphorus cycle, however, there is no gaseous phase and rainwater contains little phosphorus (Horne and Goldman, 1994). Transport by surface runoff seems to be the main source of phosphorus to lakes. In some ecosystems, significant amounts of phosphorus cycle between soil-plantdecay-soil and this is a major part of phosphorus loading to these ecosystems (Horne and Goldman, 1994). Most importantly, phosphorus is a growth-limiting element which is rapidly removed from natural waters by microbes and plant roots. The Everglades has developed as an oligotrophic ecosystem where plant communities thrive in low nutrient conditions, particularly low phosphorus conditions. Sawgrass marshes, the dominant plant community in the Everglades, require low levels of nutrients (Stewart, 1984).

In the Everglades the highest phosphorus values are found very near canals and are associated with agricultural runoff (Fig. 4.17; Reddy et al., 1991). Phosphorus-enriched areas show values of $1200 \mu \mathrm{g} / \mathrm{g}$ to $1600 \mu \mathrm{g} / \mathrm{g}$ (Reddy et al., 1991). Cattails seem to thrive in nutrient-enriched conditions and have been used as indicators of nutrient pollution in the Everglades (Reddy et al., 1991). The highest concentrations of total phosphorus correlate very well with the distribution of cattail communities in the 
Everglades.

Phosphorus in sewage and agricultural runoff is up to 90 to $95 \%$ soluble phosphorus $\left(\mathrm{PO}_{4}\right)$ and little particulate phosphorus; $\mathrm{PO}_{4}$ is rapidly incorporated into algae, and then into sediments (Horne and Goldman, 1994). Natural river and lake waters contain 5 to $10 \% \mathrm{PO}_{4}$. Figure 4.18 shows the mean concentrations of surface water phosphorus in WCA-2A measured biweekly for six years near inflow structures (Urban et al., 1993). Downstream from these structures, canal water is forced to flow overland, unlike most other areas of the Everglades. This causes dissolved phosphorus to be carried much further into the interior of WCA-2A. However, figure 4.18 shows that most phosphorus is taken up within $6 \mathrm{~km}$ of the control structures, even under these unusual conditions. Elsewhere, excess phosphorus is probably entirely taken up well within a $\mathrm{Km}$ of the canals because of the high capacity of the vegetation and soils to take up phosphorus (Urban et a1., 1993).

The results of the present study show that the surface distribution of total phosphorus concentrations in the southern half of WCA-3A does not correlate with the surface distribution of total mercury. The range of total phosphorus concentrations seem to be that typically found in the interior of WCAs, not associated with high phosphorus values that result from agricultural waste water. 
Vertical Distribution of Soil-Hg

The nine cores chosen for the determination of $\mathrm{Hg}$ in the southern half of WCA-3A showed their highest mercury concentrations in recent layers (Fig. 4.14). Similar results were obtained by Delfino et al. (1993). Differences in concentration between bottom and top layers in the soil profiles were as low as two and as high as six times. Sites A-7 and D-7 showed the greatest differences between bottom and top layers. These sites are located in the northern portion of the study area. Sites C-12 and D-14 showed profiles with alternating soil-Hg concentrations. Sites A-14 and I-7 showed the lowest Hg concentrations and only two-fold differences in concentrations between bottom and top layers. These sites were found in completely different environmental conditions.

A-14 is located in the southwest corner of the study area, had low organic matter content, a short hydroperiod, and shallow depth to bedrock. I-7 is located in the northeastern corner of the study area, had high organic matter content, permanent inundation, and deep soil profile. Lower mercury concentrations in soil profile at site A-14 are possibly because site $A-14$ is located in a region that is subjected to wetting and drying conditions which have been associated with increasing release of $\mathrm{Hg}$ from soil. In site I-7 low mercury concentrations in soil profile may result from fast rates of peat accumulation which have been 
determined in long hydroperiods and/or nutrient-enriched areas such as those along canals (Craft and Richardson, 1993). Craft and Richardson (1993) state that the rate of peat accumulation in areas subject to long or permanent inundation and/or nutrient enriched waters are two to three times faster than those areas not subject to these conditions. Delfino et al. (1993) concluded that mercury concentrations in soils may be diluted by rapid increases in sediment accumulation.

In some sites (A-7, D-7, D-14 and F-11), concentrations in the 0-2 cm layer were lower than those found in the $2-4 \mathrm{~cm}$ layer below (Fig. 4.14). This feature is accentuated in profiles normalized to bulk density (Fig. 4.15). Higher soil-Hg concentrations in the $2-4 \mathrm{~cm}$ interval in the soil profiles correlate with the levels where Eh values are lowest and methane concentrations are highest in Everglades soil profiles (Fig. 4.19; Bachoon and Jones, 1992). Eh is a measurement of the redox potential of natural systems which range from +700 to -300 millivolts, $\mathrm{mV}$ (Patrick, 1990). Ranges of +700 to $+400 \mathrm{mV}$ are considered well oxygenated; a redox potential of about $+100 \mathrm{mV}$ is moderately reducing while -200 is a strongly reducing environment (Patrick, 1990). Bachoon and Jones (1992) while studying potential rates of methanogenesis in sawgrass marshes with peat and marl soils in the Everglades also measured redox potential in these soils (Fig. 4.19). Their results show redox potential values 
in the range of +90 to +350 for marls and +75 to +210 for peats. Lowest redox values and highest methane concentrations were found around $-4 \mathrm{~cm}$ which is the level where the greatest decomposition of organic matter occurs (Fig. 4.19). Therefore, the $2-4 \mathrm{~cm}$ interval in Everglades soil profiles is probably the level where most $\mathrm{Hg}$ and phosphorus are being released because the decay of organic matter provides a mechanism for moving $\mathrm{Hg}$ from deep in the soil and concentrating it near the surface.

Log probability plots for both total soil-Hg and total phosphorus suggest the presence of two populations with depth (Fig. 4.20 and 4.21). The two populations in the soil profiles of total phosphorus and total mercury will be addressed in this discussion as background and anomalous. The background population consists of low values which are relatively constant after certain depth in the soil profile. The anomalous population consists of high values which deviate from those in the background and usually increase toward the top layers. For total phosphorus the presence of two populations in soil profiles is expected for the following :

1. Decomposition of plant material occurs near the surface where the input of detritus plant material is greatest (Horne and Goldman, 1994).

2. Phosphorus is uptaken from lower depth and transferred closer to the surface by plant roots. In 
addition, bacteria may affect the release of phosphorus from minerals in soils which can then be remobilized (Fenchel and Blackburn, 1979).

Total soil-mercury in soil profiles also show two populations with anomalous values near the surface. The anomalous mercury populations found in the upper purtion of the soil profiles may be the result of increased deposition of mercury in the region by the atmosphere and overland flow. However, most mercury soil profiles showed good correlation with total phosphorus (Fig. 4.22). This good correlation between total mercury and total phosphorus suggests that since phosphorus is remobilized by plants and microbes, then mercury concentrations in soil profiles may be due to remobilization by similar processes.

Metals are known to be taken up from the substrate by plant roots. Some species of plants are so efficient in taking metals from the environment that they may be used in exploration for ore deposits and some species may be used as good biomonitors for ambient metals (Rusmussen, 1994). At present, information on the plant communities in the Everglades and their ability to accumulate soil-Hg is not available. However, it is conceivable that soil-Hg may be remobilized by biologic activities associated with plant and microbial communities in the substrate.

Many metals seem to be remobilized by changes in redox condition; i.e., as soil-adsorbed metals are buried they may 
be subject to reducing conditions which cause metals to remobilize. Benoit et al. (1994) studied the effects of redox fluctuations on the mobility of iron, manganese, aluminum and mercury in peat columns. Their results indicate that, unlike the three other metals, mercury does not seem to be affected by redox conditions. Other studies have also determined that mercury does not correlate with other metals in organic-rich soil profiles (Percy and Borland, 1985; Martin and Hartman, 1987). Mercury adsorption to soil seems to be controlled primarily by organic matter. Once sequestered by organic matter in the soil, mercury does not leach or remobilize during seasonal changes in aerobic and anaerobic conditions (Zillioux et al. 1994). Lodenius et al. (1987) studied the effect of different factors on the remobilization of mercury in peat columns of Finnish bogs. Their results indicate that acidity, chloride, and fertilizers had little to no effect on the remobilization of Hg from the organic-rich matrices. Leaching was increased by wetting-drying conditions which were probably due to changes in the physical properties of the peats (Lodenius, 1987).

Delfino et al. (1993), based on radiometric dating of soil profiles in the region, calculated average mercury accumulation rates and concluded that these have increased throughout the entire Everglades since the turn of the century. Their results are based on the assumption that mercury, once deposited in the sediments, is completely 
immobile, so that vertical soil-Hg profiles may be treated purely as depositional records. However, this study shows that soil-Hg may be remobilized by biological processes similar to those known to affect phosphorus. If the observed vertical distributions of soil-Hg are partly or largely due to remobilization by plants, rates of mercury deposition calculated from the vertical distribution of mercury concentrations in the manner of Delfino et al. (1993) will be overestimates of the true rates.

Delfino et al. (1993) explained the lower soil-Hg concentrations in sites near canals assuming that fast peat accumulation dilutes the mercury deposited in those sites. The possible effect of fast peat accumulation rates on the slope of the curve of mercury concentrations in soil profiles were tested by the following method: total mercury concentrations were normalized to bulk density and multiplied by the interval of $2 \mathrm{~cm}$ to the depth where background concentrations are found (Appendix 1c). Assuming that mercury concentrations in soil profiles are diluted by fast peat accumulation and mercury deposition is uniform across the study area, the following should be true: the soilmercury profiles in the north-northwest portion of the study area should contain more mercury over a shorter interval than those near canals where peat accumulation is higher (Fig. 4.23). Figure 4.23 shows how dilution of mercury concentrations by rapid peat accumulation should 
theoretically affect the distribution of mercury in soil profiles. The total amount of mercury between the maximum and background mercury levels should be similar in profiles across the area, even though this interval becomes greater with faster peat accumulation. However, the total amount of mercury in the cores were neither similar nor did they show any particular pattern. Figure 4.24 shows a poor correlation between total mercury in soil profiles and the interval to background values. The fact that the amounts of mercury in the interval between maximum and background $\mathrm{Hg}$ Iines are not similar further suggests that mercury is remobilized after deposition.

The distribution of mercury concentrations in soil profiles at sites $\mathrm{C}-12$ and $\mathrm{D}-14$ does not show a decrease with depth. These profiles are double-peaked which further suggests the remobilization of mercury. It seems unlikely that mercury deposition in those sites has increased and decreased twice over the last few decades while elsewhere in the same region there is a continuous increase in mercury deposition.

Anthropogenic emissions of mercury have increased for the past 200 to 300 years with the ever growing industrialization of modern societies (Nriagu, 1990). Since the beginning of this century, large scale anthropogenic emissions increased largely due to combustion of fossil fuel and burning of industrial and municipal waste. Burning of 
fossil fuel accounts for $60 \%$ of the anthropogenic emissions of mercury, about 2.26 thousand tons per year (Nriagu, 1990) It would be surprising if soil profiles of organic-rich sediments such as peats did not reflect this increase in some way. Other studies which have obtained similar soil-Hg profiles have concluded that they do reflect an increase of mercury deposition by atmospheric input based on studies that suggest that mercury is quite immobile in organic-rich soils (Lindqvist et al., 1991; Swain et al., 1992). However, the good correlation between total phosphorus and total soil-Hg in Everglades peat profiles suggests that post-depositional mobility of soil-Hg by biological processes may be important. Estimates of soil-Hg depositional rates will need to account for this remobilization in order to give an accurate picture of mercury cycling in the Everglades. 


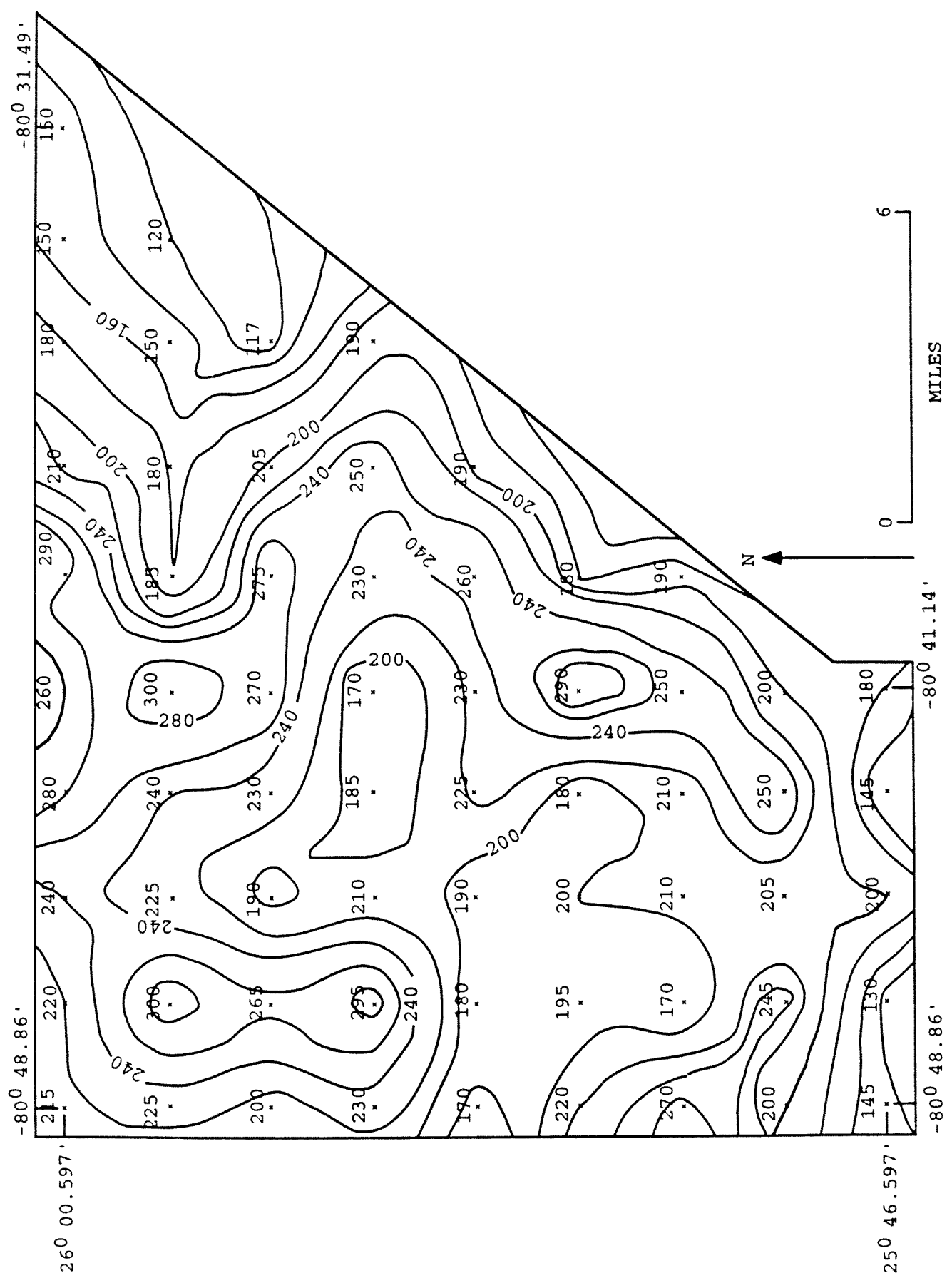

Figure 4.1. Contour map of the areal distribution of total soil-Hg concentrations in the southern half of WCA-3A. Hg concentrations are presented in $\mathrm{ng} \mathrm{Hg} / \mathrm{g}$. 


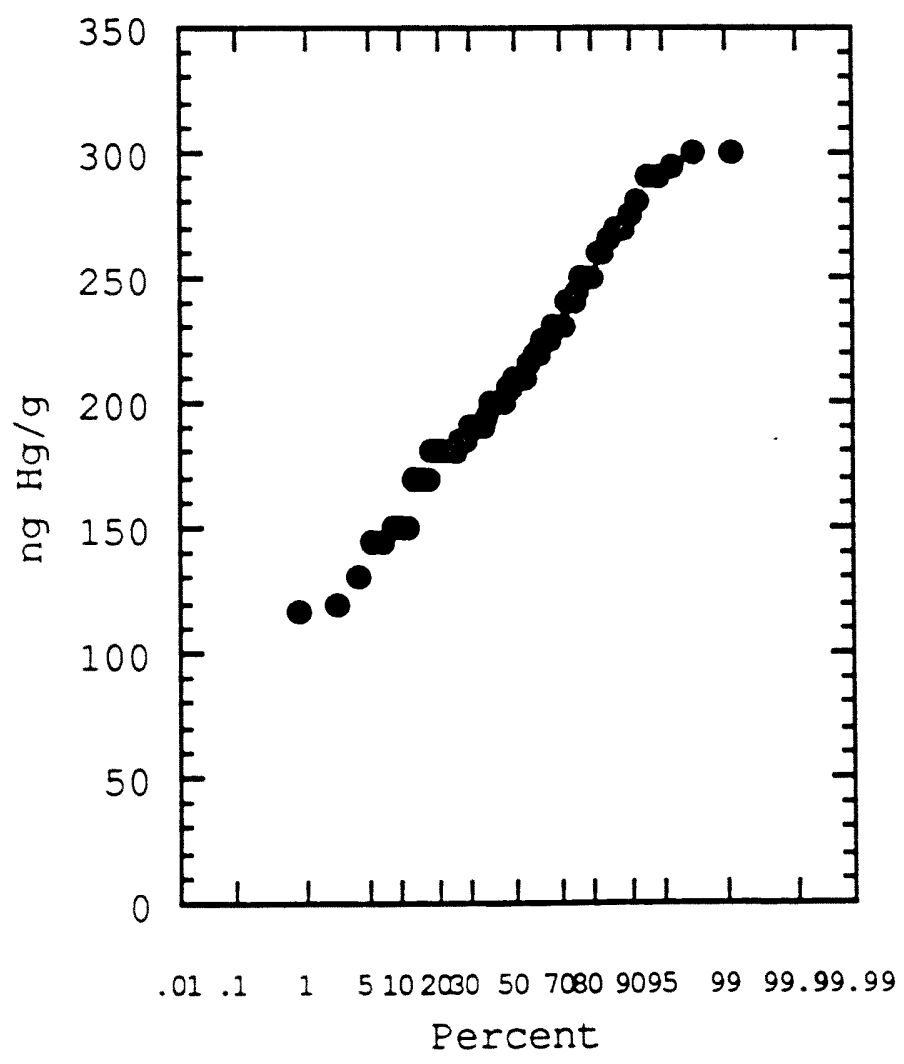

Figure 4.2. Log probability plot of surface distribution of soil-mercury concentrations (ng $\mathrm{Hg} / \mathrm{g}$ ) in the southern half of WCA-3A suggests the presence of only one population in the study area. 


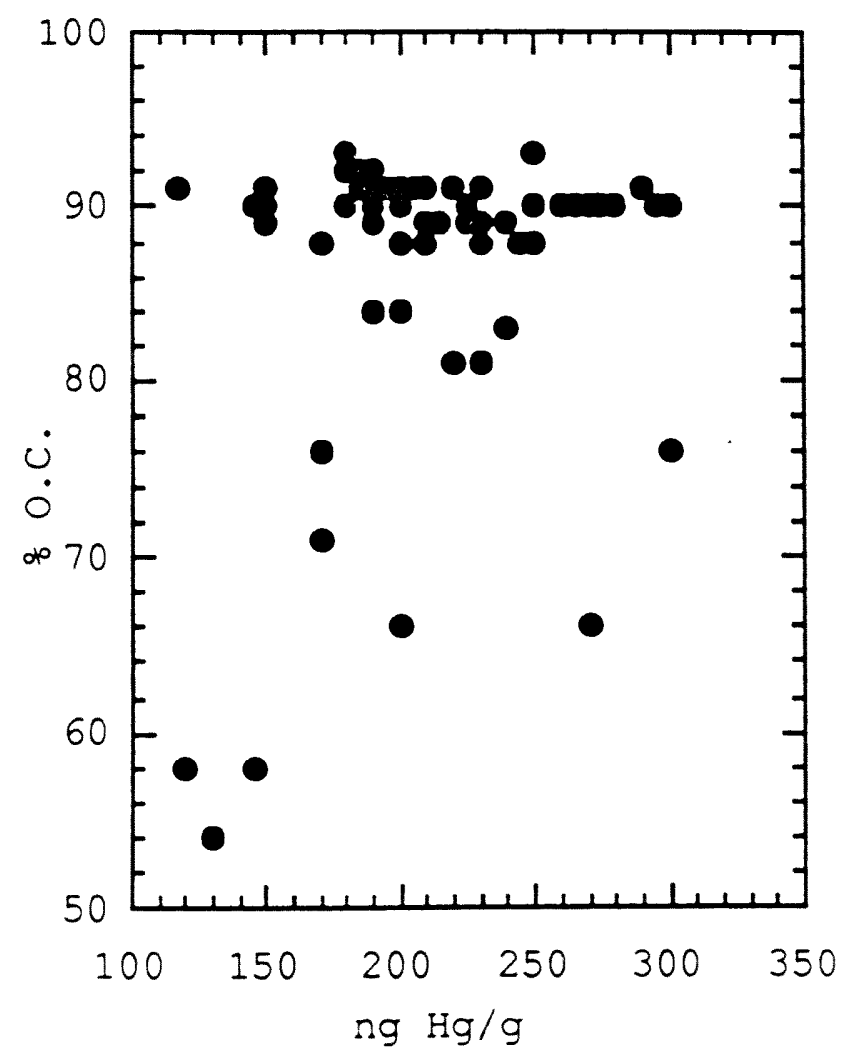

Figure 4.3. Plot of the linear correlation between areal soil-mercury concentrations and percentage of total organic carbon in soil in the southern half of WCA-3A. 


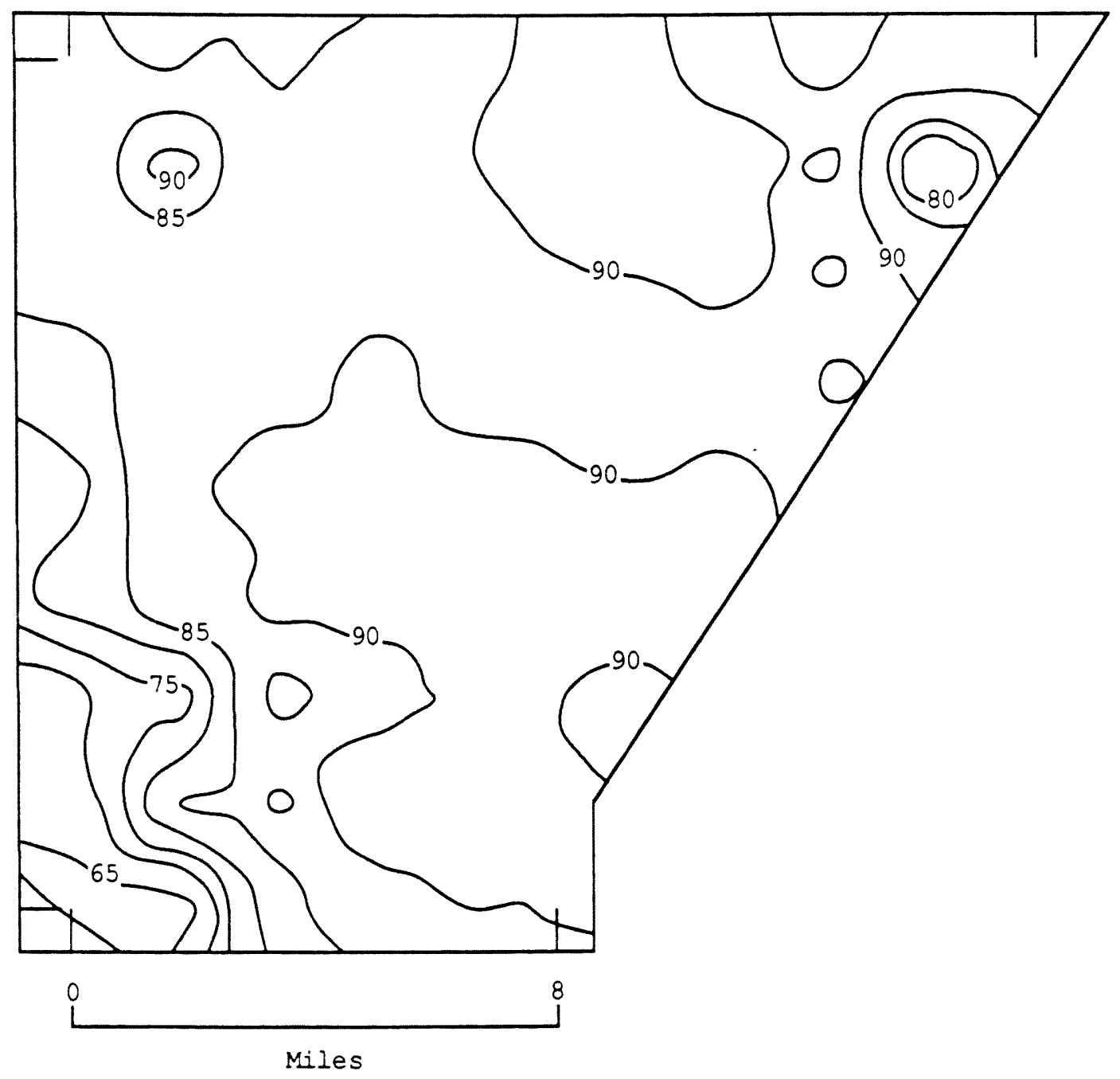

Figure 4.4. Areal distribution of percentage of total organic carbon in soils from the southern half of WCA-3A. 


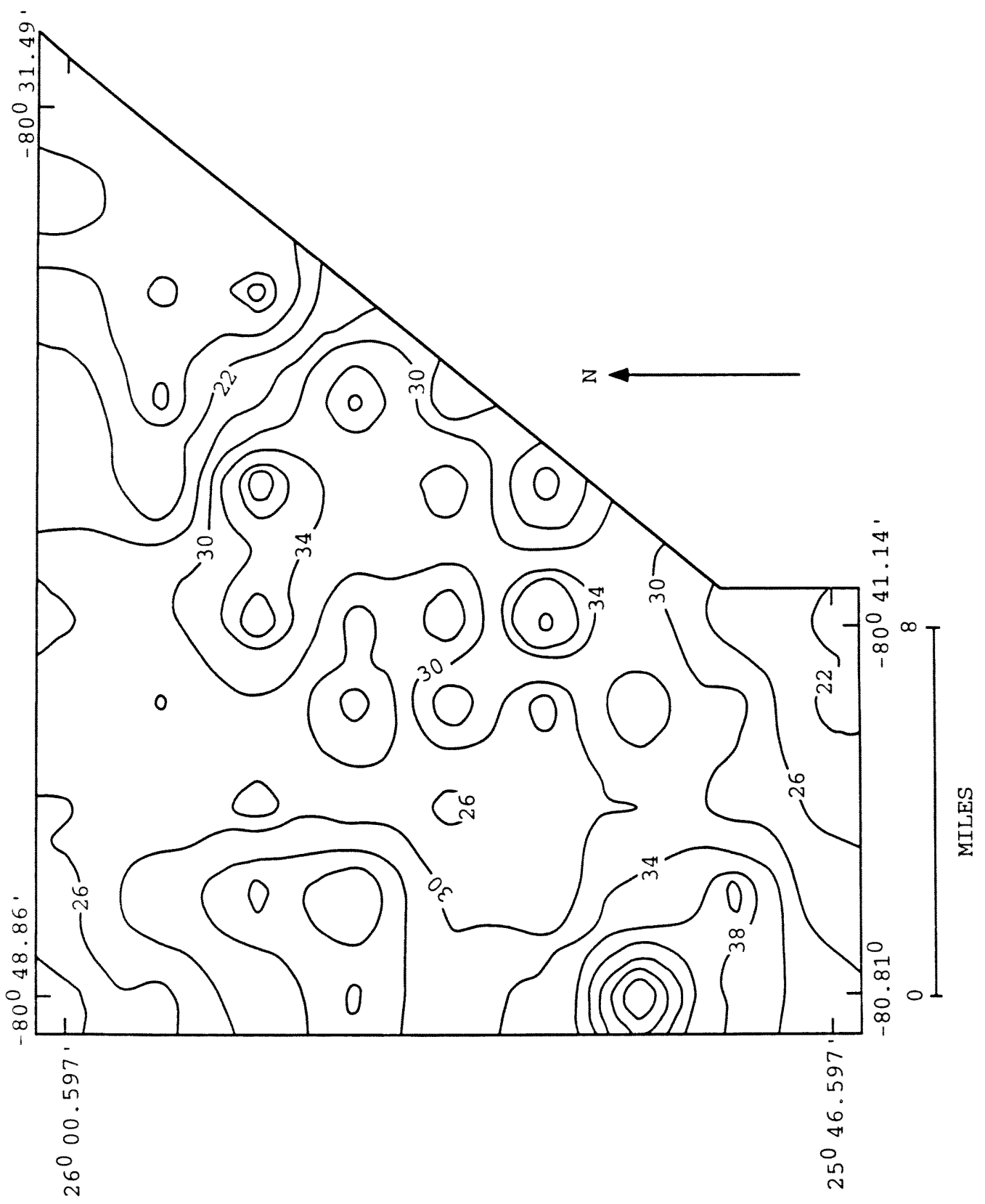

Figure 4.5. Contour map of the areal distribution of total soil-mercury concentration normalized to soil bulk density. Concentrations are given in $\mathrm{ng} \mathrm{Hg} / \mathrm{cc}$. 


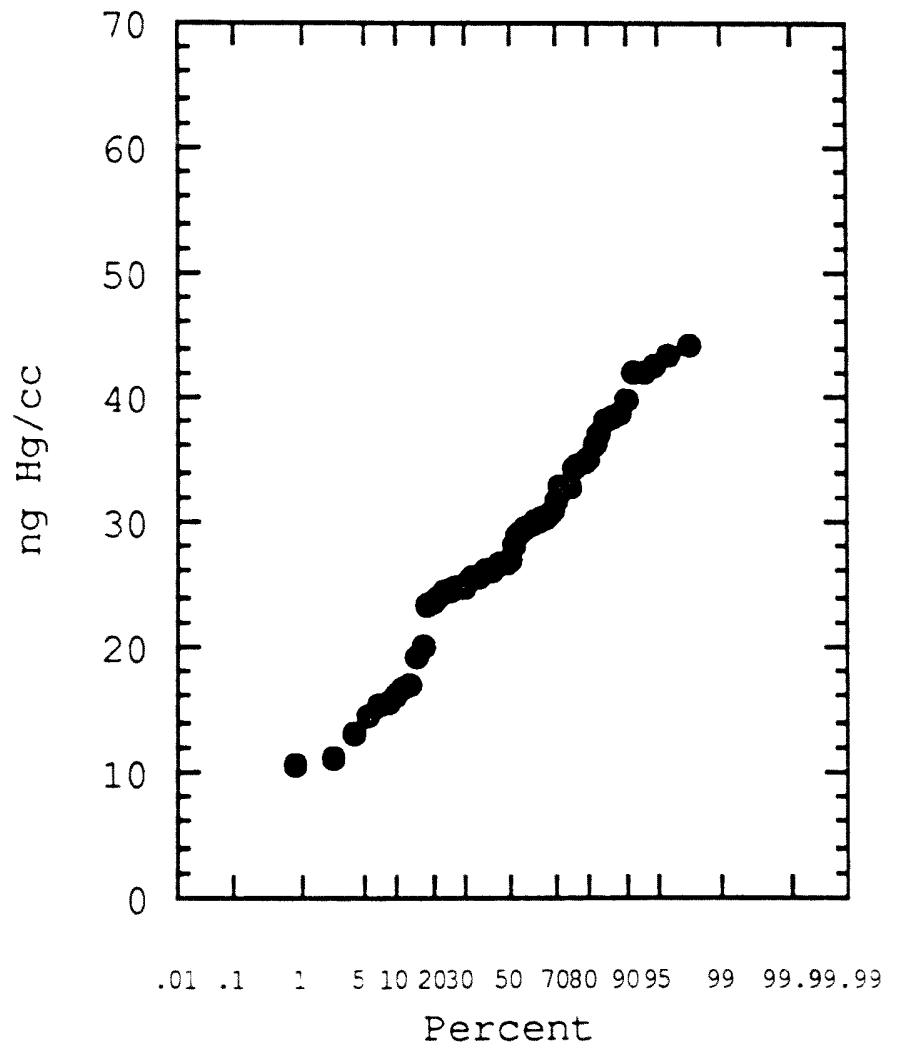

Figure 4.6. Log probability plot of surface soil-mercury concentrations normalized to soil bulk density shows that only one population exists in the southern half of WCA-3A. Mercury concentrations are presented in $\mathrm{ng} \mathrm{Hg} / \mathrm{cc}$. 

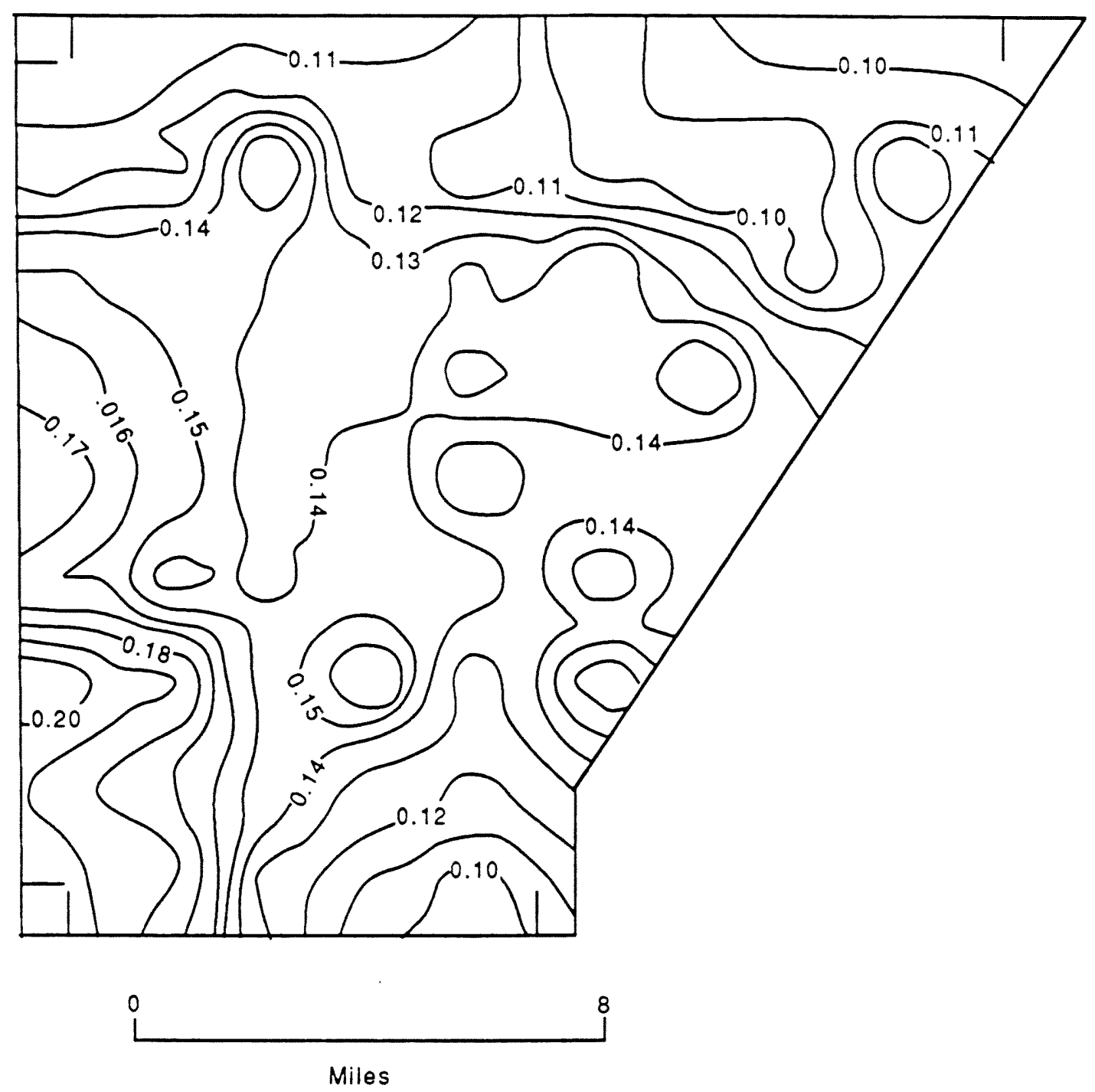

Figure 4.7. Contour map showing the surface distribution of soil bulk density in the southern half of WCA-3A. Bulk density is given in $\mathrm{g} / \mathrm{cc}$. 


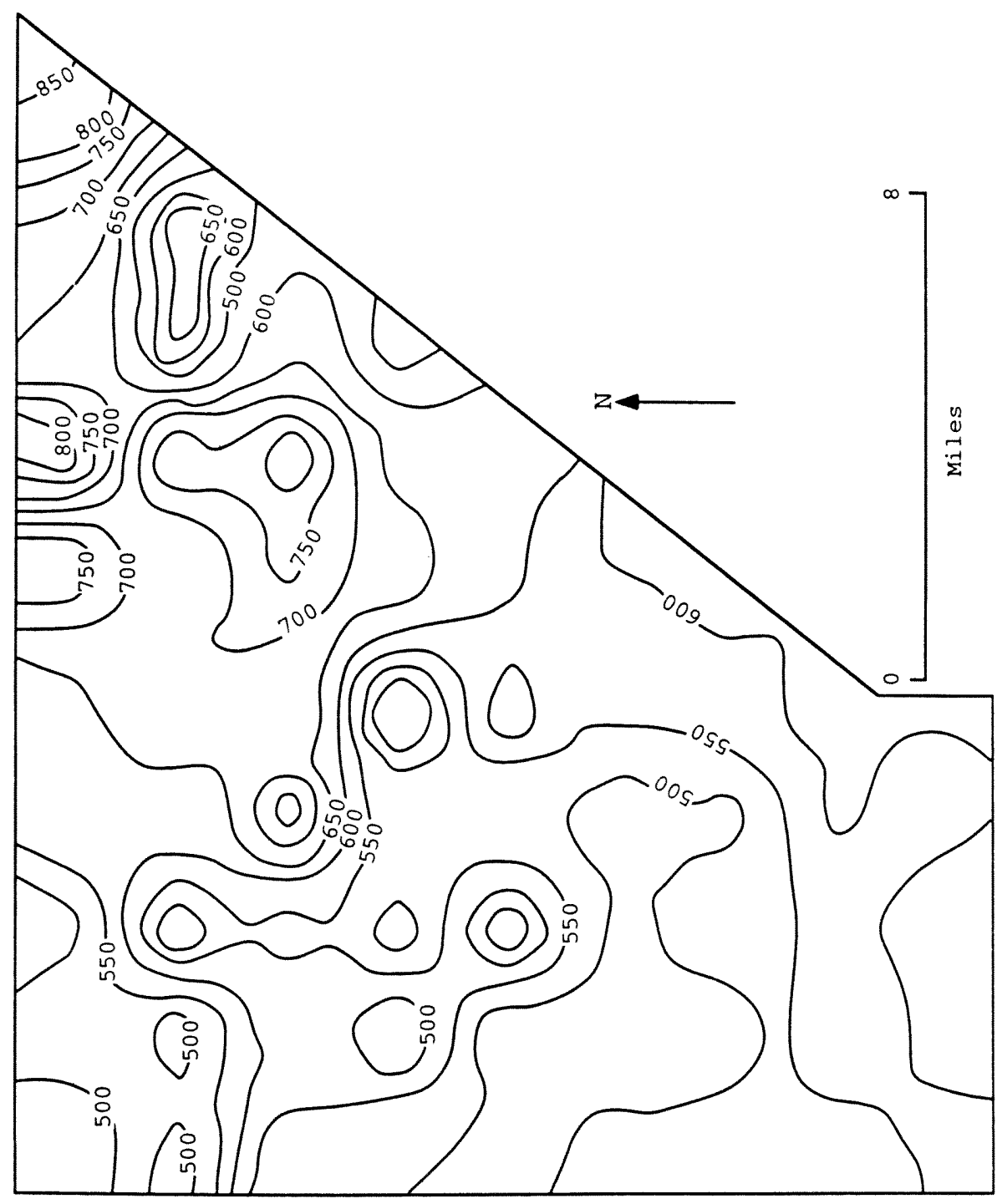

Figure 4.8. Contour map of the areal distribution of total phosphorus concentrations in the southern half of WCA-3A. Total phosphorus concentrations are given in $\mu \mathrm{g} \mathrm{P} / \mathrm{g}$. 


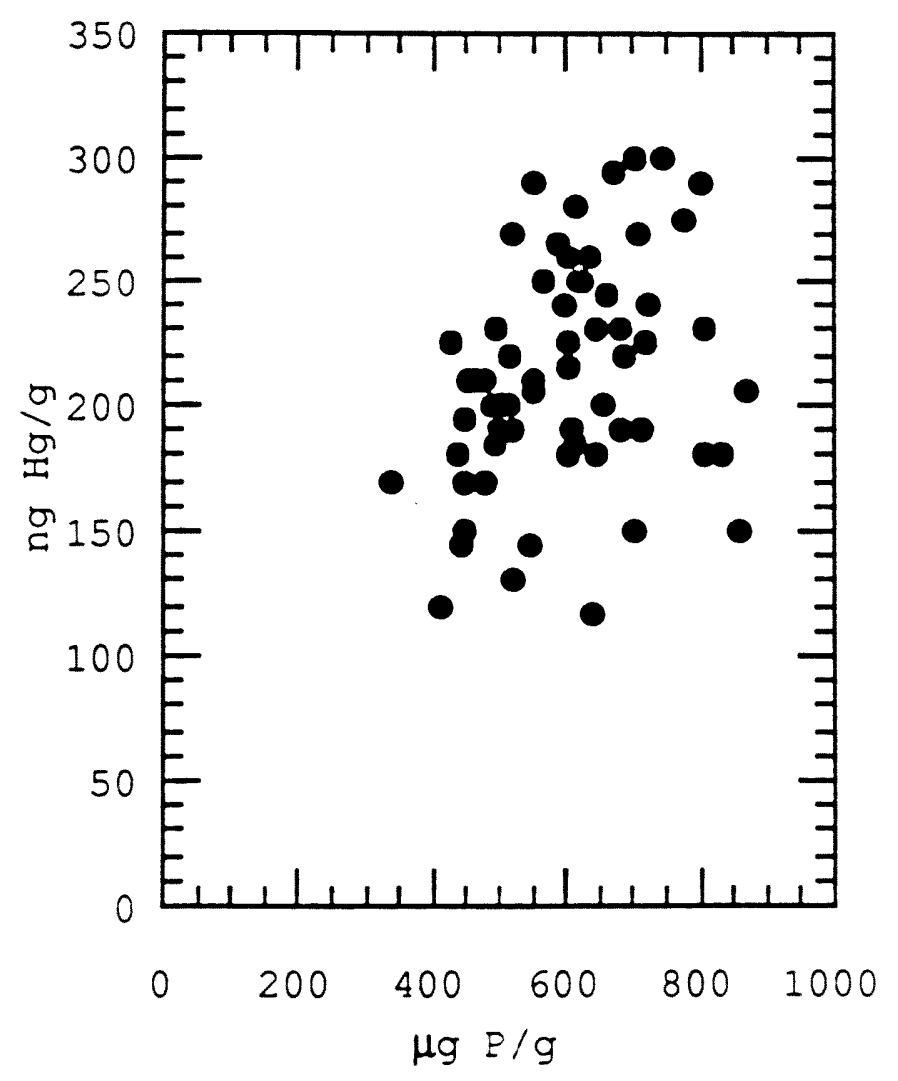

Figure 4.9. Plot of linear correlation between surface concentrations of soil-mercury (ng $\mathrm{Hg} / \mathrm{g}$ ) and total phosphorus concentrations $(\mu \mathrm{g} \mathrm{P} / \mathrm{g})$. 


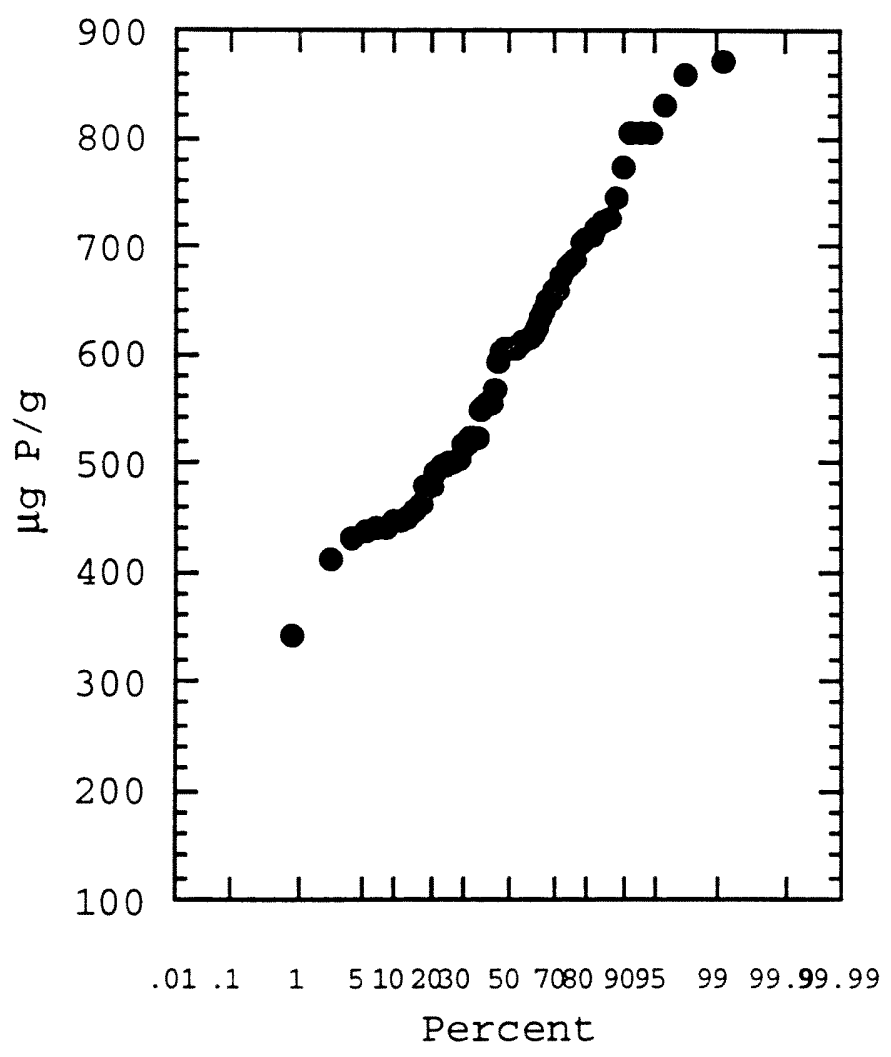

Figure 4.10. Plot of the log probability of the surface concentrations of total phosphorus $(\mu \mathrm{g} \mathrm{P} / \mathrm{g})$ in the southern half of WCA-3A shows that only one population exists in the study area. 

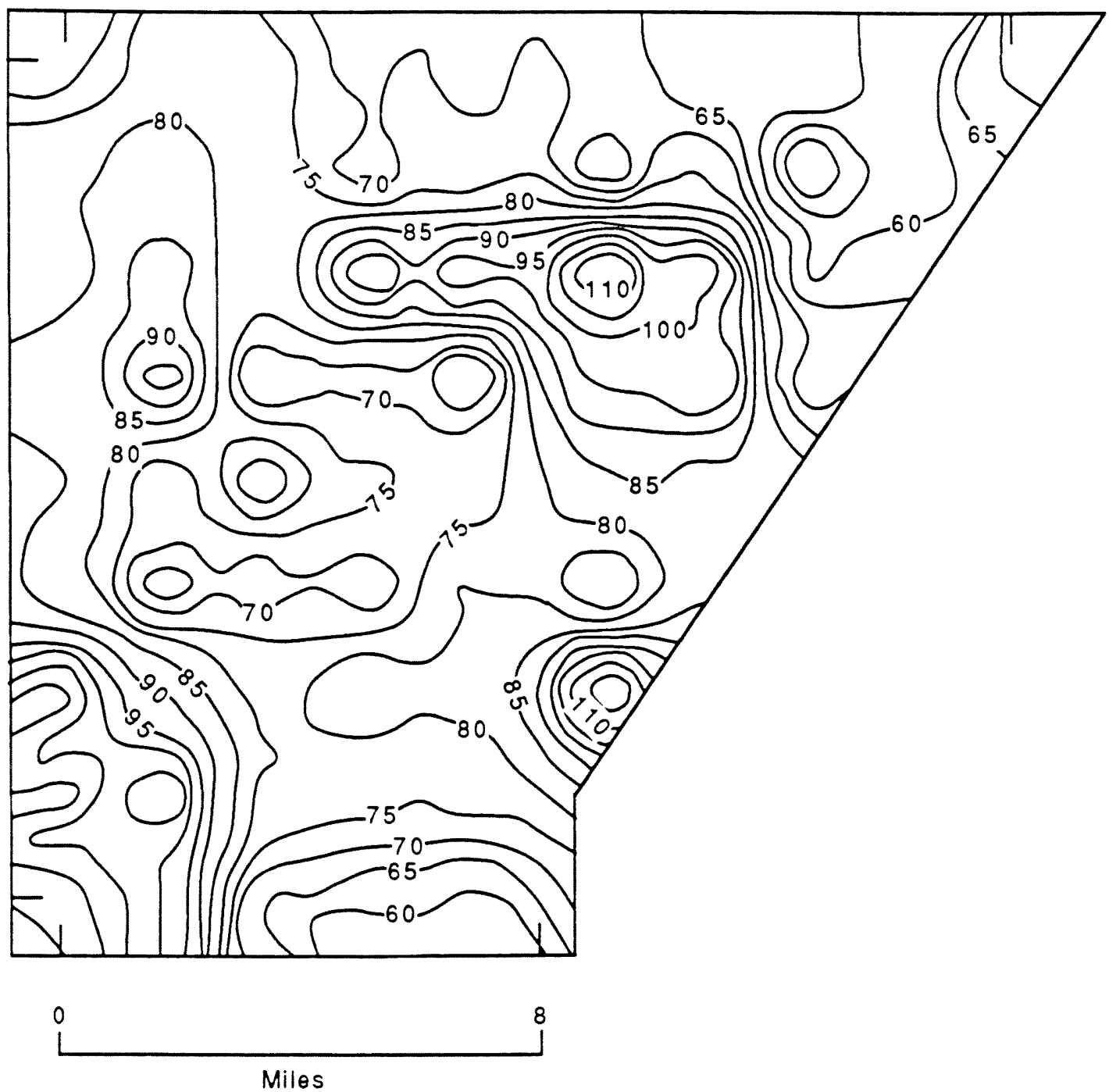

Figure 4.11. Contour map of the surface distribution of phosphorus concentrations normalized to soil bulk density. Phosphorus concentrations are presented in $\mu \mathrm{g} P / C C$. 


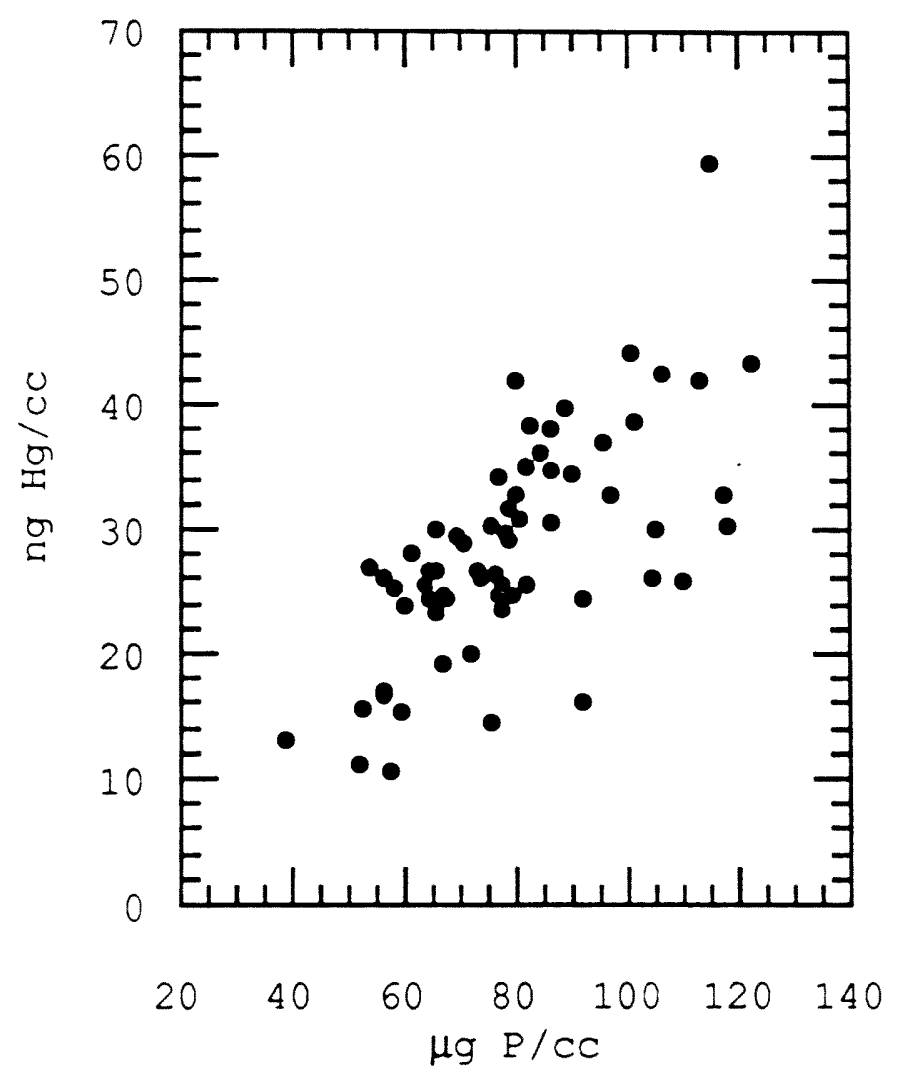

Figure 4.12. Plot of the linear correlation between surface concentrations of total soil mercury and total phosphorus. Concentrations have been normalized to soil bulk density and are presented in $\mathrm{ng} \mathrm{Hg} / \mathrm{CC}$ and $\mu \mathrm{g} \mathrm{P} / \mathrm{CC}$. 


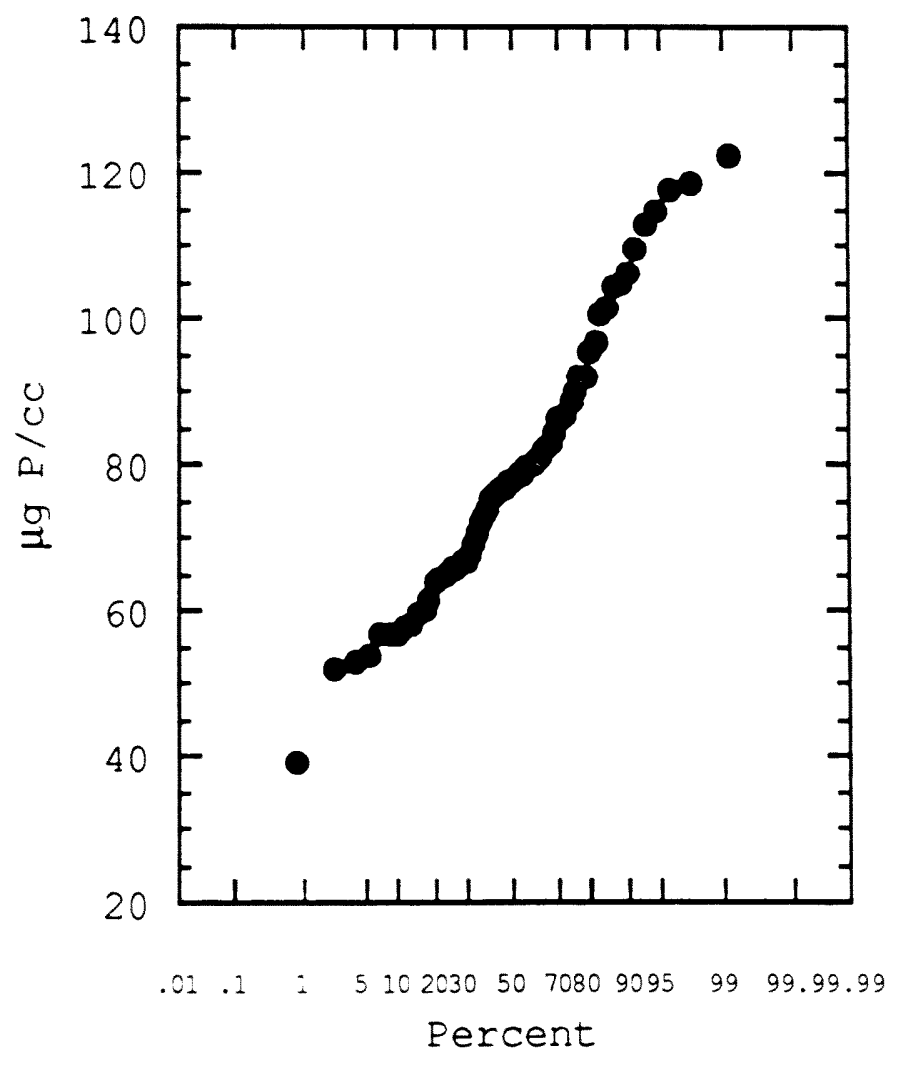

Figure 4.13. Plot of the log probability of surface phosphorus concentrations normalized to soil bulk density. Phosphorus concentrations are presented in $\mu \mathrm{g} P / \mathrm{C}$ and suggest the presence of only one population in the southern half of WCA-3A. 

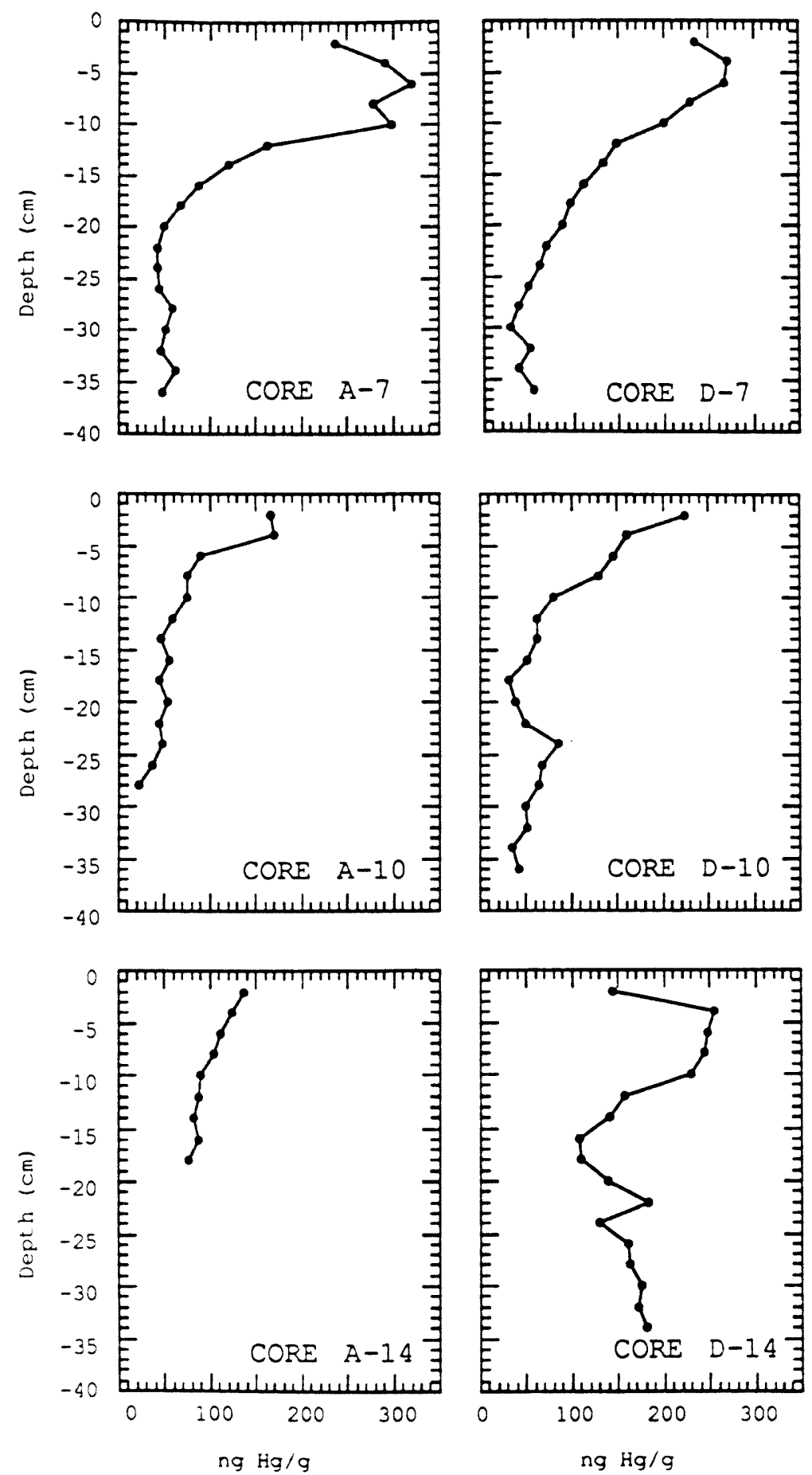

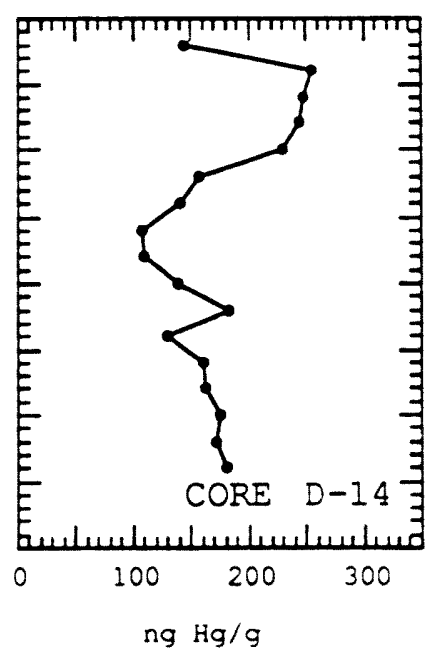

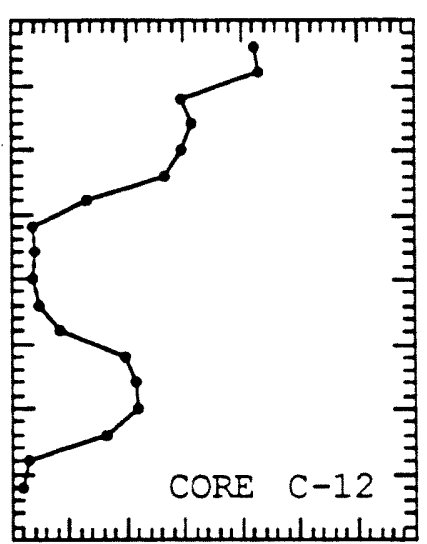
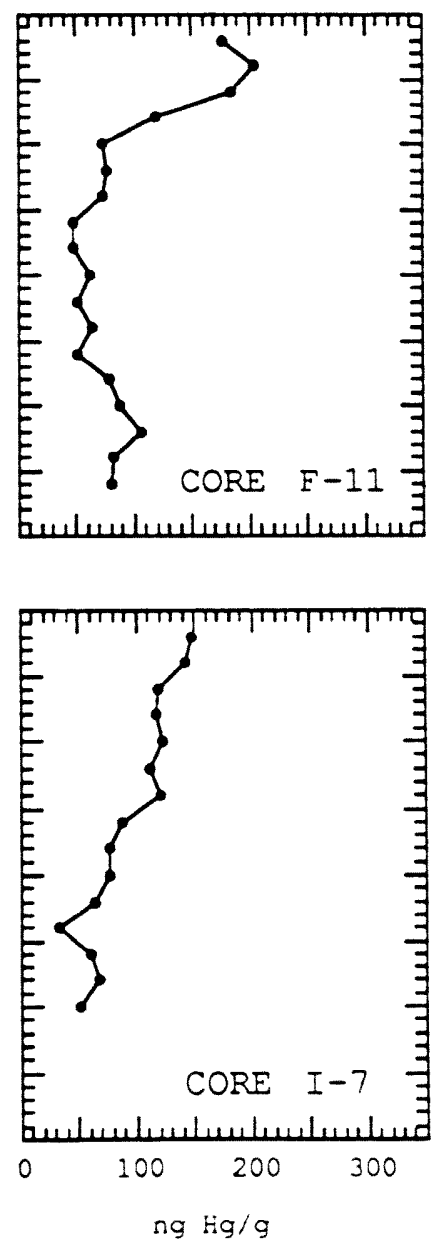

Figure 4.14. Vertical distribution of total mercury concentration ( $\mathrm{ng} \mathrm{Hg} / \mathrm{g}$ ) in soil profiles in the southern half of WCA-3A. 

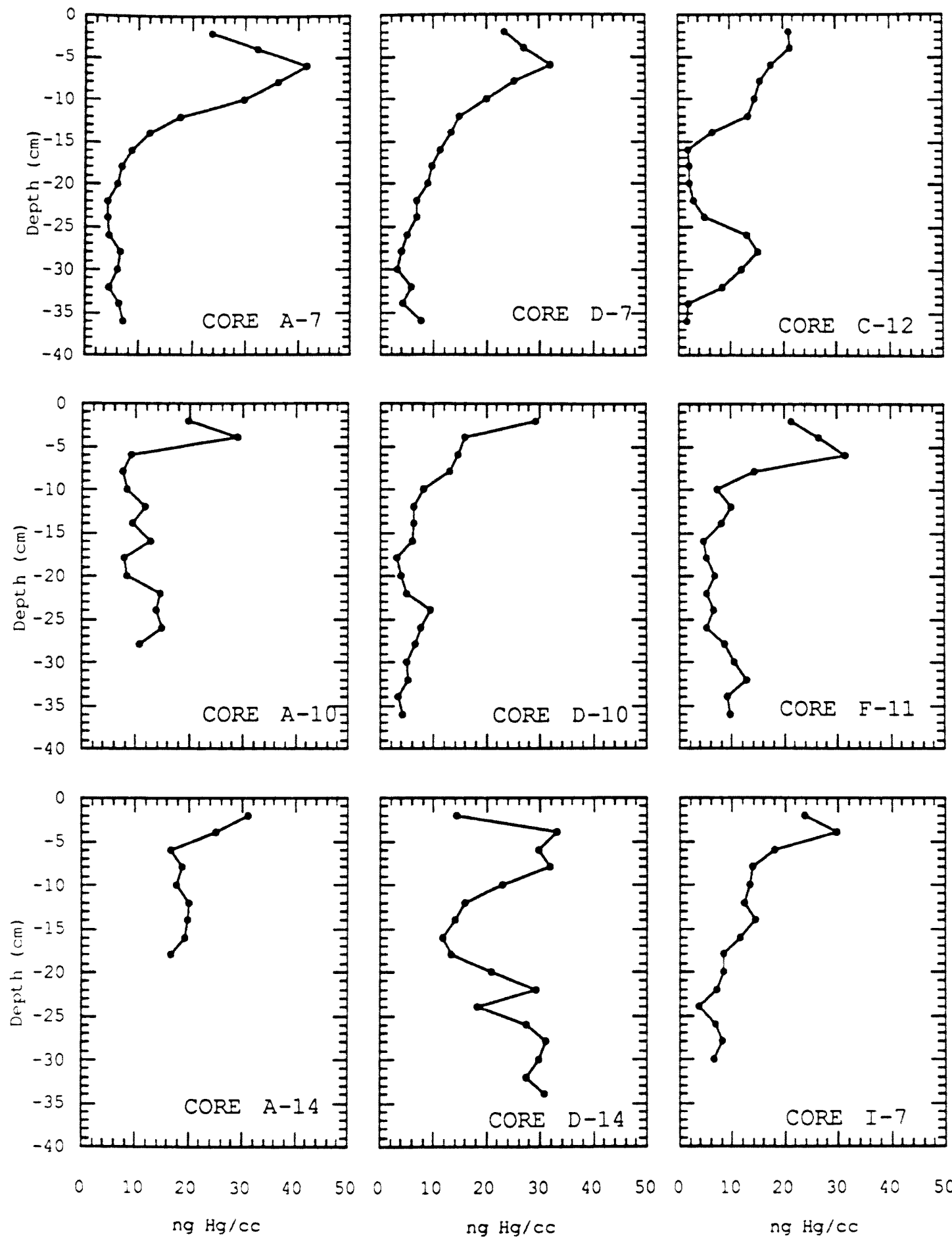
$\begin{array}{llllll}0 & 10 & 20 & 30 & 40 & 50\end{array}$
ng $\mathrm{Hg} / \mathrm{CC}$

$\mathrm{ng} \mathrm{Hg} / \mathrm{Cc}$

Figure 4.15. Vertical distribution of total mercury concentrations in soil profiles in the southern half of WCA3A. Concentrations have been normalized to soil bulk density and are give as $\mathrm{ng} \mathrm{Hg} / \mathrm{Cc}$. 

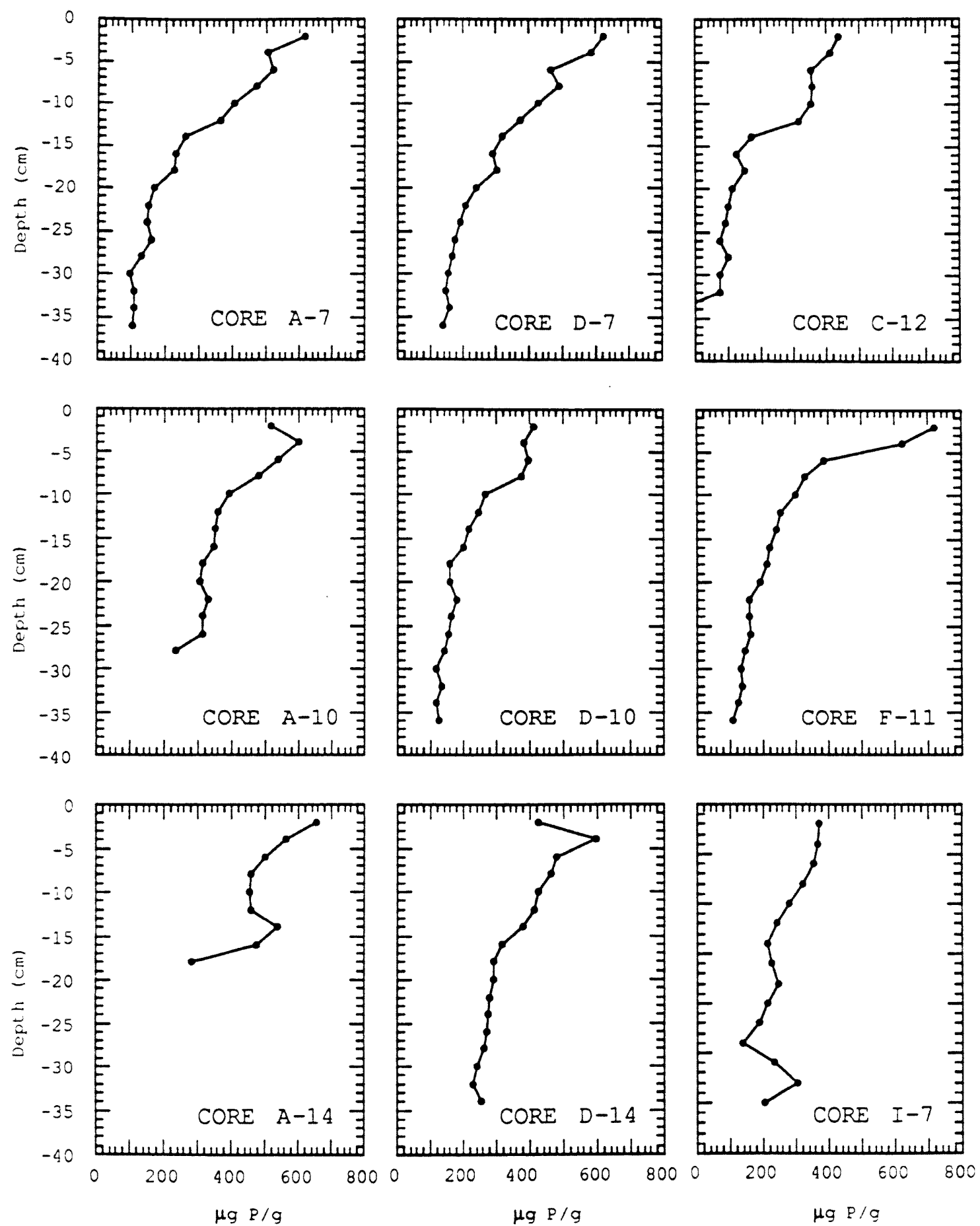

Figure 4.16. Vertical distribution of total phosphorus concentrations $(\mu \mathrm{g} \mathrm{P} / \mathrm{g})$ in soil profiles in the southern half of WCA-3A. 


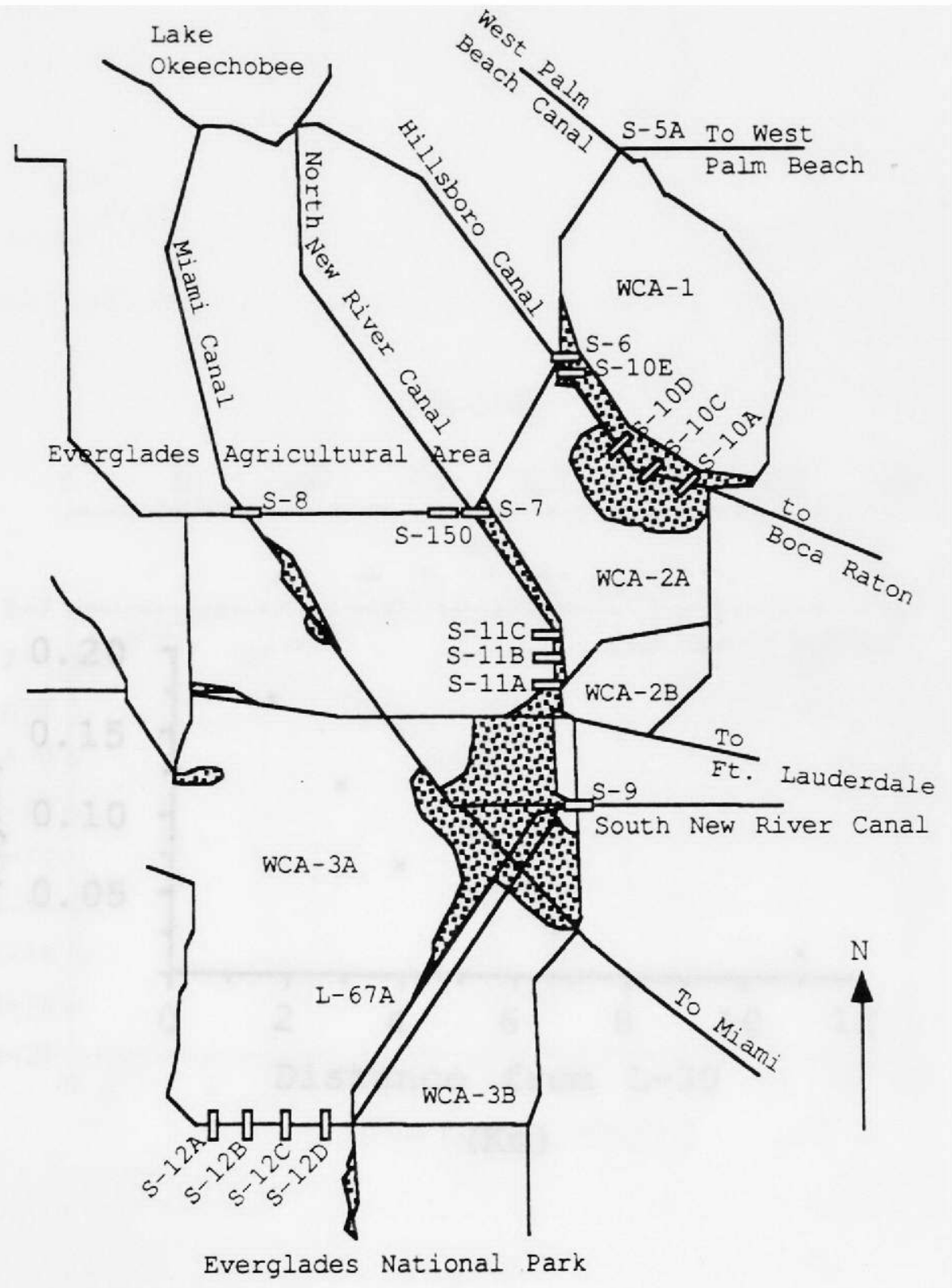

Figure 4.17. Map shows areas of highest phosphorus input to the Everglades by control structures along canals. Areas of high phosphorus corresponds to areas of dense cattail stands. (Modified from Davis, 1994). 


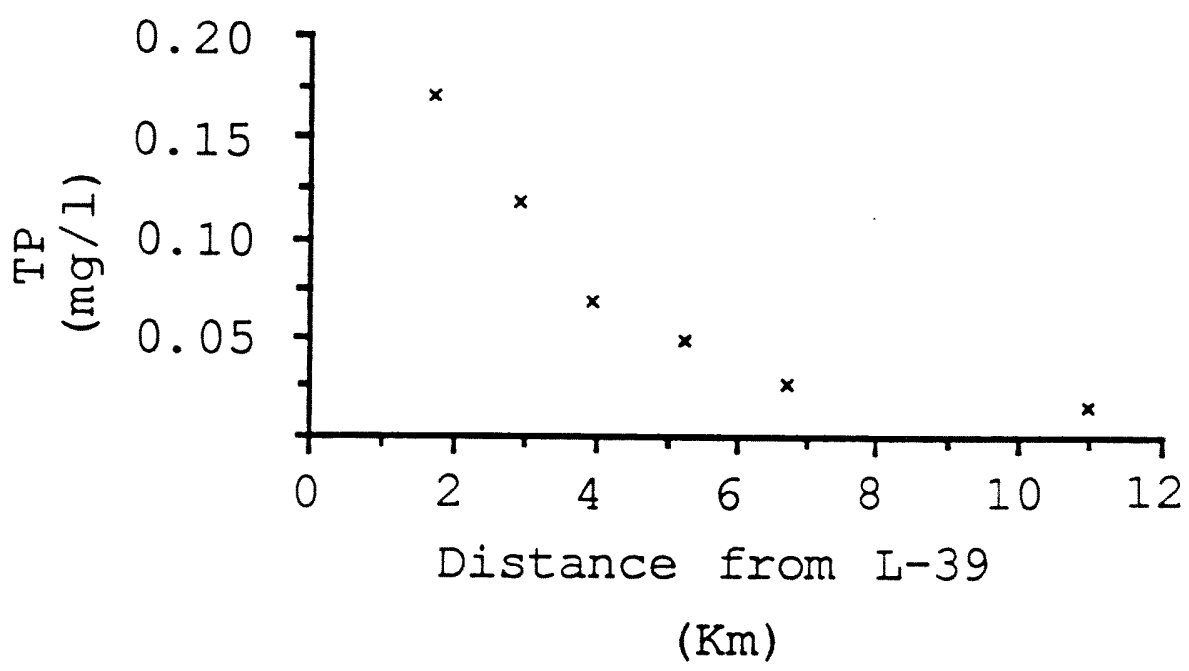

Figure 4.18. This diagram illustrates how phosphorus in surface water are is rapidly removed by plants and sediments within a distance of 4 to $6 \mathrm{~km}$ away from inflow structures. (Modified from Urban et al., 1993). 


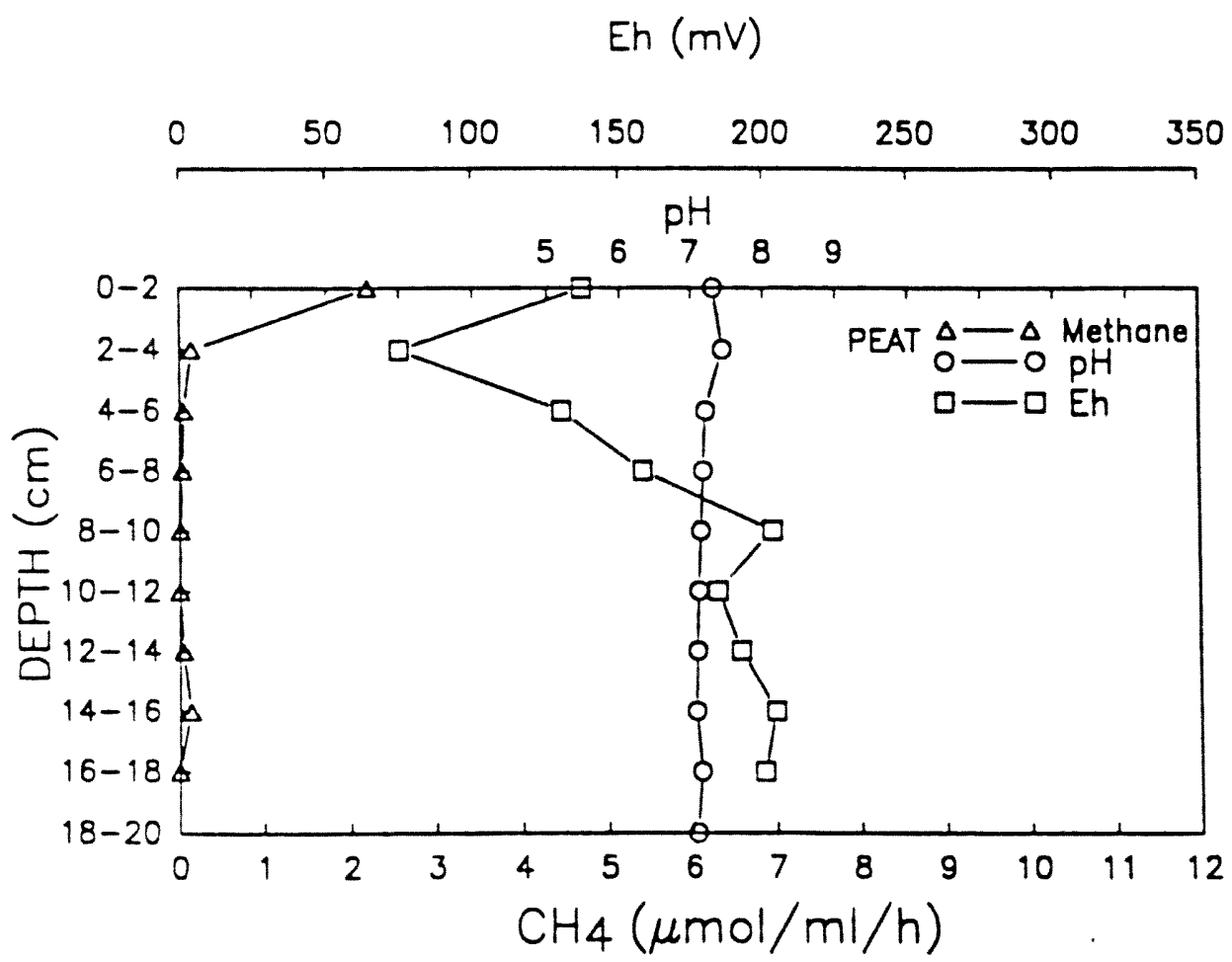

Figure 4.19. Graph shows methane production, redox potential and $\mathrm{pH}$ values typically found in Everglades peats. (From Bachoon and Jones, 1992). 

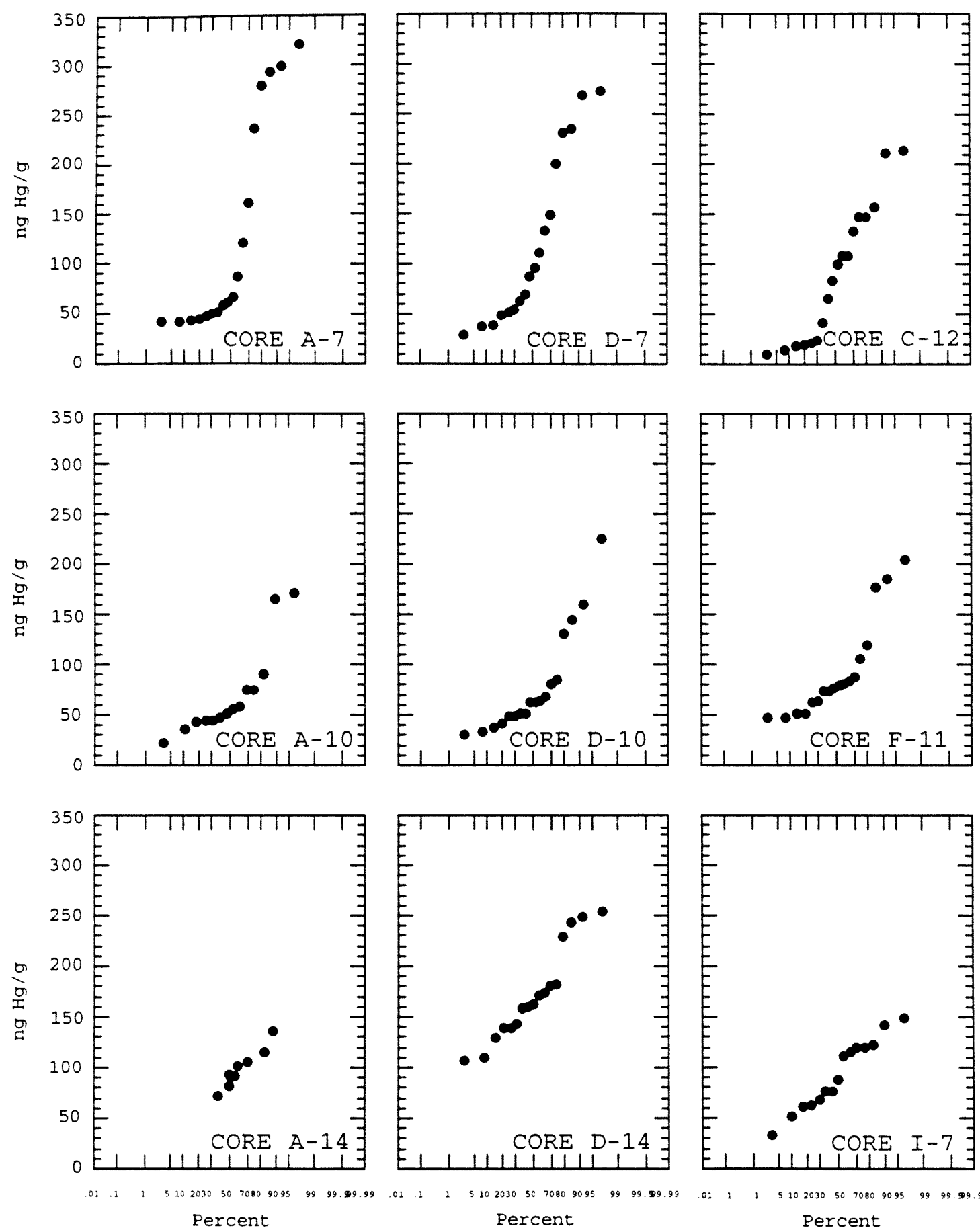

$.0212 \$ 2020305070809095 \quad 99 \quad 99.99 .99$ Percent

Figure 4.20. Plots of log probability of mercury concentrations in soil profiles suggest the presence of two populations. Mercury concentrations are given as ng $\mathrm{Hg} / \mathrm{CC}$. 

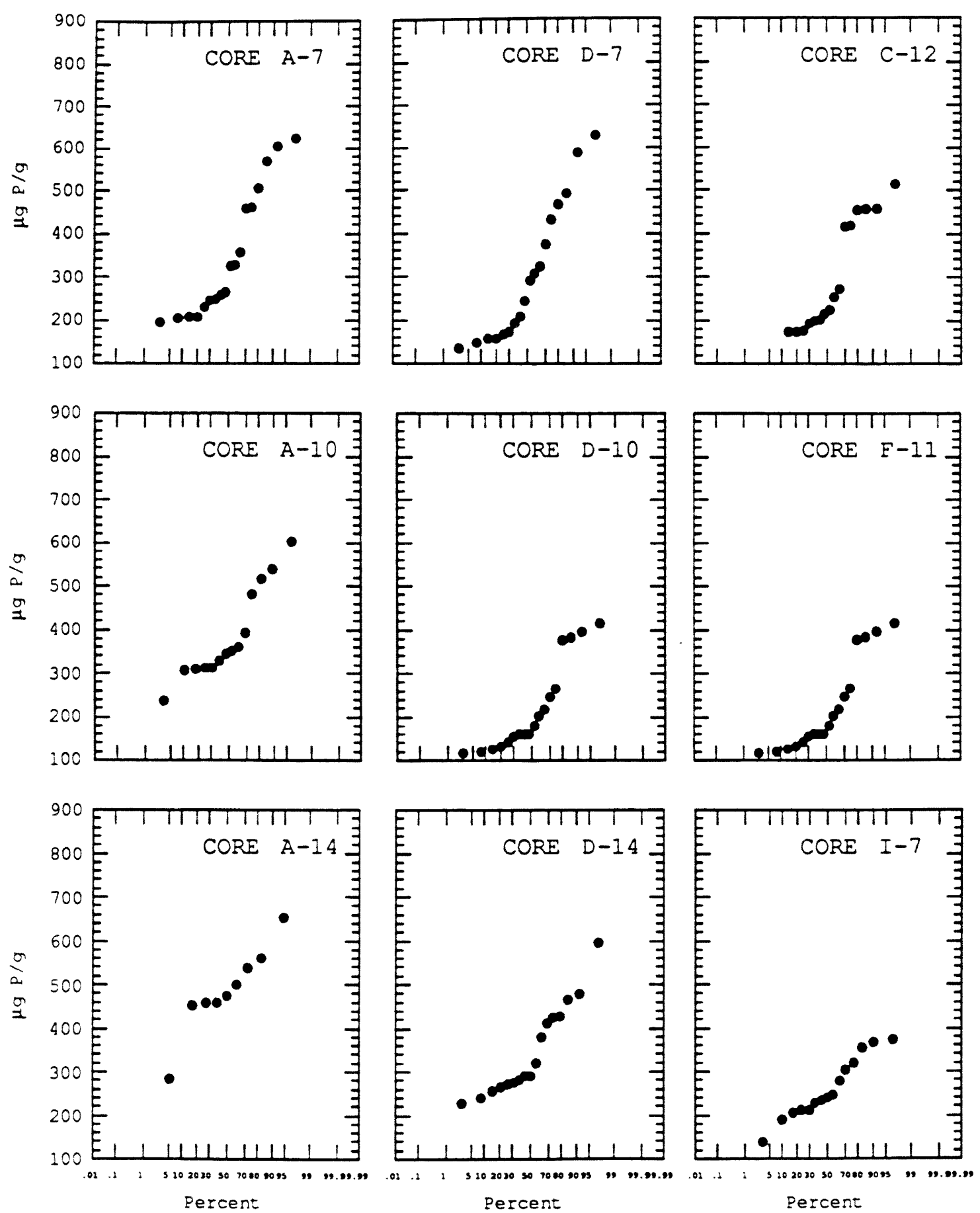

Figure 4.21. Plots of log probability of phosphorus concentrations in soil profiles suggest the presence of two populations. Phosphorus concentrations are given in $\mu \mathrm{g} P / \mathrm{g}$. 

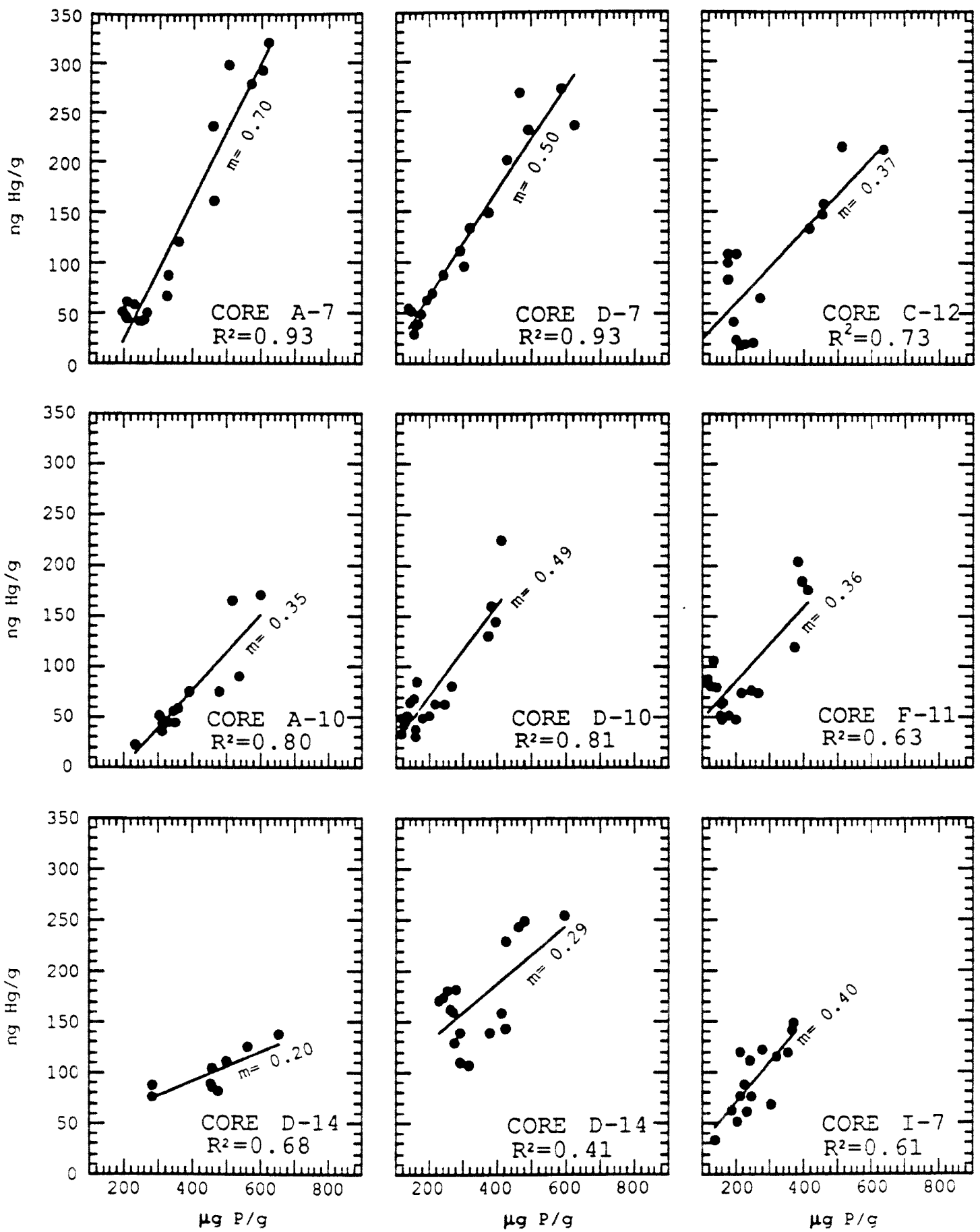

Figure 4.22. Plots of linear correlation between mercury and phosphorus in soil profiles. Concentrations are given as ng $\mathrm{Hg} / \mathrm{g}$ and $\mu \mathrm{g} \mathrm{P} / \mathrm{g}$. 


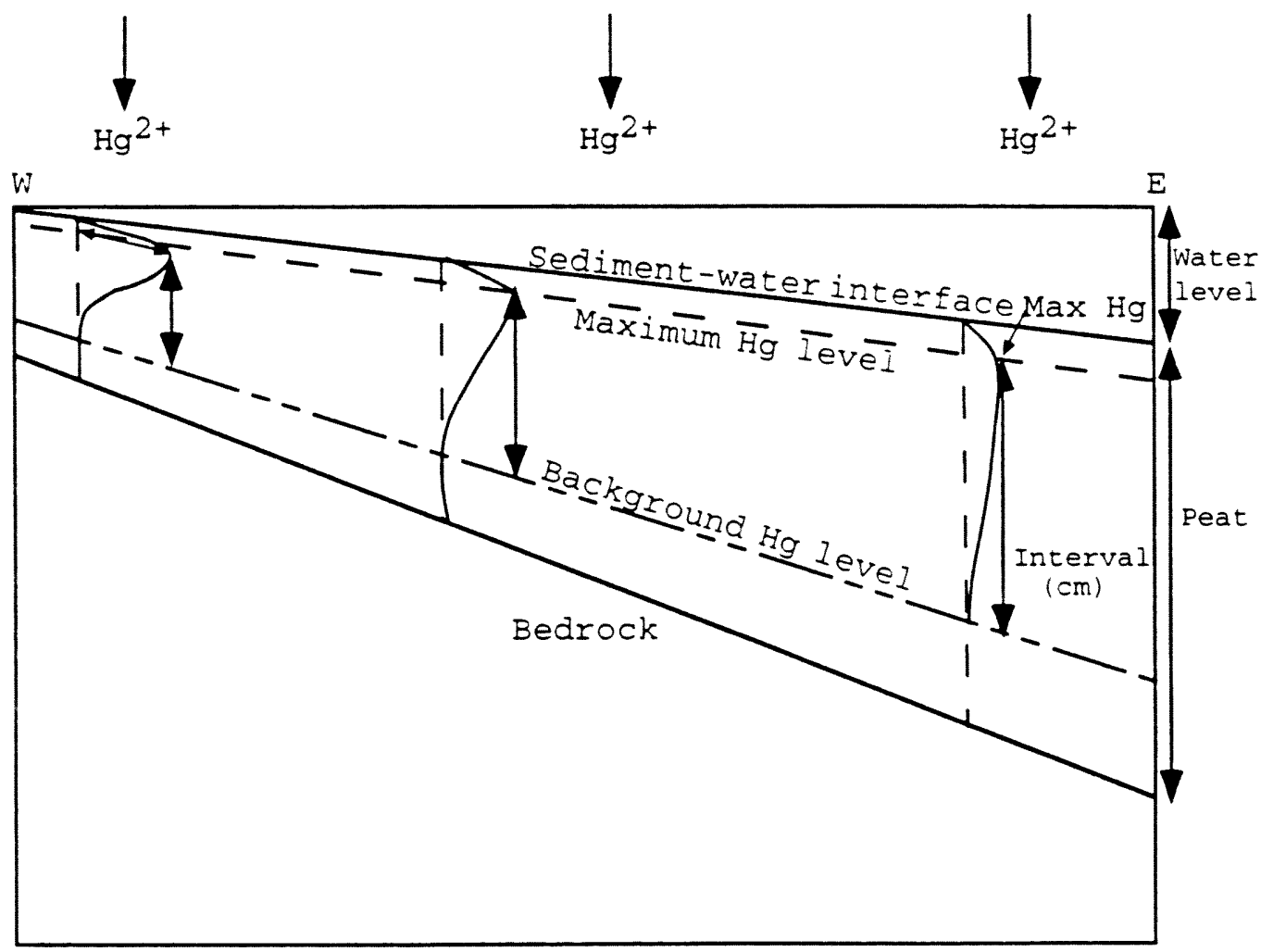

Figure 4.23. Diagram shows how increasing peat accumulation from west to east should affect the vertical distribution of mercury in soil profiles. 


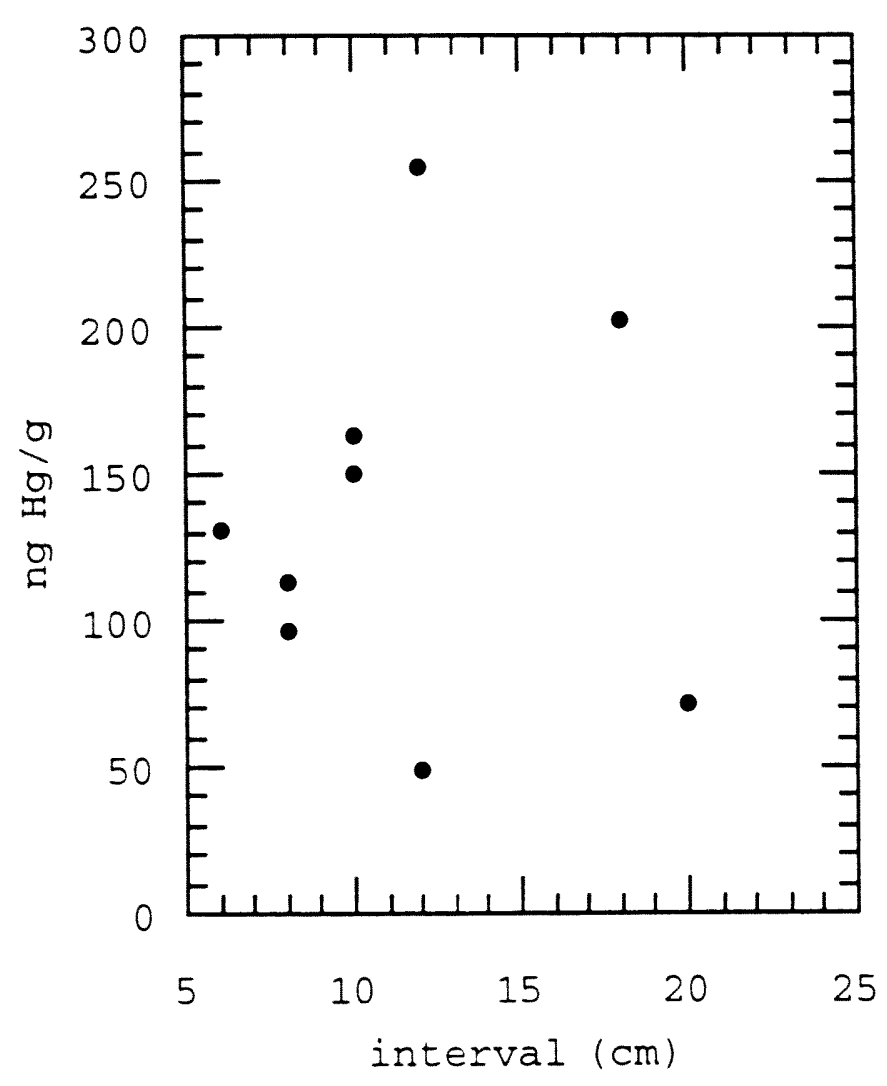

Figure 4.24. Plot shows the poor linear correlation between mercury concentrations and interval in soil profiles. Poor linear correlation supports the hypothesis that mercury undergoes post-depositional mobilization. 
Areal and vertical distributions of soil-Hg concentrations were determined for the southern half of water Conservation Area 3A. Conclusions on the spatial distribution of soil-Hg concentrations include the following: 1. Surface soil-Hg concentrations were in the range of 117 to $300 \mathrm{ng} / \mathrm{g}$. These values are common for organic-rich soils. 2. Parameters such as soil bulk density, percentage of total organic carbon and total phosphorus did not correlate with soil-Hg concentrations in surface samples.

3. Only one population of soil-Hg concentrations exists in the study area, indicating a lack of local point sources.

4. Mercury concentrations (ng $\mathrm{Hg} / \mathrm{g}$ ) decreased from west to east; however, normalization of data to soil bulk density (ng $\mathrm{Hg} / \mathrm{CC}$ ) suggests that this gradient was an artifact produced site-to-site differences in soil bulk densities..

5. The homogeneity of the surface distribution of mercury concentrations suggests that uniform regional atmospheric deposition may be the main source of mercury to the Everglades

Results on mercury soil profiles from the southern half of WCA-3A include the following:

1. All nine sites showed soil-Hg profiles with higher Hg levels in surface layers.

2. Increase in soil-Hg deposition seems to be more 
pronounced in the northern region.

3. Soil-Hg profiles in sites subject to fast peat accumulation (I-7) as well as those that have no peat accumulation $(A-14)$ show the smallest differences in soil-Hg concentrations between bottom and top layers.

4. Higher concentrations of soil-Hg in younger peat layers may reflect increased rate of deposition of this metal in the region in recent decades.

5. Correlation between total phosphorus and total $\mathrm{Hg}$ suggests post-depositional mobilization and concentration of Hg near the surface by plants and microorganisms. 


\section{CHAPTER 6: FUTURE RESEARCH}

My study has determined the amount of total mercury present in soils from the southern half of WCA-3A, but many questions remain. Future studies need to address the following problems:

1. While studies have attempted to quantify mercury emissions to the atmosphere in Florida, not much is known about the amount deposited regionally. The amount of mercury deposited by the atmosphere in Florida needs to be better quantified. This could be done by placing long term monitoring stations throughout the South Florida region. Such measurements would provide annual mercury deposition rates and information on the possibility of variations in mercury deposition rate across the Everglades.

2. The mass of mercury that enters the Everglades via surface water flow needs to be determined. Means to determine what fraction of the mercury transported by surface water is atmospheric and what fraction is being transported from the northern region of the Everglades warrant further research. This would require the determination of the residence time of mercury in surface water in the Everglades. If the residence time of mercury is known, then it might be possible to estimate how far mercury in surface water may be transported before it is deposited in soils. Since the flow of surface water is faster in canals than the sheet flow of 
surface water in most of the Everglades, the mass of mercury in these distinct areas would have to be determined separately.

3. More research is needed on the post-depositional mobility of soil-mercury in organic-rich sediments. In order to determine the possible post-depositional mobilization of mercury by plants and microbes in the Everglades, experiments should be carried out by adding mercury to soil profiles similar to those found in the Everglades and observing whether the plant species, especially sawgrass, mobilize mercury, and to what extent. 
Alloway, B.J. 1990. Heavy Metals in Soils. Glasgow, Blackie; New York. Halsted Press. 339 pp.

Bachoon, D. and R.D. Jones. 1992. Potential Rates of Methanogenesis in Sawgrass Marshes with Peat and Marl Soils in the Everglades. Soil Biol. Biochem. V.24:21-27.

Benoit, J.M., W.F. Fitzgerald, and A.W.H. Damman. 1994. Historical Atmospheric Mercury Deposition in the MidContinental U.S. as Recorded in an Ombrotrophic Peat Bog. In: Mercury Pollution: Integration and Synthesis. Ed. Watras, J.C. and J.W. Huckabee. Boca Raton, Ann Arbor, London, Tokyo. Lewis Publishers. 727 pp.

Bisogni, J.J., and A.W. Lawrence. 1975. Kinetics of Mercury Methylation in Aerobic and Anaerobic Aquatic Environments. J. of Water Pollut. Control Fed. V. $47: 135-152$.

Bloom, N.S., C.J. Watras, and J. Hurley. 1991. Impact of Acidification on the Methylmercury Cycle of Remote Seepage Lakes. Water, Air, and Soil Pollution. V. $56: 477-491$.

Brown, R.B., E.L. Stone, and V.W. Carlisle. 1991. Chapter 3: Soils. In: Ecosystems of Florida. Ed. Myers, R.L. and J.J. Ewel. U. of Central Florida Press-Orlando. $765 \mathrm{pp}$.

Compeau, G. and R. Bartha. 1984. Methylation and Demethylation of Mercury Under Controlled Redox, pH, and Salinity Conditions. Applied and Environ. Microbio. V. 48-6:1203-1207.

Craft, C.B. and C.J. Richardson. 1993. Peat Accretion and N, $P$, and Organic Accumulation in Nutrient-Enriched and Unenriched Everglades Peatlands. Ecological Applications, V.3-3:446-458.

Davis, S.M. and J.C. Ogden. 1994. Everglades: The Ecosystem and Its Restoration. St. Lucie Press. $826 \mathrm{pp}$.

Delfino, J.J., T.L. Crisman, J.F. Gottgens, B.E. Rood, and C.D.A. Earle. 1993. Spatial and Temporal Distribution of Mercury in Everglades and Okefenokee Wetland Sediments. Dept. of Envir. Eng. Sci. U. of Florida. 119 pp. 
Fenchel, T. and T.H. Blackburn. 1979. Bacteria and Mineral Cycling. Academic Press. 225 pp.

Fish, J.E. and M. Stewart. 1991. Hydrogeology of the Surficial Aquifer System, Dade County, Florida. USGS, Water-Resources Investigations Report 90-4108 and South Florida Water Management District. $50 \mathrm{pp}$.

Fitzgerald, W.F. and T.W. Clarkson. 1991. Mercury and Monomethylmercury: Present and Future Concerns. Environ. Health Perspectives. V.96:159-166.

Gleason, P.J., A.D. Cohen., P. Stone, W.G. Smith, H.K. Brooks, R. Goodrick, and W. Spackman, Jr. 1984. The Environmental Significance of Holocene Sediments from the Everglades and Saline Tidal Plain. Environments of South Florida-Present and Past II. Ed. Gleason, P.J. Coral Gables, Miami Geological Society. 297-351.

Gleason, P.J. and P. Stone. 1994. Age, Origin and Landscape Evolution of the Everglades Peatland. In: Everglades: The Ecosystem and Its Restoration. Ed. Davis, S.M. and J.C. Ogden. 149-197.

Gunderson, L.H. and W.F. Loftus. 1993. The Everglades. In: Biodiversity of the Southeastern United States/Lowland Terrestrial Communities. Edited by W.H. Martin, S.G. Boyce and A.C. Echternacht. John Wiley \& Sons, Inc. 199-255.

Hand, J. and M. Friedeman. 1990. Mercury, Largemouth Bass and Water Quality. A Preliminary Report. Florida Dept. of Environ. Reg. Rpt. Tallahassee. $112 \mathrm{pp}$.

Henning, T.A., P.I. Brezonik, and D.E. Engstrom. 1989. Historical and Areal Deposition of Mercury in N.E. Minnesota and Northern Wisconsin Lakes. Report to the Minnesota Pollution Control Agency, St. Paul, $97 \mathrm{p}$.

Hogg, T.J., J.W.B. Stewart, and J.R. Bettany. 1978 . Influence of the Chemical Form of Mercury on Its Adsorption and Ability to Leach Through Soils. Journal of Environ. Qual., V.7-3:440-445.

Horne, A.J. and C.H. Goldman. 1994. Limnology. 2nd Ed. McGraw-Hill, Inc. $576 \mathrm{pp}$.

Hurley, J.P., C.J. Watras, and N.S. Bloom. 1991. Mercury Cycling in a Northern Wisconsin Seepage Lake: The Role of Particulate Matter in Vertical Transport. Water, Air, and Soil Pollution. V.56:543-551. 
Jensen, A. and A. Jensen. 1991. Historical Deposition Rates of Mercury in Scandinavia Estimated by Dating and Measurement of Mercury in Cores of Peat Bogs. Water, Air, and Soil Pollution. V.56:769-777.

Jones, R.D. 1992. Environmental Parameters Affecting the Release of Mercury from Soils of the Florida Everglades. Project proposal.

Jones, R.D., M.E. Jacobson, R. Jaffe, J.West-Thomas, C. Arfstrom, and A. Alli. 1995. Method Development and Sample Processing of Water, Soil, and Tissue for the Analysis of Total and Organic Mercury by Cold Vapor Atomic Fluorescence Spectrometry. Water, Air, And Soil Pollution. V.80:1285-1294.

Kabata-Pendias, A. and H. Pendias. 1984. Trace Elements in Soils and Plants. CRC Press. $315 \mathrm{pp}$.

Krenkel, P. 1990. Mercury in the Environment: Methylation and sediment Reactions. In: Proceedings of Workshop on Mercury Contamination in Florida: Impacts and Solutions. $140 \mathrm{pp}$.

Lepeltier, C. 1969. A Simplified statistical Treatment o f Geochemical Data by Graphical Representation: Economical Geologic, V.64:538-550.

Light, S.S. and J.W. Dineen. 1994. Water Control in the Everglades: A historical Perspective. In: Everglades the Ecosystem and its Restoration. Ed. Davis, S.M. and J.C. Ogden. St. Lucie Press. $826 \mathrm{pp}$.

Lindberg, S. E., A.W. Andrea, and R.C. Hariss. 1975. Estuarine Res. V.1:64.

Lindqvist, 0. ed. 1991. Water, Air, and Soil pollution. Special Issue: Mercury in the Swedish Environment. V. $55 / 1-2,261 \mathrm{pp}$.

Lindqvist, O., J.M. Aastrup, and A. Anderson. 1991. Physical/Chemical Forms of Mercury. Water, Air and Soil Poll. $55: 7-17$.

Lodenius, M., S. Autio, and A. Sappanen. 1987. Leaching of Mercury from Peat Soil. Chemosphere, V.15:1215-1220.

Martin, D.B. and W.A. Hartman. 1987. Correlations Between Selected Trace Elements and Organic Matter and Texture in Sediments of Northern Prairie Wetlands. J. Assoc. off. Anal. Chem. 70:916-919. 
Matilainen, T., M. Verta, M. Niemi, and Uusi-Rauva. 1991. Specific Rates of Net Methylmercury Production in Lake Sediments. Water, Air, and Soil Pollution. V.56:595-605.

Mierle, G. and R. Ingram. (1991). The Role of Humic Substances in the Mobilization of Mercury from Watersheds. Water, Air, and Soil Pollution. V.56:349357 .

Miskimmin, B. M., J.W.M. Rudd, and C.A. Kelly. 1992. Influence of Dissolved Organic Carbon, $\mathrm{pH}$, and Microbial Respiration Rates on Mercury Methylation and Demethylation in Lake water. Can. J. Fish. Aquat. Sci. V. $49: 17-22$.

Missimer, T.M. 1984. The Geology of South Florida: A Summary. In: Environments of South Florida-Present and Past. Ed. Gleason, P.J., Miami Geological Soc. 385-404.

Mitra, S. 1986. Mercury in the Ecosystem. Switzerland, Germany, UK, and USA. Trans. Tech. Publications. 327 pp.

Myers, R.L. and J.J. Ewel. 1991. Ecosystems of Florida. U. of Central Florida Press. $765 \mathrm{pp}$.

National Academy Sciences. 1978. An Assessment of Mercury in the Environment. Report Prepared by the Panel on Mercury. Washington.

Nriagu, J. 1990. Global Metal Pollution: Poisoning of the Biosphere. Environment, 32-7:7-33.

Patrick, W. 1990. Soil Redox Processes: Bioavailability of Mercury. In: Proceedings of Workshop On Mercury Contamination in Florida: Impacts and Solutions. 55-62.

Patrick, W.H., R.P. Gambrel1, P. Parkpian, and F. Tan. 1994. Mercury in Soils and Plants in the Florida Everglades Sugarcane Area. In: Mercury Pollution: Integration and Synthesis. Ed. Watras, C.J. and J.W. Huckabee. CRC Press. 727 pp.

Percy, K.E. and S.A. Borland. Multivariate Analysis of Element Concentrations in Sphagnum magellanicum brid. in the Maritime Provinces, Canada. Water, Air, and Soil pollution. V.25:331-338. 
Reddy, K.R., W.F. DeBusk, Y. Wang, R. Delaune, and M. Koch. 1991. Physico-Chemical Properties of Soils in the water Conservation Area 2 of the Everglades-Final Report. Soils Science Department, Institute of Food and Agricultural Sciences. University of Florida, Gainsville, Florida 32611.214 pp.

Regnel1, O., and A. Tunlid. 1991. Laboratory Study of Chemical speciation of Mercury in Lake sediment and Water Under Aerobic and Anaerobic Conditions. Applied and Environ. Microbio. V.57-3:789-795.

Regional Environmental Monitoring and Assessment Program. 1993. EPA/625/R-93/012.

Rogers, R.D. and J.C. McFarlane. 1978. Factors Influencing the Volatilization of Mercury from Soils. EPA-600/378054. USEPA, Office of Research and Development, Environ. Monitoring and Support Laboratory. $13 \mathrm{pp}$.

Rusmussen, P.E. 1994. Mercury in Vegetation of the Precambrian Shield. In: Mercury Pollution: Integration and Synthesis. Ed. Watras, C.J. and J.W. Huckabee. CRC press, $727 \mathrm{pp}$.

Sinclair, A.J. 1974. Selection of Threshold Values in Geochemical Data Using Probability Graphs: Journal

Geochemical Exploration, V.3:129-149.

Scott, T.M. 1992. A Geological Overview of Florida. Florida Geological Survey, Tallahasse. open File Report No. 50. $78 \mathrm{pp}$.

Solorzano, L. and J.H. Sharp. 1980. Determination of Total Dissolved Phosphorus and Particulate Phosphorus in Natural Waters. Limnology Oceanography, V. 25:754-758.

Stewart, K.K. 1984. Physiological, Edaphic and Environmental Characteristics of Everglades Sawgrass Communities. In: Environments of South Florida Present and Past II. Ed. Gleason, P.J. Miami Geological Society, Coral Gables, 551 pp.

Swain, E.B., D.R. Engstrom, M.A. Brigham, T.A. Henning, and P.L. Brezonik. 1992. Increasing Rates of Atmospheric Mercury Deposition in Midcontinental North America. Science, 257:784-787. 
Urban, N.H., S.M. Davis, and N.G. Aumen. 1993. Fluctuations in Sawgrass and Cattail Densities in the Everglades Water Conservation Area 2A Under Varying Nutrient, Hydrologic and Fire Regimes. Aquat. Bot. 46:203-223. Cited in: Davis, S.M. 1994. Phosphorus Inputs and Vegetation Sensitivity in the Everglades. In: Everglades the Ecosystem and its Restoration. Ed. Davis, S.M. and J.C. Ogden. St. Lucie Press. 826 pp.

Volk, B.G., S.D. Schemnitz, J.F. Gamble, and J.B. Sartain. 1975. Baseline Data on Everglades Soil-Plant Systems: Elemental Composition, Biomass and Soil Depth. Pages 658-672 in F.G. Howell, J.B. Gentry, and M.H. Smith, Editors. Mineral Cycling in Southeastern Ecosystems. National Technical Information Service, U.S. Department of Commerce, Springfield, VA.

$\mathrm{Xu}, \mathrm{H}$. and B. Allard. 1991. Effects of A Fulvic Acid on the Speciation and Mobility of Mercury in Aqueous Solutions. Water, Air, and Soil Pollution 56:709-717.

Xun, L., N.E.R. Campbell, and J.W.M. Rudd. 1987. Can. J. Fish. Aquat. Sci. V.44, 750.

Winfrey, M.R., and J.W.M. Rudd. 1990. Environmental Factors Affecting the Formation of Methylmercury in Low $\mathrm{pH}$ Lakes. Environ. Toxicol. and Chem. V.9:853-869.

Zillioux, E.J.; D.B. Porcella, and J.M. Benoit. 1993. Mercury Cycling and Effects in Freshwater Wetland Ecosystems. Environ. Toxicol. and Chem. V.12:2245-2264. 
APPENDIXES 


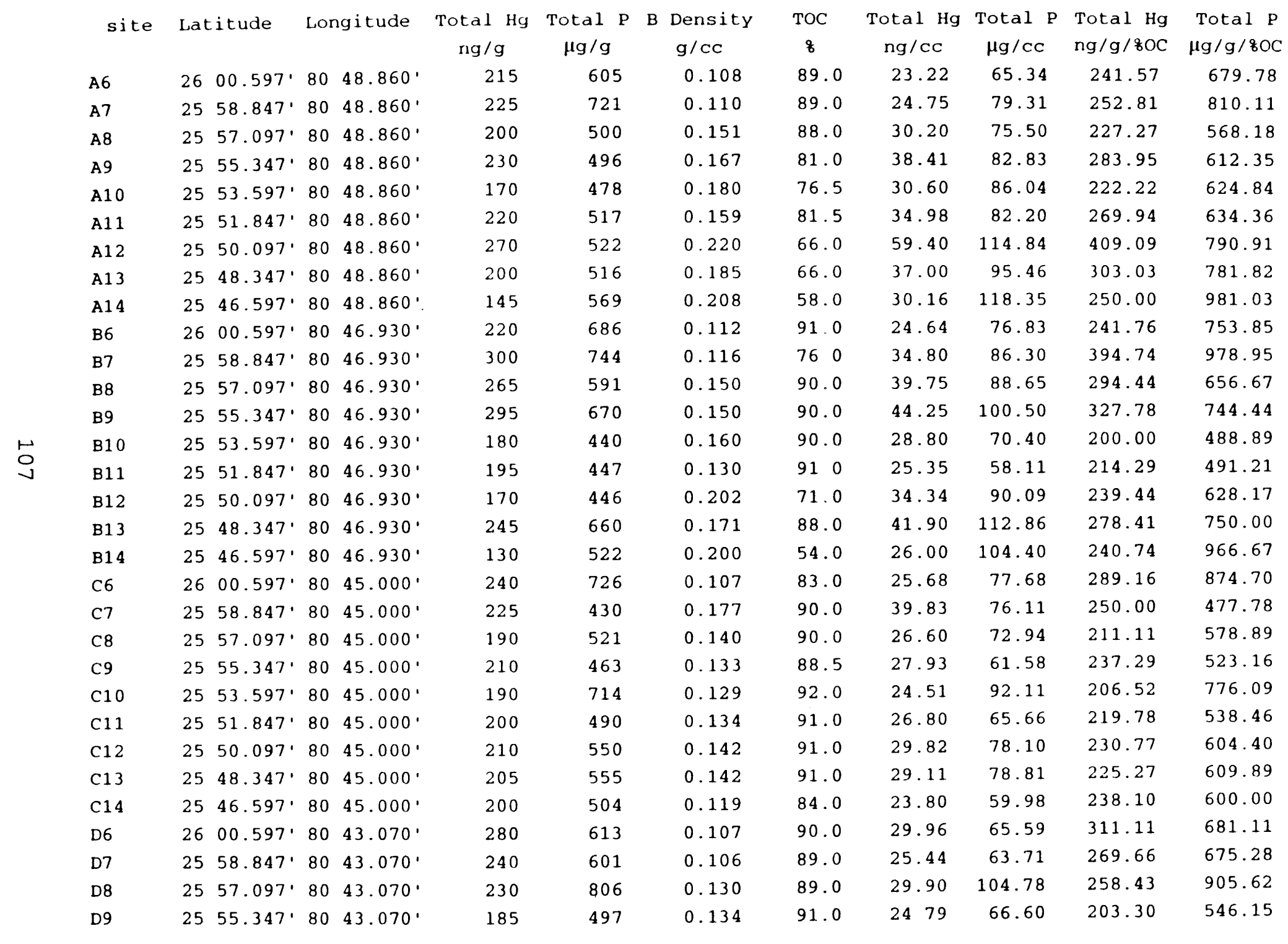




\begin{tabular}{|c|c|c|c|c|c|c|c|c|c|c|c|c|}
\hline D 10 & 25 & $53.597^{\circ}$ & 80 & $43.070^{\circ}$ & 225 & 505 & 0.152 & 90.0 & 34.20 & 76.76 & 250.00 & 561.11 \\
\hline D11 & 25 & $51.847^{\circ}$ & 80 & $43.070^{\circ}$ & 180 & 437 & 0.148 & 90.0 & 26.64 & 64.68 & 200.00 & 485.56 \\
\hline D12 & 25 & $50.097^{\circ}$ & 80 & $43.070^{\circ}$ & 210 & 478 & 0.181 & 89.0 & 38.01 & 86.52 & 235.96 & 537.08 \\
\hline D13 & 25 & $48.347^{\prime}$ & 80 & $43.070^{\circ}$ & 250 & 618 & 0.127 & 93.0 & 31.75 & 78.49 & 268.82 & 664.52 \\
\hline D14 & 25 & $46.597^{\circ}$ & 80 & $43.070^{\circ}$ & 145 & 549 & 0.105 & 90.0 & 15.23 & 57.65 & 161.11 & 610.00 \\
\hline E6 & 26 & $00.597^{\circ}$ & 80 & $41.140^{\circ}$ & 260 & 635 & 0.126 & 90.0 & 32.76 & 80.01 & 288.89 & 705.56 \\
\hline E7 & 25 & $58.847^{\prime}$ & 80 & $41.140^{\circ}$ & 300 & 705 & 0.098 & 90.0 & 29.40 & 69.09 & 333.33 & 783.33 \\
\hline E8 & 25 & $57.097^{\prime}$ & 80 & $41.140^{\circ}$ & 270 & 710 & 0.143 & 90.0 & 38.61 & 101.53 & 300.00 & 788.89 \\
\hline E9 & 25 & $55.347^{\prime}$ & 80 & $41.140^{\circ}$ & 170 & 341 & 0.158 & 88.0 & 26.86 & 53.88 & 193.18 & 387.50 \\
\hline E10 & 25 & $53.597^{\prime}$ & 80 & $41.140^{\circ}$ & 230 & 648 & 0.114 & 91.5 & 26.22 & 73.87 & 251.37 & 708.20 \\
\hline E11 & 25 & $51.847^{\circ}$ & 80 & $41.140^{\circ}$ & 290 & 554 & 0.145 & 91.0 & 42.05 & 80.33 & 318.68 & 608.79 \\
\hline E12 & 25 & $50.097^{\prime}$ & 80 & $41.140^{\circ}$ & 250 & 657 & 0.123 & 90.0 & 30.75 & 80.81 & 277.78 & 730.00 \\
\hline E13 & 25 & $48.347^{\prime}$ & 80 & $41.140^{\circ}$ & 200 & 657 & 0.118 & 90.0 & 23.60 & 77.53 & 222.22 & 730.00 \\
\hline E14 & 25 & $46.597^{\prime}$ & 80 & $41.140^{\circ}$ & 180 & 606 & 0.087 & 90.0 & 15.66 & 52.72 & 200.00 & 673.33 \\
\hline F6 & 26 & $00.597^{\prime}$ & 80 & $39.210^{\circ}$ & 290 & 803 & 0.084 & 91.0 & 24.36 & 67.45 & 318.68 & 882.42 \\
\hline F7 & 25 & $58.847^{\prime}$ & 80 & $39.210^{\circ}$ & 185 & 615 & 0.092 & 92.0 & 17.02 & 56.58 & 201.09 & 668.48 \\
\hline F 8 & 25 & $57.097^{\prime}$ & 80 & $39.210^{\circ}$ & 275 & 774 & 0.158 & 90.0 & 43.45 & 122.29 & 305.56 & 860.00 \\
\hline F9 & 25 & $55.347^{\circ}$ & 80 & $39.210^{\circ}$ & 230 & 681 & 0.142 & 88.0 & 32.66 & 96.70 & 261.36 & 773.86 \\
\hline F10 & 25 & $53.597^{\prime}$ & 80 & $39.210^{\circ}$ & 260 & 605 & 0.139 & 90.0 & 36.14 & 84.10 & 288.89 & 672.22 \\
\hline F11 & 25 & $51.847^{\circ}$ & 80 & $39.210^{\circ}$ & 180 & 625 & 0.107 & 93.0 & 19.26 & 66.88 & 193.55 & 672.04 \\
\hline F12 & 25 & $50.097^{\prime}$ & 80 & $39.210^{\circ}$ & 190 & 683 & 0.172 & 89.0 & 32.68 & 117.48 & 213.48 & 767.42 \\
\hline G6 & 26 & $00.597^{\circ}$ & 80 & $37.280^{\circ}$ & 210 & 456 & 0.124 & 88.0 & 26.04 & 56.54 & 238.64 & 518.18 \\
\hline G7 & 25 & $58.847^{\circ}$ & 80 & $37.280^{\circ}$ & 180 & 931 & 0.081 & 92.0 & 14.58 & 75.41 & 195.65 & 1011.96 \\
\hline G8 & 25 & $57.097^{\circ}$ & 80 & $37.280^{\circ}$ & 205 & 871 & 0.126 & 91.0 & 25.83 & 109.75 & 225.27 & 957.14 \\
\hline G9 & 25 & $55.347^{\prime}$ & 80 & $37.280^{\circ}$ & 250 & 625 & 0.170 & 88.0 & 42.50 & 106.25 & 284.09 & 710.23 \\
\hline G10 & 25 & $53.597^{\circ}$ & 80 & $37.280^{\circ}$ & 190 & 608 & 0.135 & 91.0 & 25.65 & 82.08 & 208.79 & 668.13 \\
\hline H6 & 26 & $00.597^{\prime}$ & 80 & $35.350^{\circ}$ & 180 & 648 & 0.111 & 92.0 & 19.98 & 71.93 & 195.65 & 704.35 \\
\hline H7 & 25 & $58.847^{\circ}$ & 80 & $35.350^{\circ}$ & 150 & 449 & 0.087 & 91.0 & 13.05 & 39.06 & 164.84 & 493.41 \\
\hline H8 & 25 & $57.097^{\prime}$ & 80 & $35.350^{\circ}$ & 117 & 640 & 0.090 & 91.0 & 10.53 & 57.60 & 128.57 & 703.30 \\
\hline H9 & 25 & $55.347^{\circ}$ & 80 & $35.350^{\circ}$ & 190 & 501 & 0.128 & 84.0 & 24.32 & 64.13 & 226.19 & 596.43 \\
\hline I 6 & 26 & $00.597^{\circ}$ & 80 & $33.420^{\circ}$ & 150 & 703 & 0.074 & 90.0 & 11.10 & 52.02 & 166.67 & 781.11 \\
\hline I7 & 25 & $58.847^{\circ}$ & 80 & $33.420^{\circ}$ & 120 & 410 & 0.138 & 58.0 & 16.56 & 56.58 & 206.90 & 706.90 \\
\hline J6 & 26 & $00.597^{\circ}$ & 80 & $31.490^{\circ}$ & 150 & 860 & 0.107 & 89.0 & 16.05 & 92.02 & 168.54 & 966.29 \\
\hline
\end{tabular}




\begin{tabular}{|c|c|c|c|c|c|c|}
\hline Site & $\begin{array}{c}\text { Depth } \\
\mathrm{cm}\end{array}$ & $\begin{array}{c}\text { Total } \mathrm{Hg} \mathrm{B} . \\
\mathrm{ng} / \mathrm{g}\end{array}$ & $\begin{array}{l}\text { Density } \\
\text { g/cc }\end{array}$ & $\begin{array}{c}\text { Total Hg } \\
\mathrm{ng} / \mathrm{Cc}\end{array}$ & $\begin{array}{c}\text { Total P } \\
\mu \mathrm{g} / \mathrm{g}\end{array}$ & $\begin{array}{l}\text { Totalp } \\
\mu \mathrm{g} / \mathrm{cc}\end{array}$ \\
\hline \multirow[t]{18}{*}{ Core $A-7$} & -2 & 236 & 0.10 & 23.6 & 716 & 71.60 \\
\hline & -4 & 293 & 0.11 & 32.2 & 603 & 66.33 \\
\hline & -6 & 322 & 0.13 & 41.8 & 623 & 80.99 \\
\hline & -8 & 279 & 0.13 & 36.3 & 569 & 73.97 \\
\hline & -10 & 298 & 0.10 & 29.8 & 505 & 50.50 \\
\hline & -12 & 162 & 0.11 & 17.8 & 463 & 50.93 \\
\hline & -14 & 120 & 0.10 & 12.0 & 358 & 35.80 \\
\hline & -16 & 87 & 0.10 & 8.7 & 329 & 32.90 \\
\hline & -18 & 67 & 0.10 & 6.7 & 327 & 32.70 \\
\hline & -20 & 50 & 0.12 & 6.0 & 266 & 31.92 \\
\hline & -22 & 42 & 0.10 & 4.2 & 249 & 24.90 \\
\hline & -24 & 41 & 0.10 & 4.1 & 247 & 24.70 \\
\hline & -26 & 43 & 0.10 & 4.3 & 259 & 25.90 \\
\hline & -28 & 58 & 0.11 & 6.4 & 229 & 25.19 \\
\hline & -30 & 51 & 0.12 & 6.1 & 194 & 23.28 \\
\hline & -32 & 45 & 0.10 & 4.5 & 207 & 20.70 \\
\hline & -34 & 62 & 0.10 & 6.2 & 209 & 20.90 \\
\hline & -36 & 47 & 0.15 & 7.1 & 205 & 30.75 \\
\hline \multirow[t]{14}{*}{ Core $A-10$} & -2 & 165 & 0.12 & 19.9 & 515 & 61.80 \\
\hline & -4 & 171 & 0.17 & 29.0 & 601 & 102.17 \\
\hline & -6 & 90 & 0.10 & 9.0 & 539 & 53.90 \\
\hline & -8 & 75 & 0.10 & 7.5 & 479 & 47.90 \\
\hline & -10 & 75 & 0.11 & 8.2 & 393 & 43.23 \\
\hline & -12 & 58 & 0.20 & 11.6 & 360 & 72.00 \\
\hline & -14 & 45 & 0.21 & 9.5 & 351 & 73.71 \\
\hline & -16 & 55 & 0.23 & 12.7 & 346 & 79.58 \\
\hline & -18 & 44 & 0.18 & 7.9 & 311 & 55.98 \\
\hline & -20 & 52 & 0.16 & 8.3 & 305 & 48.80 \\
\hline & -22 & 44 & 0.33 & 14.5 & 330 & 108.90 \\
\hline & -24 & 48 & 0.29 & 13.8 & 314 & 91.06 \\
\hline & -26 & 36 & 0.41 & 14.7 & 311 & 127.51 \\
\hline & -28 & 23 & 0.47 & 10.7 & 235 & 110.45 \\
\hline \multirow[t]{9}{*}{ Core A-14 } & -2 & 137 & 0.26 & 31.0 & 653 & 169.78 \\
\hline & -4 & 125 & 0.20 & 24.9 & 562 & 112.40 \\
\hline & -6 & 112 & 0.15 & 16.8 & 501 & 75.15 \\
\hline & -8 & 104 & 0.18 & 18.7 & 458 & 82.44 \\
\hline & -10 & 89 & 0.20 & 17.8 & 453 & 90.60 \\
\hline & -12 & 87 & 0.23 & 20.0 & 460 & 105.80 \\
\hline & -14 & 82 & 0.24 & 19.7 & 538 & 129.12 \\
\hline & -16 & 88 & 0.22 & 19.3 & 476 & 104.72 \\
\hline & -18 & 76 & 0.22 & 16.8 & 284 & 62.48 \\
\hline
\end{tabular}




\begin{tabular}{|c|c|c|c|c|c|c|}
\hline \multirow[t]{18}{*}{ Core D-7 } & -2 & 235 & 0.20 & 23.5 & 627 & 62.7 \\
\hline & -4 & 272 & 0.20 & 27.2 & 587 & 58.7 \\
\hline & -6 & 268 & 0.12 & 32.2 & 465 & 55.8 \\
\hline & -8 & 230 & 0.21 & 25.3 & 491 & 54.01 \\
\hline & -10 & 200 & 0.10 & 20.0 & 429 & 42.9 \\
\hline & -12 & 148 & 0.10 & 14.8 & 374 & 37.4 \\
\hline & -14 & 133 & 0.10 & 13.3 & 322 & 32.2 \\
\hline & -16 & 111 & 0.10 & 11.1 & 291 & 29.1 \\
\hline & -18 & 96 & 0.10 & 9.6 & 306 & 30.6 \\
\hline & -20 & 88 & 0.10 & 8.8 & 243 & 24.3 \\
\hline & -22 & 69 & 0.10 & 6.9 & 208 & 20.8 \\
\hline & -24 & 62 & 0.11 & 6.8 & 192 & 19.2 \\
\hline & -26 & 49 & 0.10 & 4.9 & 174 & 17.4 \\
\hline & -28 & 39 & 0.10 & 3.9 & 168 & 16.8 \\
\hline & -30 & 29 & 0.11 & 3.2 & 156 & 17.16 \\
\hline & -32 & 51 & 0.11 & 5.6 & 148 & 16.28 \\
\hline & -34 & 38 & 0.11 & 4.2 & 157 & 17.27 \\
\hline & -36 & 54 & 0.24 & 7.6 & 136 & 19.04 \\
\hline \multirow[t]{18}{*}{ Core D-10 } & -2 & 225 & 0.13 & 29.3 & 413 & 53.69 \\
\hline & -4 & 160 & 0.10 & 16.0 & 383 & 38.30 \\
\hline & -6 & 145 & 0.10 & 14.5 & 396 & 39.60 \\
\hline & -8 & 130 & 0.10 & 13.0 & 377 & 37.70 \\
\hline & -10 & 81 & 0.10 & 8.1 & 266 & 26.60 \\
\hline & -12 & 62 & 0.10 & 6.2 & 247 & 24.70 \\
\hline & -14 & 62 & 0.10 & 6.2 & 218 & 21.80 \\
\hline & -16 & 51 & 0.12 & 6.1 & 202 & 24.24 \\
\hline & -18 & 31 & 0.10 & 3.1 & 160 & 16.00 \\
\hline & -20 & 38 & 0.20 & 3.8 & 160 & 16.00 \\
\hline & -22 & 49 & 0.20 & 4.9 & 179 & 17.90 \\
\hline & -24 & 85 & 0.12 & 9.4 & 162 & 17.82 \\
\hline & -26 & 68 & 0.11 & 7.5 & 154 & 16.94 \\
\hline & -28 & 64 & 0.10 & 6.4 & 141 & 14.10 \\
\hline & -30 & 49 & 0.10 & 4.9 & 118 & 11.80 \\
\hline & -32 & 51 & 0.10 & 5.1 & 132 & 13.20 \\
\hline & -34 & 34 & 0.10 & 3.4 & 117 & 11.70 \\
\hline & -36 & 42 & 0.10 & 4.2 & 125 & 12.50 \\
\hline \multirow[t]{8}{*}{ Core D-14 } & -2 & 144 & 0.10 & 14.4 & 427 & 42.70 \\
\hline & -4 & 255 & 0.13 & 33.1 & 595 & 77.35 \\
\hline & -6 & 248 & 0.12 & 29.8 & 478 & 57.36 \\
\hline & -8 & 244 & 0.13 & 31.7 & 464 & 60.32 \\
\hline & -10 & 229 & 0.10 & 22.9 & 425 & 42.50 \\
\hline & -12 & 158 & 0.10 & 15.8 & 412 & 41.20 \\
\hline & -14 & 140 & 0.10 & 14.0 & 379 & 37.90 \\
\hline & -16 & 107 & 0.11 & 11.7 & 318 & 34.98 \\
\hline
\end{tabular}




\begin{tabular}{|c|c|c|c|c|c|c|}
\hline & -18 & 110 & 0.12 & 13.2 & 291 & 34.92 \\
\hline & -20 & 139 & 0.15 & 20.9 & 292 & 43.80 \\
\hline & -22 & 182 & 0.16 & 29.2 & 280 & 44.80 \\
\hline & -24 & 130 & 0.14 & 18.2 & 274 & 38.36 \\
\hline & -26 & 160 & 0.17 & 27.3 & 273 & 46.41 \\
\hline & -28 & 163 & 0.19 & 30.9 & 265 & 50.35 \\
\hline & -30 & 174 & 0.17 & 29.6 & 241 & 40.97 \\
\hline & -32 & 171 & 0.16 & 27.3 & 228 & 36.48 \\
\hline & -34 & 180 & 0.17 & 30.7 & 255 & 43.35 \\
\hline Core $c-12$ & -2 & 212 & 0.10 & 21.2 & 538 & 53.80 \\
\hline & -4 & 215 & 0.10 & 21.5 & 513 & 51.30 \\
\hline & -6 & 148 & 0.12 & 17.7 & 454 & 54.48 \\
\hline & -8 & 157 & 0.10 & 15.7 & 457 & 45.70 \\
\hline & -10 & 147 & 0.10 & 14.7 & 454 & 45.40 \\
\hline & -12 & 134 & 0.10 & 13.4 & 415 & 41.50 \\
\hline & -14 & 65 & 0.10 & 6.5 & 270 & 27.00 \\
\hline & -16 & 19 & 0.10 & 1.9 & 225 & 22.50 \\
\hline & -18 & 21 & 0.10 & 2.1 & 251 & 25.10 \\
\hline & -20 & 18 & 0.11 & 2.0 & 214 & 23.54 \\
\hline & -22 & 23 & 0.13 & 3.0 & 202 & 26.26 \\
\hline & -24 & 41 & 0.12 & 5.0 & 193 & 23.16 \\
\hline & -26 & 99 & 0.13 & 12.9 & 174 & 22.62 \\
\hline & -28 & 108 & 0.14 & 15.1 & 198 & 27.72 \\
\hline & -30 & 109 & 0.11 & 12.0 & 176 & 19.36 \\
\hline & -32 & 83 & 0.10 & 8.3 & 173 & 17.30 \\
\hline & -34 & 14 & 0.13 & 1.8 & 55 & 7.15 \\
\hline & -36 & 10 & 0.17 & 1.7 & 46 & 7.82 \\
\hline Core E-11 & -2 & 177 & 0.12 & 21.2 & 413 & 49.56 \\
\hline & -4 & 204 & 0.13 & 26.5 & 383 & 49.79 \\
\hline & -5 & 185 & 0.17 & 31.5 & 396 & 67.32 \\
\hline & -8 & 119 & 0.12 & 14.3 & 377 & 45.24 \\
\hline & -10 & 73 & 0.10 & 7.3 & 266 & 26.60 \\
\hline & -12 & 77 & 0.13 & 10.0 & 247 & 32.11 \\
\hline & -14 & 73 & 0.11 & 8.0 & 218 & 23.98 \\
\hline & -16 & 47 & 0.10 & 4.7 & 202 & 20.20 \\
\hline & -18 & 47 & 0.11 & 5.2 & 160 & 17.60 \\
\hline & -20 & 62 & 0.11 & 6.8 & 160 & 17.60 \\
\hline & -22 & 52 & 0.10 & 5.2 & 179 & 17.90 \\
\hline & -24 & 64 & 0.10 & 6.4 & 162 & 16.20 \\
\hline & -26 & 52 & 0.10 & 5.2 & 154 & 15.40 \\
\hline & -28 & 79 & 0.11 & 8.7 & 141 & 15.51 \\
\hline & -30 & 87 & 0.12 & 10.4 & 118 & 14.16 \\
\hline & -32 & 106 & 0.12 & 12.7 & 132 & 15.84 \\
\hline & -34 & 83 & 0.11 & 9.1 & 117 & 12.87 \\
\hline
\end{tabular}




$\begin{array}{ccccccc} & -36 & 80 & 0.12 & 9.6 & 125 & 15.00 \\ \text { Core }=-7 & -2 & 148 & 0.16 & 23.7 & 373 & 59.68 \\ & -4 & 142 & 0.21 & 29.8 & 366 & 76.86 \\ & -6 & 119 & 0.15 & 17.9 & 353 & 52.95 \\ -8 & 116 & 0.12 & 13.9 & 319 & 38.28 \\ -10 & 122 & 0.11 & 13.4 & 278 & 30.58 \\ -12 & 111 & 0.11 & 12.2 & 240 & 26.40 \\ -14 & 120 & 0.12 & 14.4 & 211 & 25.32 \\ -16 & 88 & 0.13 & 11.4 & 226 & 29.38 \\ -18 & 77 & 0.11 & 8.5 & 247 & 27.17 \\ -20 & 76 & 0.11 & 8.4 & 212 & 23.32 \\ -22 & 63 & 0.11 & 6.9 & 188 & 20.68 \\ -24 & 33 & 0.11 & 3.6 & 138 & 15.18 \\ -26 & 61 & 0.11 & 6.7 & 235 & 25.85 \\ -28 & 68 & 0.12 & 8.2 & 303 & 36.36 \\ -30 & 51 & 0.13 & 6.6 & 204 & 26.52\end{array}$




\begin{tabular}{|c|c|c|c|c|c|c|}
\hline $\begin{array}{l}\text { Site } \\
\text { A-7 }\end{array}$ & $\begin{array}{l}\text { Depth } \\
(\mathrm{cm})\end{array}$ & $\begin{array}{l}\text { Total Hg } \\
\mathrm{ng} \mathrm{Hg} / \mathrm{g}\end{array}$ & $\begin{array}{l}\text { B. Density } \\
\text { BD }(g / c c)\end{array}$ & $\begin{array}{c}\text { Total Hg } \\
\mathrm{ng} \mathrm{Hg}\end{array}$ & $\begin{array}{c}\text { Total } \mathrm{Hg} \\
\mathrm{ng} / \mathrm{g}\end{array}$ & $\begin{array}{l}\mathrm{Hg} \text { sed. rate } \\
\mu \mathrm{g} / \mathrm{m} 2 / \mathrm{yr}\end{array}$ \\
\hline \multirow{18}{*}{$A-7$} & $1-3$ & 236.00 & 0.10 & 47.20 & & 94.40 \\
\hline & $3-5$ & 293.00 & 0.11 & 64.46 & & 128.92 \\
\hline & $5-7$ & 322.00 & 0.13 & 83.72 & & 167.44 \\
\hline & $7-9$ & 279.00 & 0.13 & 72.54 & & 145.08 \\
\hline & $9-11$ & 298.00 & 0.10 & 59.60 & & 119.20 \\
\hline & $11-13$ & 162.00 & 0.11 & 35.64 & & 71.28 \\
\hline & $13-15$ & 120.00 & 0.10 & 24.00 & & 48.00 \\
\hline & $15-17$ & 87.00 & 0.10 & 17.40 & & 34.80 \\
\hline & $17-19$ & 67.00 & 0.10 & 13.40 & & 26.80 \\
\hline & $19-21$ & 50.00 & 0.12 & $12: 00$ & 429.96 & 24.00 \\
\hline & $21-23$ & 42.00 & 0.10 & 8.40 & & 16.80 \\
\hline & $23-25$ & 41.00 & 0.10 & 8.20 & & 16.40 \\
\hline & $25-27$ & 43.00 & 0.10 & 8.60 & & 17.20 \\
\hline & $27-29$ & 58.00 & 0.11 & 12.76 & & 25.52 \\
\hline & $29-31$ & 51.00 & 0.12 & 12.24 & & 24.48 \\
\hline & $31-33$ & 45.00 & 0.10 & 9.00 & & 18.00 \\
\hline & $33-35$ & 62.00 & 0.10 & 12.40 & Total & 24.80 \\
\hline & $35-37$ & 47.00 & 0.12 & 11.28 & 512.84 & 22.56 \\
\hline \multirow[t]{15}{*}{$A-10$} & Depth & $\mathrm{ng} \mathrm{Hg} / \mathrm{g}$ & $\mathrm{BD}(\mathrm{g} / \mathrm{CC})$ & $\mathrm{ng} \mathrm{Hg}$ & & \\
\hline & $1-3$ & 165.00 & 0.12 & 39.60 & & 79.20 \\
\hline & $3-5$ & 171.00 & 0.17 & 58.14 & & 116.28 \\
\hline & $5-7$ & 90.00 & 0.10 & 18.00 & & 36.00 \\
\hline & $7-9$ & 75.00 & 0.10 & 15.00 & & 30.00 \\
\hline & $9-11$ & 75.00 & 0.11 & 16.50 & & 33.00 \\
\hline & $11-13$ & 58.00 & 0.20 & 23.20 & 270.44 & 46.40 \\
\hline & $13-15$ & 45.00 & 0.21 & 18.90 & & 37.80 \\
\hline & $15-17$ & 55.00 & 0.23 & 25.30 & & 50.60 \\
\hline & $17-19$ & 44.00 & 0.18 & 15.84 & & 31.68 \\
\hline & $19-21$ & 52.00 & 0.16 & 16.64 & & 33.28 \\
\hline & $21-23$ & 44.00 & 0.33 & 29.04 & & 58.08 \\
\hline & $23-25$ & 48.00 & 0.29 & 27.84 & & 55.68 \\
\hline & $25-27$ & 36.00 & 0.41 & 29.52 & Total & 59.04 \\
\hline & $27-29$ & 23.00 & 0.47 & 21.62 & 355.14 & 43.24 \\
\hline \multirow[t]{7}{*}{$A-14$} & Depth & $\mathrm{ng} \mathrm{Hg} / \mathrm{g}$ & $\mathrm{BD}(g / c c)$ & $\mathrm{ng} \mathrm{Hg}$ & & \\
\hline & $1-3$ & 137.00 & 0.26 & 71.24 & & 142.48 \\
\hline & $3-5$ & 125.00 & 0.20 & 50.00 & & 100.00 \\
\hline & $5-7$ & 112.00 & 0.15 & 33.60 & & 67.20 \\
\hline & $7-9$ & 104.00 & 0.18 & 37.44 & 192.28 & 74.88 \\
\hline & $9-11$ & 89.00 & 0.20 & 35.60 & & 71.20 \\
\hline & $11-13$ & 87.00 & 0.23 & 40.02 & & 80.04 \\
\hline
\end{tabular}




$\begin{array}{rrrrrr}13-15 & 82.00 & 0.24 & 39.36 & & 78.72 \\ 15-17 & 88.00 & 0.22 & 38.72 & \operatorname{total} & 77.44 \\ 17-19 & 76.00 & 0.22 & 33.44 & 379.42 & 66.88\end{array}$

\begin{tabular}{|c|c|c|c|c|c|c|}
\hline$D-7$ & Depth & $\mathrm{ng} \mathrm{Hg} / \mathrm{g}$ & $B D(g / C C)$ & $\mathrm{ng} \mathrm{Hg}$ & & \\
\hline & $1-3$ & 235.00 & 0.10 & 47.00 & & 94.00 \\
\hline & $3-5$ & 272.00 & 0.10 & 54.40 & & 108.80 \\
\hline & $5-7$ & 268.00 & 0.12 & 64.32 & & 128.64 \\
\hline & $7-9$ & 230.00 & 0.11 & 50.60 & & 101.20 \\
\hline & $9-11$ & 200.00 & 0.10 & 40.00 & & 80.00 \\
\hline & $11-13$ & 148.00 & 0.10 & 29.60 & & 59.20 \\
\hline & $13-15$ & 133.00 & 0.10 & 26.60 & & 53.20 \\
\hline & $15-17$ & 111.00 & 0.10 & 22.20 & & 44.40 \\
\hline & $17-19$ & 96.00 & 0.10 & 19.20 & & 38.40 \\
\hline & $19-21$ & 88.00 & 0.10 & 17.60 & & 35.20 \\
\hline & $21-23$ & 59.00 & 0.11 & 15.18 & & 30.36 \\
\hline & $23-25$ & 62.00 & 0.10 & 12.40 & 399.1 & 24.80 \\
\hline & $25-27$ & 49.00 & 0.10 & 9.80 & & 19.60 \\
\hline & $27-29$ & 39.00 & 0.11 & 8.58 & & 17.16 \\
\hline & $29-31$ & 29.00 & 0.11 & 6.38 & & 12.76 \\
\hline & $31-33$ & 51.00 & 0.11 & 11.22 & & 22.44 \\
\hline & $33-35$ & 38.00 & 0.11 & 8.36 & Total & 16.72 \\
\hline & $35-37$ & 54.00 & 0.14 & 15.12 & 458.56 & 30.24 \\
\hline
\end{tabular}

D-10 Depth ng Hg/g BD $(\mathrm{g} / \mathrm{CC}) \quad \mathrm{ng} \mathrm{Hg}$

$\begin{array}{llll}1-3 & 225.00 & 0.13 & 58.50\end{array}$

$\begin{array}{llll}3-5 & 160.00 & 0.10 & 32.00\end{array}$

117.00

64.00

$\begin{array}{llll}5-7 & 145.00 & 0.10 & 29.00\end{array}$

58.00

$\begin{array}{llll}7-9 & 130.00 & 0.10 & 26.00\end{array}$

52.00

$9-11$

0.10

16.20

32.40

$11-13$

0.10

12.40

24.80

$13-15$

0.10

12.40

24.80

15-17

0.12

12.24

24.48

$17-19 \quad 31.00$

0.10

6.20

12.40

19-21

0.10

7.60

15.20

$21-23$

0.10

9.80

19.60

23-25

0.11

18.70

37.40

25-27

0.11

14.96

29.92

27-29

0.10

12.80

25.60

29-31

c. 10

9.80

19.60

$31-33$

0.10

10.20

20.40

$33-35$

0.10

6.80

13.60

$35-37$

0.10

8.40

16.80

$D-14$

Depth

$\mathrm{ng} \mathrm{Hg} / \mathrm{g} B D(\mathrm{~g} / \mathrm{CC})$

$\mathrm{ng} \mathrm{Hg}$

$1-3$

144.20

0.10

28.80

57.60 


\begin{tabular}{|c|c|c|c|c|c|c|}
\hline & $3-5$ & 255.00 & 0.13 & 66.30 & & 132.60 \\
\hline & $5-7$ & 248.00 & 0.12 & 59.52 & & 119.04 \\
\hline & $7-9$ & 244.00 & 0.13 & 63.44 & & 126.88 \\
\hline & $9-11$ & 229.00 & 0.10 & 45.80 & & 91.60 \\
\hline & $11-13$ & 158.00 & 0.10 & 31.60 & 295.46 & 63.20 \\
\hline & $13-15$ & 140.00 & 0.10 & 28.00 & & 56.00 \\
\hline & $15-17$ & 107.00 & 0.11 & 23.54 & & 47.08 \\
\hline & $17-19$ & 110.00 & 0.12 & 26.40 & & 52.80 \\
\hline & $19-21$ & 139.00 & 0.15 & 41.70 & & 83.40 \\
\hline & $21-23$ & 182.00 & 0.16 & 58.24 & & 116.48 \\
\hline & $23-25$ & 130.00 & 0.14 & 36.40 & & 72.80 \\
\hline & $25-27$ & 160.00 & 0.17 & 54.40 & & 108.80 \\
\hline & $27-29$ & 163.00 & 0.19 & 61.94 & & 123.88 \\
\hline & $29-31$ & 174.00 & 0.17 & 59.16 & & 118.32 \\
\hline & $31-33$ & 171.00 & 0.16 & 54.72 & Total & 109.44 \\
\hline & $33-35$ & 180.00 & 0.17 & 61.20 & 801.16 & 122.40 \\
\hline$c-12$ & Depth & $\mathrm{ng} \mathrm{Hg} / \mathrm{g}$ & $B D(g / C C)$ & $\mathrm{ng} \mathrm{Hg}$ & & \\
\hline & $1-3$ & 212.00 & 0.10 & 42.40 & & 84.80 \\
\hline & $3-5$ & 215.00 & 0.10 & 43.00 & & 86.00 \\
\hline & $5-7$ & 148.00 & 0.10 & 29.60 & & 59.20 \\
\hline & $7-9$ & 157.00 & 0.10 & 31.40 & & 62.80 \\
\hline & $9-11$ & 147.00 & 0.10 & 29.40 & & 58.80 \\
\hline & $11-13$ & 134.00 & 0.10 & 26.80 & & 53.60 \\
\hline & $13-15$ & 65.00 & 0.10 & 13.00 & 215.6 & 26.00 \\
\hline & $15-17$ & 19.00 & 0.10 & 3.80 & & 7.60 \\
\hline & $17-19$ & 21.00 & 0.10 & 4.20 & & 8.40 \\
\hline & $19-21$ & 18.00 & 0.11 & 3.96 & & 7.92 \\
\hline & $21-23$ & 23.00 & 0.13 & 5.98 & & 11.96 \\
\hline & $23-25$ & 41.00 & 0.12 & 9.84 & & 19.68 \\
\hline & $25-27$ & 99.00 & 0.13 & 25.74 & & 51.48 \\
\hline & $27-29$ & 108.00 & 0.14 & 30.24 & & 60.48 \\
\hline & $29-31$ & 109.00 & 0.11 & 23.98 & & 47.96 \\
\hline & $31-33$ & 83.00 & 0.10 & 16.60 & & 33.20 \\
\hline & $33-35$ & 14.00 & 0.13 & 3.64 & Total & 7.28 \\
\hline & $35-37$ & 10.00 & 0.17 & 3.40 & 346.98 & 6.80 \\
\hline$F-11$ & Depth & $\mathrm{ng} \mathrm{Hg} / \mathrm{g}$ & $B D(g / c C)$ & $\mathrm{ng} \mathrm{Hg}$ & & \\
\hline & $1-3$ & 177.00 & 0.12 & 42.48 & & 84.96 \\
\hline & $3-5$ & 204.00 & 0.13 & 53.04 & & 106.08 \\
\hline & $5-7$ & 185.00 & 0.17 & 62.90 & & 125.80 \\
\hline & $7-9$ & 119.00 & 0.12 & 28.56 & & 57.12 \\
\hline & $9-11$ & 73.00 & 0.10 & 14.60 & & 29.20 \\
\hline & $11-13$ & 77.00 & 0.13 & 20.02 & & 40.04 \\
\hline & $13-15$ & 73.00 & 0.11 & 16.06 & & 3.2 .12 \\
\hline & $15-17$ & 47.00 & 0.10 & 9.40 & 247.06 & 18.80 \\
\hline
\end{tabular}




$\begin{array}{lcllll}17-19 & 47.00 & 0.11 & 10.34 & & 20.68 \\ 19-21 & 62.00 & 0.11 & 13.64 & & 27.28 \\ 21-23 & 52.00 & 0.10 & 10.40 & & 20.80 \\ 23-25 & 64.00 & 0.10 & 12.80 & & 25.60 \\ 25-27 & 52.00 & 0.10 & 10.40 & & 20.80 \\ 27-29 & 79.00 & 0.11 & 17.38 & & 34.76 \\ 29-31 & 87.00 & 0.22 & 20.88 & & 41.76 \\ 31-33 & 106.00 & 0.12 & 25.44 & & 50.88 \\ 33-35 & 83.00 & 0.11 & 18.26 & \text { total } & 36.52 \\ 35-37 & 80.00 & 0.12 & 19.20 & 405.8 & 38.40\end{array}$

\begin{tabular}{|c|c|c|c|c|c|c|}
\hline$I-7$ & Depth & $\mathrm{ng} \mathrm{Hg} / \mathrm{g}$ & $B D(g / C C)$ & $\mathrm{ng} \mathrm{Hg}$ & & \\
\hline & $1-3$ & 148.00 & 0.16 & 47.36 & & 94.72 \\
\hline & $3-5$ & 142.00 & 0.21 & 59.64 & & 119.28 \\
\hline & $5-7$ & 119.00 & 0.25 & 35.70 & & 71.40 \\
\hline & $7-9$ & 116.00 & 0.12 & 27.84 & & 55.68 \\
\hline & $9-11$ & 122.00 & 0.11 & 26.84 & & 53.68 \\
\hline & $11-13$ & 111.00 & 0.11 & 24.42 & & 48.84 \\
\hline & $13-15$ & 120.00 & 0.12 & 28.80 & & 57.60 \\
\hline & $15-17$ & 88.00 & 0.13 & 22.88 & & 45.76 \\
\hline & $17-19$ & 77.00 & 0.11 & 16.94 & 290.42 & 33.88 \\
\hline & $19-21$ & 76.00 & 0.11 & 16.72 & & 33.44 \\
\hline & $21-23$ & 63.00 & 0.21 & 13.86 & & 27.72 \\
\hline & $23-25$ & 33.00 & 0.21 & 7.26 & & 14.52 \\
\hline & $25-27$ & 61.00 & 0.11 & 13.42 & & 26.84 \\
\hline & $27-29$ & 68.00 & 0.12 & 16.32 & Total & 32.64 \\
\hline & $29-31$ & 51.00 & 0.23 & 13.26 & 371.26 & 26.52 \\
\hline
\end{tabular}

